HO YEH LI

\title{
Comparação de resposta à vacinação com três esquemas diferentes de vacina antipneumocócica em indivíduos infectados por vírus de imunodeficiência humana
}

Tese apresentada à Faculdade de Medicina da Universidade de São Paulo para obtenção do título de Doutor em Ciências

Programa de: Doenças Infecciosas e Parasitárias

Orientadora: Profa. Dra. Marta Heloisa Lopes

Coorientadora: Profa. Dra. Maria Cristina de Cunto Brandileone

São Paulo 
Dados Internacionais de Catalogação na Publicação (CIP)

Preparada pela Biblioteca da

Faculdade de Medicina da Universidade de São Paulo

Oreprodução autorizada pelo autor

Ho, Yeh Li

Comparação de resposta à vacinação com três esquemas diferentes de vacina antipneumocócica em indivíduos infectados por vírus de imunodeficiência humana / Ho Yeh Li-- São Paulo, 2013.

Tese(doutorado)--Faculdade de Medicina da Universidade de São Paulo.

Programa de Doenças Infecciosas e Parasitárias.

Orientadora: Marta Heloisa Lopes.

Co-orientador: Maria Cristina de Cunto Brandileone.

Descritores: 1.Vacinas conjugadas 2.Vacinas polissacarídicas 3.Vacinas pneumocócicas 4. Aids 5.HIV 6.Adulto 7.Formação de anticorpos

8.Vacinas/efeitos adversos 9.Colonização de nasofaringe

USP/FM/DBD-048/13 
Dedico esta tese aos pacientes que, apesar dos seus sofrimentos, da sua solidão e das suas dificuldades, voluntariam-se a contribuir com o crescimento da ciência.

Aos cientistas e pesquisadores brasileiros que, apesar das restrições financeiras e das limitações tecnológicas, mantêm acesas as chamas de curiosidade científica.

À minha família que sempre me deu o apoio e confiança, apesar das minhas frequentes ausências. 


\section{AGRADECIMENTOS}

Aos pacientes do Serviço de Extensão de Atendimento aos Pacientes HIV/aids - "Casa da Aids" - HCFMUSP pela participação voluntária neste trabalho.

Ao Serviço de Extensão de Atendimento aos Pacientes HIV/aids - "Casa da Aids" - HCFMUSP pela ajuda dos médicos no recrutamento dos pacientes; da equipe de enfermagem pela ajuda na coleta das amostras de sangue; dos funcionários dos setores de Registro e Arquivo Médico pela disponibilização do prontuário; da diretoria pela disponibilização de toda a infraestrutura do serviço.

Aos funcionários do Laboratório de Bacteriologia do Instituto Adolfo Lutz pelo carinhoso acolhimento, especialmente à Dra. Samanta C.G. Almeida pela paciência por me ensinar as técnicas microbiológicas, Dra. Ângela $P$. Brandão, pela disponibilidade e paciência em ensinar a executar reações de ELISA, e à Profa. Dra. Maria Cristina Cunto Brandileone por permitir meu acesso ao laboratório, por confiar na minha capacidade e pela paciência na orientação.

Ao Prof. Dr. David Goldblatt do Pneumococcal Serology Reference Laboratories, Institute of Child Health, University College London por permitir 
meu estágio no laboratório para aperfeiçoamento da minha técnica de ELISA.

À Profa. Dra. Silvia Figuereido Costa por permitir meu acesso ao Laboratório de Investigação Médica de Bacteriologia (LIM-54), pela disponibilização da infraestrutura e, especialmente à Camila Fonseca Rizek pela ajuda na execução das reações de ELISA.

A todos os diretores da Divisão de Moléstias Infecciosas e Parasitárias, especialmente Dr. Marcello M.C. Magri, pela compreensão e apoio, além do estímulo que sempre ofereceram.

Aos Professores Titulares do Departamento de Moléstias Infecciosas e Parasitárias, e do Prof. Antônio Alci Barone, pela confiança e credibilidade, além das oportunidades que sempre me ofereceram.

A todos meus colegas da equipe médica, enfermagem e fisioterapia da Unidade de Terapia Intensiva da Divisão de Moléstias Infecciosas e Parasitárias pela confiança e coleguismo.

A todos os médicos residentes do Departamento de Moléstias Infecciosas e Parasitárias que sempre estimularam a minha curiosidade científica. 
À Profa. Dra. Marta Heloisa Lopes que, com a sua seriedade e competência, sempre foi um exemplo de profissionalismo para mim. Agradeço pelo incentivo que sempre me deu, pela orientação e conselhos, e pela paciência. 
Este estudo foi realizado com o apoio financeiro da:

Fundação de Apoio à Pesquisa do Estado de São Paulo (Processo: 2005/01414-7)

Coordenação de Aperfeiçoamento de Pessoal de Nível superior - Bolsa de Doutorado 
Esta tese está de acordo com as seguintes normas, e vigor no momento desta publicação:

Referências: adaptado de International commitee of Medical Journal Editors (Vancouver modificado)

Universidade de São Paulo. Faculdade de Medicina. Serviço de Biblioteca e Documentação. Guia de apresentação de dissertações, teses e monografias. Elaborado por Anneliese Carneiro da Cunha, Maria Julia de A. L. Freddi, Maria Fazanelli Crestana, Marinalva de Souza Aragão, Suely Campos Cardoso, Valéria Vilhena. 3a ed. - São Paulo: Divisão de Biblioteca e Documentação - SBD/FMUSP, 2011.

Abreviaturas dos títulos dos periódicos de acordo com Listo $f$ Journal Indexed in Index Medicus 


\section{Sumário}

Lista de abreviaturas

Lista de símbolos

Lista de siglas

Lista de figuras

Lista de gráficos

Lista de tabelas

Resumo

Summary

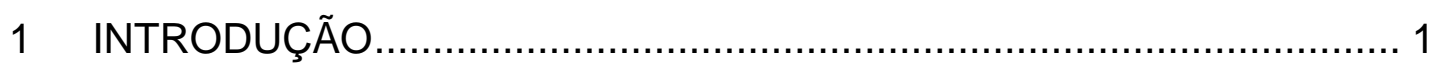

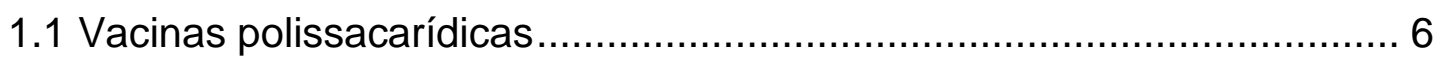

1.1.1 Vacina antipneumocócica polissacarídica .................................. 6

1.1.2 Vacina antipneumocócica polissacarídica em adultos imunocompetentes...................................................................... 7

1.1.3 Vacina antipneumocócica polissacarídica em adultos infectados por

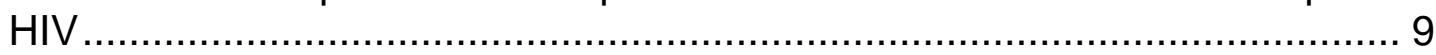

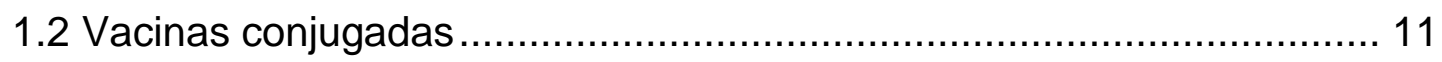

1.2.1 Vacina antipneumocócica conjugada..................................... 11

1.2.2 Vacina antipneumocócica conjugada em crianças não infectadas por HIV ...................................................................................... 12

1.2.3 Vacina antipneumocócica conjugada em adultos não infectados por HIV

1.2.4 Vacina antipneumocócica conjugada em adultos infectados por HIV. 15

1.3 Esquemas combinados da vacinação antipneumocócica .................... 16

1.3.1 Combinação de vacinas polissacarídicas .................................... 16 
1.3.2 Combinação de vacina polissacarídica com vacina conjugada 17

1.4 - Estado de colonização de S. pneumoniae após a vacinação ............... 19

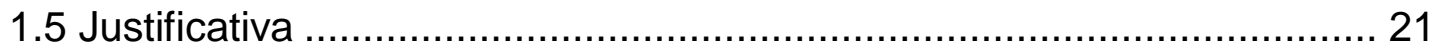

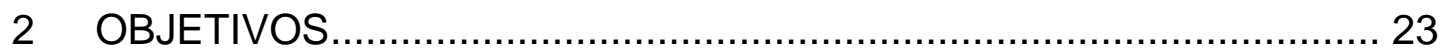

3 Casuística e Métodos ................................................................... 25

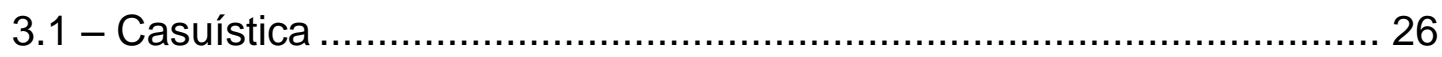

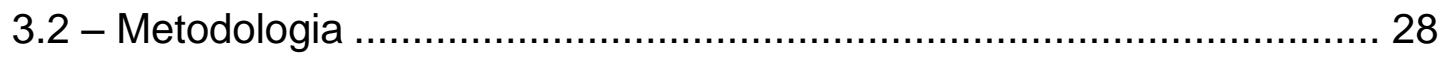

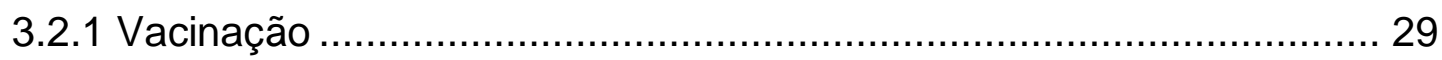

3.2.2 Avaliação das concentrações de anticorpos antipneumocócicos ....... 30

3.2.3 Colonização da nasofaringe ............................................... 32

3.2.4 Avaliação dos eventos adversos............................................ 32

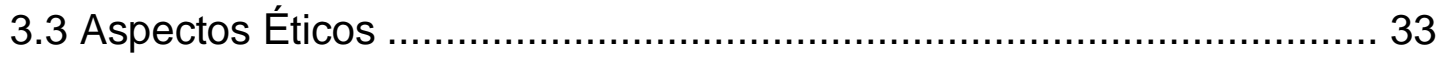

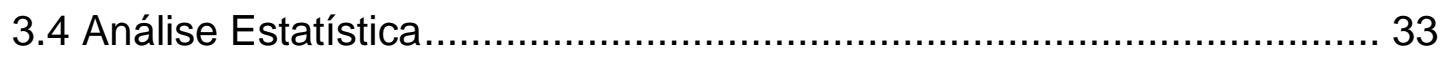

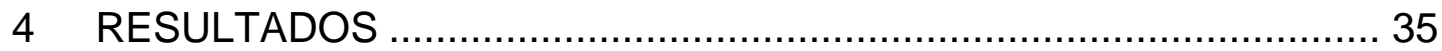

4.1 Imunogenicidade .................................................................... 39

4.1.1 Avaliação anticórpica pré-vacinal............................................... 39

4.1.2 Avaliação anticórpica 60 dias após a primeira vacinação .................. 40

4.1.3 Avaliação anticórpica 180 dias pós a primeira vacinação .................. 41

4.1.4 Avaliação do efeito do booster com PP23V após PC7V na resposta

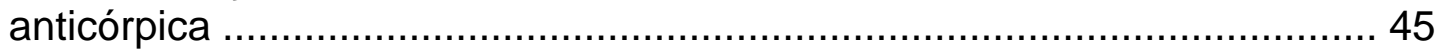

4.2 Eventos adversos ................................................................. 47

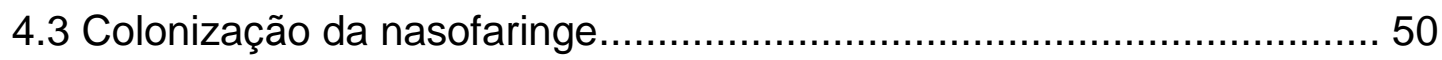

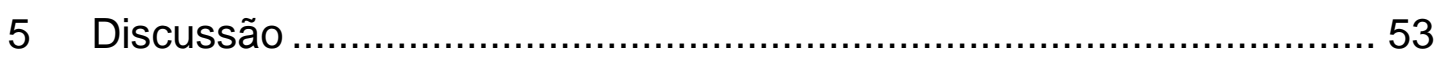

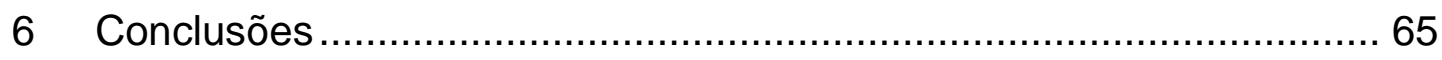

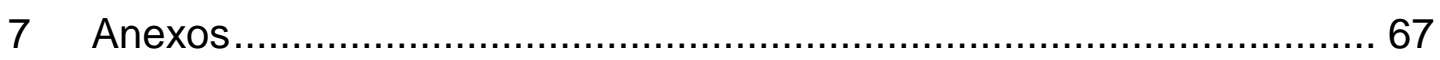

Anexo I - Termo de consentimento Livre e Esclarecido ...........................68 68 
Anexos II - Tabela de Randomização

Anexo III - Questionário demográfico, epidemiológico, imunológico, virológico e de uso de antimicrobianos.

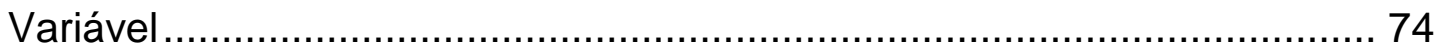

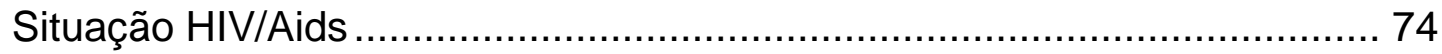

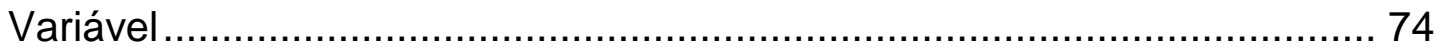

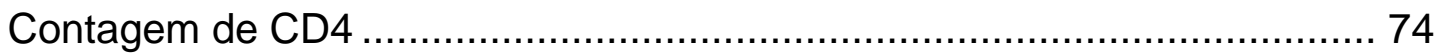

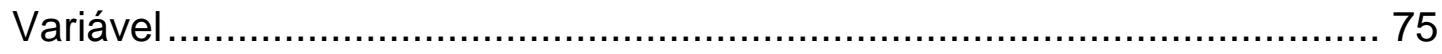

Anexo IV - Questionário de Eventos Adversos pós-vacinação. ................... 76

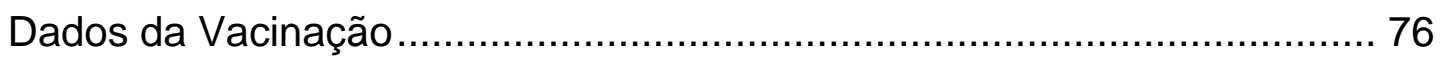

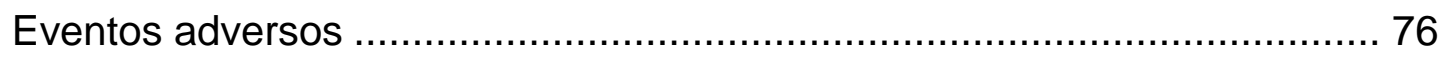

Anexo V - Aprovação CAPPESq ……………………........................ 77

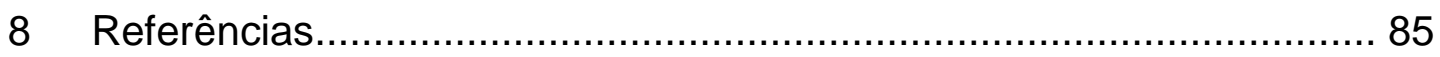




\section{Lista de Abreviaturas}

$\begin{array}{ll}\text { IC }_{95 \%} & \text { Intervalo de confiança 95\% } \\ \text { OR } & \text { Odds ration } \\ \text { PP23V } & \text { Vacina antipneumocócica polissacarídica 23-valente } \\ \text { PC13V } & \text { Vacina antipneumocócica conjugada 13-valente } \\ \text { PC7V } & \text { Vacina antipneumocócica conjugada heptavalente } \\ \text { PC5V } & \text { Vacina antipneumocócica conjugada pentavalente } \\ \text { TMG } & \text { Títulos Médios Geométricos }\end{array}$




\section{Lista de Siglas}

$\begin{array}{ll}\text { EUA } & \text { Estados Unidos da América } \\ \text { HIV } & \text { Vírus da Imunodeficiência Humana } \\ \text { HAART } & \text { Terapia antirretroviral altamente potente } \\ \text { CDC } & \text { Centro de Controle e Prevenção de Doenças } \\ \text { DPOC } & \text { Doença pulmonar obstrutiva crônica } \\ \text { MHC } & \text { Complexo Principal de Histocompatibilidade } \\ \text { OMS } & \text { Organização Mundial da Saúde } \\ \text { ELISA } & \text { Ensaio Imunoenzimático } \\ \text { LIM } & \text { Laboratório de Investigação Médica } \\ \text { USP } & \text { Universidade de São Paulo } \\ \text { HC-FMUSP } & \text { Hospital das Clínicas da Faculdade de Medicina USP }\end{array}$




\section{Lista de figuras}

Figura 1 - Diagrama da inclusão dos pacientes em cada visita programada, para os três grupos ( $A=P P 23 V, B=P C 7 V, C=P C 7 V+P P 23 V)$ no estudo conduzido no SEAP-Casa da Aids, HC-FMUSP, de $10 / 2005$ a 05/2009

\section{Lista de gráficos}

Gráfico 1 - Evolução dos títulos médios geométricos das concentrações dos anticorpos contra sorotipo 6B dos indivíduos dos três diferentes esquemas de vacinação. SEAP - Casa da Aids, HCFMUSP

Gráfico 2 - Evolução dos títulos médios geométricos das concentrações dos anticorpos contra sorotipo $9 \mathrm{~V}$ dos indivíduos dos três diferentes esquemas de vacinação. SEAP - Casa da Aids, HCFMUSP .44

Gráfico 3 - Evolução dos títulos médios geométricos das concentrações dos anticorpos contra sorotipo 14 dos indivíduos dos três diferentes esquemas de vacinação. SEAP - Casa da Aids, HCFMUSP 


\section{Lista de tabelas}

Tabela 1 - Características demográficas e relacionadas à infecção pelo HIV dos indivíduos incluídos nos três grupos (A=PP23V, $B=P C 7 V$, $\mathrm{C}=\mathrm{PC7V}+\mathrm{PP} 23 \mathrm{~V}$ ) no momento da aplicação da primeira dose da vacina - SEAP - Casa da Aids, HC-FMUSP, de 10/2005 a 05/2009.

Tabela 2 - Concentrações de anticorpos e títulos médios geométricos das concentrações dos anticorpos em adultos infectados pelo HIV incluídos nos três grupos ( $A=P P 23 V, \quad B=P C 7 V$, $\mathrm{C}=\mathrm{PC7V}+\mathrm{PP} 23 \mathrm{~V})$ antes da administração da $1^{\text {a }}$ dose da vacina - SEAP- Casa da Aids, HC-FMUSP, de 10/2005 a 05/2009 39

Tabela 3 - Concentrações de anticorpos, títulos médios geométricos das concentrações dos anticorpos e proporção de indivíduos com aumento da concentração de anticorpos sorotipo-específicos maior ou igual a quatro vezes em relação às concentrações basais, em adultos infectados pelo HIV incluídos nos três grupos ( $\mathrm{A}=\mathrm{PP} 23 \mathrm{~V}, \quad \mathrm{~B}=\mathrm{PC7V}, \quad \mathrm{C}=\mathrm{PC7V}+\mathrm{PP} 23 \mathrm{~V}) \quad 60$ dias após a administração da $1^{\underline{a}}$ dose da vacina - SEAP - Casa da Aids, HC-FMUSP, de 10/2005 a 05/2009

Tabela 4 - Concentrações de anticorpos, títulos médios geométricos das concentrações dos anticorpos e proporção de indivíduos com aumento da concentração de anticorpos sorotipo-específicos maior ou igual a quatro vezes em relação às concentrações basais, em adultos infectados pelo HIV incluídos nos três grupos ( $\mathrm{A}=\mathrm{PP} 23 \mathrm{~V}, \quad \mathrm{~B}=\mathrm{PC7V}, \quad \mathrm{C}=\mathrm{PC7V}+\mathrm{PP} 23 \mathrm{~V}) 180$ dias após a administração da $1^{\underline{a}}$ dose da vacina - SEAP - Casa da Aids, HC-FMUSP, de 10/2005 a 05/2009 
Tabela 5 - Concentrações de anticorpos, títulos médios geométricos das concentrações dos anticorpos e proporção de indivíduos com aumento da concentração de anticorpos sorotipo-específicos maior ou igual a quatro vezes em relação às concentrações basais em adultos infectados pelo HIV dos grupos B (PC7V) e C (PC7V+PP23V) 120 dias após a administração da $1^{\text {a }}$ dose da vacina - SEAP - Casa da Aids, HC-FMUSP, de 10/2005 a 05/2009.

Tabela 6 - Eventos adversos locais e sistêmicos em adultos infectados pelo HIV incluídos nos três grupos ( $A=P P 23 V, B=P C 7 V$, $\mathrm{C}=\mathrm{PC7V}+\mathrm{PP} 23 \mathrm{~V}$ ) após a administração da $1^{\underline{a}}$ e $2^{\underline{a}}$ dose da vacina - SEAP-Casa da Aids, HC-FMUSP, 10/2005 a 05/2009

Tabela 7 - Eventos adversos locais e sistêmicos após a primeira vacinação (PP23V e PC7V). SEAP - Casa da Aids, HC-FMUSP - 10/2005 a $05 / 2009$ 49

Tabela 8 - Eventos adversos locais e sistêmicos após aplicação da vacina PP23V em indivíduos dos grupos A e C. SEAP - Casa da Aids, HC-FMUSP - 10/2005 a 05/2009 .50

Tabela 9 - Colonização da nasofaringe antes e 180 dias após a vacinação nos pacientes infectados pelo HIV - SEAP - Casa da Aids, HCFMUSP - 10/2005 a 05/2009 .51

Tabela 10 - Colonização da nasofaringe antes e 180 dias após, de acordo com a vacina recebida na primeira intervenção (PP23V ou PC7V) nos indivíduos infectados pelo HIV - SEAP - Casa da Aids, HC-FMUSP - 10/2005 a 05/2009 .52 


\section{Resumo}

Ho YL. Comparação de resposta à vacinação com três esquemas diferentes de vacina antipneumocócica em indivíduos infectados por vírus de imunodeficiência humana [tese]. São Paulo: Faculdade de Medicina, Universidade de São Paulo; 2013.

INTRODUÇÃO: Pacientes infectados pelo HIV apresentam maior risco de doença pneumocócica invasiva com maior mortalidade que a população geral. Estratégias para redução da carga de doença pneumocócica são importantes. A vacina antipneumocócica polissacarídica 23-valente é recomendada para adultos infectados pelo HIV, entretanto, a imunogenicidade desta vacina nessa população ainda é discutível. A vacina antipneumocócica ideal e o regime vacinal de maior eficácia ainda são controversos na literatura. Os poucos estudos publicados com vacina antipneumocócica conjugada 7-valente em adultos infectados pelo HIV apresentam resultados discrepantes. Esse estudo visa comparar a resposta de anticorpos e a reatogenicidade de três esquemas diferentes de vacina antipneumocócica, em adultos infectados pelo HIV; e avaliar o impacto da vacinação no estado de colonização da nasofaringe. MÉTODOS: ensaio clínico randomizado e duplo-cego, envolvendo 331 pacientes infectados pelo HIV, de 18 a 60 anos de idade, com contagem de linfócitos T-CD4 acima de $200 \mathrm{cél} / \mathrm{mm}^{3}$. Os pacientes foram alocados em grupos de duas intervenções com intervalos de 60 dias entre elas: a) vacina antipneumocócica polissacarídica 23-valente + placebo; b) vacina antipneumocócica conjugada 7-valente + placebo; c) vacina antipneumocócica conjugada 7-valente + vacina antipneumocócica polissacarídica 23-valente. A imunogenicidade das vacinas foi determinada através da reação de ELISA para sorotipos $6 \mathrm{~B}, 9 \mathrm{~V}$ e 14, realizadas no momento pré-vacinal, 60 dias e 180 dias após a primeira intervenção. A reatogenicidade foi avaliada através de entrevista após cada vacinação. A colonização da nasofaringe foi avaliada antes do início da 
vacinação e 180 dias após. RESULTADOS: Os grupos foram similares nas características demográficas e condições associadas à infecção pelo HIV. Nos três grupos foi observado um aumento significativo dos níveis de anticorpo-lgG para todos os três sorotipos avaliados. Foi observada uma maior proporção de indivíduos que sustentaram aumento de quatro vezes ou mais na concentração de anticorpos para sorotipos $6 \mathrm{~B}$ e $9 \mathrm{~V}$ nos grupos que receberam PC7V na primeira vacinação. A combinação das vacinas conjugada 7-valente seguida da vacina polissacarídica 23-valente não aumentou a imunogenicidade para nenhum dos sorotipos avaliados. Ambas as vacinas foram bem toleradas, entretanto, eventos adversos sistêmicos foram mais frequentes após aplicação da vacina conjugada 7-valente. Nenhum evento grave foi reportado. O uso da vacina polissacarídica 23valente após a aplicação da vacina conjugada 7-valente não aumentou a reatogenicidade. A colonização da nasofaringe por S.pneumoniae foi significantemente menor 180 dias após a vacinação, embora não tenha sido observada diferença entre os três grupos. CONCLUSÃO: nesse ensaio clínico conduzido em adultos brasileiros infectados pelo HIV, observamos que as vacinas antipneumocócicas polissacarídica 23-valente e conjugada 7valente foram seguras e imunogênicas. As evidências sugerem que a vacina conjugada 7-valente foi mais imunogênica que a polissacarídica 23-valente para os sorotipos 6B e 9V. Não houve benefício da aplicação da vacina antipneumocócica polissacarídica 23-valente após vacina conjugada 7valente. A vacinação antipneumocócica reduziu a colonização da nasofaringe por S.pneumoniae, independentemente do esquema vacinal aplicado.

Descritores: 1. Vacinas conjugadas; 2. Vacinas polissacarídicas; 3. Vacinas pneumocócicas; 4. Aids; 5. HIV; 6. Adulto; 7. Formação de anticorpos; 8. Vacinas/efeitos adversos; 9 . Colonização de nasofaringe. 


\section{Summary}

Ho YL. Comparison of antibody response to three different pneumococcal vaccine schedules in HIV-infected adults. [Thesis]. São Paulo: Faculdade de Medicina, Universidade de São Paulo; 2013.

BACKGROUND: The risk and the mortality of invasive pneumococcal disease are higher in HIV-infected patients than in uninfected individuals. Strategy to reduce the burden of invasive pneumococcal disease is crucial. Pneumococcal polysaccharide vaccine 23-valent is recommended for HIVadults, but its immunogenicity is still controversial. The ideal antipneumococcal vaccine and effective vaccination regimen remain controversial. Few trials with 7-valent pneumococcal conjugate vaccine in HIV-adults revealed disparate results. This study aims to compare antibody response and reactogenicity to three different pneumococcal vaccine schedules in HIV-infected adults, and impact of vaccine in nasopharyngeal carriage of Streptococcus pneumoniae. METHODS: a randomized, blinded clinical trial was conducted in Brazil with 331 HIV-patients aged 18 to 60 years with CD4+ T-lymphocytes count $\geq 200$ cells/mm3. Two interventions 60 days apart were done in three schedules: a) 23-valent pneumococcal polysaccharide vaccine + placebo; b) 7-valent pneumococcal conjugate vaccine + placebo; and c) 7-valent pneumococcal conjugate vaccine + pneumococcal polysaccharide vaccine 23-valent. Immunogenicity was assessed by an IgG enzyme-linked immunosorbent assay to $S$. pneumoniae serotypes $6 \mathrm{~B}, 9 \mathrm{~V}$ and 14 , performed at baseline, 60 and 180 days after first intervention. Reactogenicity was evaluated by individual interview. Nasopharyngeal colonization was evaluated before first dose and 180 days after. RESULTS: Demographic and HIV conditions were similar between all groups. Significant increase in IgG-antibodies was observed to all serotypes evaluated. A greater proportion of individuals who reached and sustained IgG antibody concentrations at least four times as high as those at baseline, for 
serotypes $6 \mathrm{~B}$ and $9 \mathrm{~V}$ received $\mathrm{PC7V}$ at first vaccination. A pneumococcal polysaccharide vaccine 23-valent dose after 7-valent pneumococcal conjugate vaccine did not enhance immunogenicity. Both vaccines were well tolerated across vaccine groups; however, more systemic adverse events were reported after 7-valent pneumococcal conjugate vaccine despite none severe events were described. Pneumococcal polysaccharide vaccine 23valent after 7-valent pneumococcal conjugate vaccine did not increased reactogenicity. Nasopharyngeal colonization of S. pneumoniae 180 days after vaccination was statistically significant lower than pre-vaccination, although none difference was been observed between three groups. CONCLUSIONS: In this clinical trial conducted in Brazilian HIV-infected adults, both pneumococcal polysaccharide vaccine 23-valent and 7-valent pneumococcal conjugate vaccine were safe and immunogenic. Evidence suggesting 7-valent pneumococcal conjugate vaccine was more immunogenic than pneumococcal polysaccharide vaccine 23 -valent, as it elicited higher and persistent $\geq 4$-fold increase of antibodies for serotypes $6 \mathrm{~B}$ and $9 \mathrm{~V}$ in a greater proportion of HIV-patients, is noteworthy. No benefit of a pneumococcal polysaccharide vaccine 23-valent dose following 7-valent pneumococcal conjugate vaccine was observed. Pneumococcal vaccination reduced nasopharyngeal colonization of S.pneumoniae in this population, without statistical difference between groups.

Descriptors: 1. Conjugate vaccines; 2. Polysaccharide vaccines; 3. Pneumococcal vaccines 4. Aids; 5. HIV; 6. Adults; 7. Immunogenicity; 8. Reactogenicity; 9. Nasopharyngeal colonization. 
In tro d u ção o $\mathbf{1}$ 
Streptococcus pneumoniae é um dos principais agentes bacterianos que podem levar a quadros infecciosos, desde de leve intensidade às complicações sistêmicas com altos índices de letalidade.

Nos Estados Unidos da América (EUA), anualmente, S. pneumoniae é responsável por 100.000 a 135.000 hospitalizações por pneumonia, mais de 6 milhões de casos de otite média e mais de 60.000 casos de outras doenças invasivas, sendo 3300 casos meningite ${ }^{1}$. Complicações que levam ao óbito ocorrem em $14 \%$ dos adultos hospitalizados com doença invasiva. Além disso, as meningites podem resultar em seqüelas neurológicas.

Estima-se que nos EUA, em 2004, doenças pneumocócicas foram responsáveis por 4 milhões de episódios de adoecimento, 22.000 óbitos, 445.000 hospitalizações, 774.000 atendimentos emergenciais, 5 milhões de consultas ambulatoriais e 4,1 milhões de prescrições de antimicrobianos, representando um custo total de 3,5 bilhões de dólares americanos ${ }^{2}$.

No Brasil, entre janeiro de 2004 a dezembro de 2006, em levantamento baseado no Sistema de Informações Hospitalares, Novaes et $\mathrm{al}^{3}$ observaram que a doença pneumocócica foi responsável por 34.217 hospitalizações no Sistema Único de Saúde, representando 0,1\% de todas as hospitalizações, com 2.746 óbitos, sendo a pneumonia pneumocócica a principal causa da internação $(64,8 \%)$. Além disso, no mesmo período, houve 1.276 óbitos secundários a meningite pneumocócica registrado no Sistema de Informação de Agravos de Notificação, representando uma letalidade de $31,7 \%$ em todas as faixas etárias. 
Os grupos de maior risco para infecções por $S$. pneumoniae são idosos acima de 65 anos de idade, crianças abaixo de 2 anos de idade e pessoas com doenças crônicas, inclusive infecção pelo HIV ${ }^{1,3}$.

Com a introdução da terapia antirretroviral altamente potente (HAART), houve uma redução significativa de óbitos secundários às doenças oportunistas. Inversamente, as infecções bacterianas e sepse ganharam uma importância crescente como causa de hospitalização em pacientes infectados pelo $\mathrm{HIV}^{4,5}$.

Hirschtick et $\mathrm{al}^{6}$ encontraram maior incidência de pneumonia bacteriana em pacientes infectados por HIV em comparação com controles soronegativos, sendo que 0 S. pneumoniae foi o principal agente responsável pela pneumonia adquirida na comunidade. A infecção por HIV representa um aumento de risco de 23 a 60 vezes na incidência de doença invasiva por $S$. pneumoniae quando comparada à população não infectada pelo $\mathrm{HIV}^{7-11}$. Além disso, mesmo após a era HAART, a mortalidade dessa população mantém-se superior a dos indivíduos HIV negativos ${ }^{9-12}$.

Nas duas últimas décadas, a incidência de $S$. pneumoniae resistentes a antimicrobianos tem aumentado no mundo. No Brasil, 32,2\% das amostras isoladas do sistema nervoso central coletadas em 2010 eram resistentes à penicilina e $1,9 \%$ resistentes a ceftriaxona ${ }^{13}$.

Crewe Brown et al $^{14}$ encontraram uma significante associação entre bacteremia por pneumococos resistentes à penicilina e soropositividade para o HIV, tanto em população pediátrica quanto em adultos. Grau et al $^{15}$ também observaram maior incidência de pneumococos resistentes à 
penicilina e ao cotrimoxazol em amostras recuperadas de locais habitualmente estéreis em pacientes infectados pelo HIV, em relação à população geral.

Em vista dos impactos econômicos e de saúde pública que este agente representa para a sociedade, em especial para a população infectada por HIV, tornou-se necessário o estudo de meios que auxiliem a conter esta tendência mundial.

Em 1977, foi licenciada nos EUA a primeira vacina antipneumocócica que continha antígenos polissacarídicos de 14 sorotipos de $S$. pneumoniae (vacina14-valente). Posteriormente, em 1983 foi substituída pela vacina 23valente, utilizada até os dias atuais. Atualmente, o Centro de Controle e Prevenção de Doenças dos Estados Unidos (CDC) recomenda o uso da vacina antipneumocócica polissacarídica 23 -valente para ${ }^{16}$ :

- Indivíduos com 65 anos ou mais de idade; e

- Indivíduos a partir de 2 anos de idade, portadores de condições clínicas que aumentem o risco de complicações graves, como doenças cardiovasculares, doença pulmonar obstrutiva crônica (DPOC) ou enfisema pulmonar, diabetes mellitus, asplenia (anatômica ou funcional);

O Ministério da Saúde do Brasil, em sua normatização de imunobiológicos especiais, recomenda o uso da vacina antipneumocócica polissacarídica 23-valente (PP23V) para crianças com 2 anos ou mais e adultos com as seguintes situações ${ }^{17}$ : 
- Portadores de doença pulmonar ou cardiovascular crônicas graves;

- Portadores de insuficiência renal crônica, síndrome nefrótica, diabetes mellitus insulino-dependente, cirrose hepática e fístula liquórica;

- Indivíduos com asplenia anatômica ou funcional;

- $\quad$ Portadores de hemoglobinopatias;

- Portadores de imunodeficiência congênita ou adquirida, pessoas HIV positivas assintomáticas e doentes com aids.

Em 2000, foi licenciada nos EUA a vacina conjugada heptavalente contra S. pneumoniae, que tem a vantagem de induzir resposta imunológica células-T dependente, mais duradoura. Posteriormente, vacina antipneumocócica conjugada 13-valente (PC13V) também foi licenciada nos EUA para população pediátrica, sendo incorporada no programa nacional de imunização em alguns países como Austrália. No segundo semestre de 2012, o CDC passou a recomendar a vacina PC13V para adultos imunocomprometidos, inclusive os infectados pelo HIV.

Em 2002, foi licenciada a primeira vacina antipneumocócica conjugada heptavalente no Brasil, indicada pelo Programa Nacional de Imunizações para situações especiais ${ }^{17}$. Em 2010, a vacina conjugada decavalente foi implantada pelo Programa Nacional de Imunizações do Ministério da Saúde para crianças abaixo de 2 anos de idade ${ }^{18}$. 


\subsection{Vacinas polissacarídicas}

As vacinas inicialmente desenvolvidas contra as bactérias encapsuladas, como $S$. pneumoniae, $N$. meningitidis e $H$. influenzae sorotipo b utilizavam como antígeno seus polissacárides capsulares. Porém, as vacinas polissacarídicas têm a característica de induzir uma resposta pouco imunogênica e protetora em crianças jovens e alguns grupos de pacientes imunocomprometidos, uma vez que os antígenos polissacarídicos produzem uma resposta imune independente da célula-T, caracterizada por ausência de memória imunológica e ausência de resposta anamnéstica ${ }^{19}$.

\subsubsection{Vacina antipneumocócica polissacarídica}

A vacina antipneumocócica polissacarídica 23-valente (PP23V) contém polissacárides capsulares dos sorotipos $1,2,3,4,5,6 \mathrm{~B}, 7 \mathrm{~F}, 8,9 \mathrm{~N}$, 9V, 10A, 11A, 12F, 14, 15B, 17F, 18C, 19A, 19F, 20, 22F, 23F e $33 \mathrm{~F}$. Esses sorotipos são responsáveis por $90 \%$ ou mais dos todos sorotipos envolvidos nas infecções pneumocócicas invasivas em países desenvolvidos e pouco mais de $80 \%$ no Brasil $^{20}$. Além disso, alguns sorotipos como 15B e 15C possuem polissacárides semelhantes e seus anticorpos têm reatividade altamente cruzada, assim como os sorotipos $6 \mathrm{~A}$ e $6 \mathrm{~B}$, que apresentam reatividade cruzada parcial. Portanto, a cobertura vacinal torna-se maior do que apenas para os sorotipos presentes ${ }^{21}$. 
Em pacientes infectados por HIV, a distribuição dos sorotipos responsáveis pela doença pneumocócica invasiva não difere da população não infectada pelo HIV. No estudo realizado por Fry et $\mathrm{al}^{22}$ mais de $90 \%$ das cepas isoladas em pacientes infectados pelo HIV, nos Estados Unidos, estavam representadas na vacina polissacáride 23-valente.

\subsubsection{Vacina antipneumocócica polissacarídica em adultos imunocompetentes}

A resposta anticórpica após a vacinação foi avaliada em voluntários jovens saudáveis, em estudos iniciais. Um mês após a vacinação, $86 \%$ dos voluntários apresentaram algum anticorpo IgG dos sorotipos avaliados, porém com variação entre os sorotipos, sendo que $99 \%$ obtiveram resposta ao sorotipo $18 \mathrm{C}$ e somente $75 \%$ tiveram resposta ao sorotipo $12 \mathrm{~F}^{23}$. Muitos estudos mostraram que algumas pessoas respondem vigorosamente a todos ou quase todos os componentes da vacina, enquanto outros respondem somente a poucos componentes e com baixos títulos de $\operatorname{lgG}$. Musher et $\mathrm{al}^{24}$ mostraram que a capacidade de resposta ao polissacáride capsular do pneumococo é controlada geneticamente e possui um padrão codominante.

A resposta pós-vacinal também foi analisada em pacientes idosos nos quais se obteve um resultado similar em relação aos voluntários jovens sadios. Porém, nesta população, foi observado que o nível sérico dos anticorpos sofre um declínio substancial a um nível pré-vacinal em 3 a 5 $\operatorname{anos}^{25}$. 
A eficácia clínica da vacina PP23V em adultos ainda é controversa em alguns aspectos ${ }^{26}$. Estudos para avaliação da prevenção da bacteremia pneumocócica ou doença pneumocócica invasiva (patógeno isolado na hemocultura, líquor ou outros fluidos normalmente estéreis) foram analisados.

Shapiro et al observaram que a vacinação pneumocócica foi responsável pela prevenção de $56 \%$ dos casos de bacteremia por pneumococos dos sorotipos vacinais e $47 \%$ de todas bacteremias pneumocócicas, independentemente dos sorotipos ${ }^{27}$. Vila-Corcoles et $\mathrm{al}^{28}$ observaram efetividade vacinal de $48 \%$ contra pneumonias pneumocócicas, $66 \%$ contra bacteremias pneumocócicas e 76\% quando considerados apenas bacteremias causadas por sorotipos presentes na vacina, em indivíduos acima de 50 anos de idade.

Na revisão realizada por Fedson em 1999, observou-se que a vacinação antipneumocócica polissacarídica teve eficácia de 50 a 80\% na prevenção da doença pneumocócica invasiva ${ }^{29}$. Na metanálise recente realizada pelo Huss et $\mathrm{al}^{30}$, foi observada redução de episódios de pneumonia pneumocócica ( $\left.R R \quad 0,64 ; \quad I_{95 \%} \quad 0,43-0,96\right)$ e de todas as pneumonias (RR 0,73; IC $95 \%$ 0,56-0,94) nos indivíduos adultos vacinados. Entretanto, nessa mesma metanálise, não foi observada a redução da mortalidade relacionada à doença pneumocócica invasiva.

Outras revisões e metanálises obtiveram resultados variáveis em relação à efetividade da vacina PP23V contra diversas doenças pneumocócicas, principalmente em relação à doença pneumocócica 
invasiva $^{31-34}$. Esses dados levaram alguns autores a sugerirem estratégias mais eficazes para prevenção de doença pneumocócica invasiva, principalmente objetivando a redução de mortalidade.

\subsubsection{Vacina antipneumocócica polissacarídica em adultos infectados por HIV}

A resposta após vacinação antipneumocócica em pacientes infectados pelo HIV foi avaliada em vários estudos, tanto em crianças quanto em adultos. A maioria dos estudos concluiu que pacientes infectados por HIV mostram uma resposta anticórpica pós-vacinal inferior em relação aos pacientes controles. Após a vacinação, há uma elevação de títulos de anticorpos IgG total e lgG2, embora esta resposta seja inferior àquela de indivíduos não infectados pelo HIV ${ }^{35-37}$, e mesmo naqueles que obtiveram uma boa resposta inicial, seus títulos de anticorpos decaíam rapidamente ${ }^{37}$.

No estudo de Janoff et al ${ }^{35}$ houve uma resposta anticórpica em 88,5\% dos voluntários saudáveis enquanto em infectados pelo HIV a resposta foi observada em apenas $62 \%$ dos indivíduos. Alguns estudos observaram que a resposta anticórpica tende a ser mais baixa em pacientes em estado de imunodepressão mais avançada ${ }^{36,38-40}$. Rodriguez-Barrada et al. ${ }^{36}$ obtiveram uma resposta pós-vacinal em $75 \%$ dos pacientes com infecção pelo HIV com contagem de linfócitos T-CD4 superior a 500 cél/ $\mathrm{mm}^{3}$ e em $24 \%$ dos indivíduos com linfócitos T-CD4 inferior a 500 cél $/ \mathrm{mm}^{3}$; nesse 
estudo, não foi observada diferença de resposta entre pacientes com linfócitos T-CD4 abaixo de 200 e de 200-500 cél/ $\mathrm{mm}^{3}$.

Falcó et al ${ }^{41}$ observaram que, em indivíduos infectados por HIV com contagem de linfócitos T-CD4 acima de 200 cél $/ \mathrm{mm}^{3}$ no momento da vacinação, o nadir de linfócitos T-CD4 e o número de linfócitos T-CD4 no momento da vacinação não influenciaram na resposta anticórpica pósvacinal.

Em relação à efetividade da vacinal, Gebo et $\mathrm{al}^{39}$ encontraram uma proteção de $78 \%$ para infecção pneumocócica em pacientes com contagem de linfócitos T-CD4 maior que $200 \mathrm{cé} / \mathrm{mm}^{3}$, o que não foi observado em pacientes com contagem inferior a esta. Breiman et a ${ }^{42}$ encontraram uma eficácia clínica contra doença pneumocócica invasiva de 49\% em pacientes HIV positivos. No estudo retrospectivo conduzido por Penaranda et $\mathrm{al}^{43}$ observou-se redução da doença pneumocócica invasiva em indivíduos vacinados (OR $0.44 ; \quad \mathrm{IC}_{95 \%} \quad 0.22-0.88$ ). Resultado similar também foi observado por Teshale et at. Entretanto, estes autores não observaram benefício vacinal em indivíduos com carga plasmática de HIV acima de 100.000 cópias/mL no momento da vacinação ${ }^{44}$.

A influência étnica foi aventada no estudo realizado por French et al ${ }^{45}$ em Uganda, onde se observou que, apesar da elevação das concentrações de anticorpos nos pacientes vacinados, não houve eficácia clínica na proteção contra doenças pneumocócicas. 


\subsection{Vacinas conjugadas}

Muitos antígenos polissacarídicos bacterianos têm sido ligados covalentemente a proteínas carreadoras formando vacinas conjugadas. Esta ligação permite que a célula apresentadora de antígeno processe as moléculas conjugadas polissacáride-proteína e apresente os peptídeos em associação com moléculas MHC classe II na sua superfície, o que induz as células-T a estimular linfócitos B polissacáride-específica. Esses linfócitos B produzirão anticorpos e se transformarão em células de memória. Desta forma, o antígeno polissacarídico é reconhecido pelo sistema imune junto com a sua proteína carreadora como T-dependente ${ }^{46}$.

\subsubsection{Vacina antipneumocócica conjugada}

Em 2000 foi licenciada nos EUA a primeira vacina antipneumocócica conjugada heptavalente (PC7V), a qual possui os antígenos capsulares dos sorotipos 4, 6B, 9V, 14, 18C, 19F e 23F de $S$. pneumoniae conjugados individualmente com a proteína diftérica CRM197. Em 2002, esta vacina foi licenciada no Brasil. A proteína CRM 197 é uma variante não tóxica da toxina diftérica, isolada de culturas de Corynebacterium diphtheriae cepa C7.

Os sorotipos presentes nesta vacina representavam $83 \%$ dos sorotipos responsáveis pelas doenças pneumocócicas invasivas nas crianças e aproximadamente $60 \%$ dos sorotipos responsáveis pelas otites pneumocócicas $^{47}$, e 65 a $68 \%$ dos responsáveis pelas doenças 
pneumocócicas em adultos nos EUA ${ }^{48}$. De acordo com últimos dados da Organização Panamericana de Saúde, os sete sorotipos presentes na vacina conjugada heptavalente representariam $79,1 \%$ dos sorogrupos das doenças pneumocócicas invasivas nas crianças com até 5 anos de idade e representariam 33,6\% dos sorotipos das doenças pneumocócicas invasivas em adultos no Brasil $^{13}$.

\subsubsection{Vacina antipneumocócica conjugada em crianças não infectadas por HIV}

No estudo de imunogenicidade da vacina heptavalente em crianças Shinefield et al $^{49}$ observaram uma resposta após três doses de vacina em 97\% das crianças, com concentrações de anticorpos que variaram de 1,01 $\mu \mathrm{g} / \mathrm{mL}$ para sorotipo $9 \mathrm{~V}$ a $3,72 \mu \mathrm{g} / \mathrm{mL}$ para sorotipo 14 . Na avaliação pré dose de reforço, aplicada entre 12 a 15 meses de idade, houve uma queda marcante da concentração de anticorpos para abaixo de $0,23 \mu \mathrm{g} / \mathrm{mL}$, para todos os sorotipos, exceto o 14 (concentração de $1,94 \mu \mathrm{g} / \mathrm{mL}$ ). A percentagem de crianças que mantinha concentrações acima de $1,0 \mu \mathrm{g} / \mathrm{mL}$ era de $51 \%$ para sorotipo $9 \mathrm{~V}$ e $89 \%$ para sorotipo 14 .

A Organização Mundial da Saúde tem adotado o ponto de corte de 0,35 $\mu \mathrm{g} / \mathrm{mL}$ como concentração protetora contra doenças pneumocócicas invasivas para crianças que receberam vacinas conjugadas ${ }^{50,51}$.

Adotando o critério de corte de $0,35 \mu \mathrm{g} / \mathrm{mL}$, Vieira et al, em estudo conduzido no Brasil, observaram resposta vacinal adequada em 100\% das 
crianças nefropatas que receberam vacina antipneumocócica conjugada heptavalente ${ }^{52}$. Outros estudos avaliaram a eficácia da vacina PC7V aplicadas em crianças de até 2 anos de idade. Foram observadas eficácia de 83 a 94\% contra doenças pneumocócicas invasivas por sorotipos vacinais $^{53,54}$ e $18 \%$ contra pneumonias diagnosticadas por critérios radiológicos ${ }^{55}$.

Além disso, estudo realizado nos EUA avaliando o impacto da introdução da vacina PC7V no calendário vacinal de rotina nas crianças abaixo de 2 anos de idade observou uma redução de $75 \%$ na doença pneumocócica invasiva, quando comparados períodos pré implantação da vacina ao período pós introdução da vacina. Essa redução também ocorreu nas faixas etárias não indicadas para vacinação, evidenciando o efeito rebanho promovido por esta vacina. Adicionalmente, observou-se também o impacto na redução de isolados de cepas de pneumococo penicilinaresistentes ${ }^{56-58}$.

\subsubsection{Vacina antipneumocócica conjugada em adultos não infectados por HIV}

O uso da vacina antipneumocócica conjugada em adultos ainda é controverso na literatura ${ }^{59-61}$. Além disso, a concentração de anticorpo necessária para proteção contra doenças invasivas pneumocócicas também não está bem estabelecida. 
Shelly et al avaliaram a resposta imunológica para os sorotipos 14 e 6B após vacinação com a vacina antipneumocócica conjugada pentavalente (PC5V), composta por sorotipos 6B, 14, 19C, 19F e 23, comparada à PP23V em adultos jovens e idosos ${ }^{62}$. Observaram que, para sorotipo 14, houve resposta anticórpica similar entre ambas as vacinas em população jovem (68\% versus $64 \%$, respectivamente), porém com resposta inferior para vacina conjugada em voluntários acima de 60 anos de idade (32\% versus $67 \%$ ). Entretanto, a conjugação do sorotipo 6B representou um aumento de imunogenicidade para ambos os grupos de população, com a imunogenicidade de $36 \%$ para vacina polissacarídica contra 56\% para vacina conjugada.

Roux et al compararam a imunogenicidade das vacinas PP23V e PC7V em idosos saudáveis de 70 a 79 anos de idade na Alemanha e observaram maiores títulos médios geométricos (TMG) das concentrações dos anticorpos no grupo vacinado com PC7V, exceto para sorotipo $19 \mathrm{~F}^{63}$. Resultado similar foi encontrado pelo Goldblatt et al em estudo realizado no Reino Unido em indivíduos de 50 a 80 anos de idade ${ }^{64}$.

Em estudo mais recente, Lazarus et $\mathrm{al}^{65}$ observaram que a vacina PC7V promoveu maiores TMG de IgG sorotipos específicos para os sorotipos 4, 9V, 18C e 23F um mês após a vacinação nos indivíduos entre 50 a 70 anos de idade. 


\subsubsection{Vacina antipneumocócica conjugada em adultos infectados por} HIV

Em estudo comparativo da resposta de anticorpos à PP23V e à PC5V em adultos infectados por HIV, Ahmed et al observaram que ambas vacinas promoveram aumento dos títulos de anticorpos para todos os sorotipos incluídos na vacina conjugada pentavalente $(6 \mathrm{~B}, 14,18 \mathrm{C}, 19 \mathrm{~F}$ e 23$)$ tanto em voluntários HIV infectados quanto naqueles não-HIV infectados ${ }^{66}$. Entretanto, nos indivíduos não infectados pelo HIV, houve maior aumento dos títulos médios geométricos dos anticorpos específicos contra sorotipos 6B, 18C e 23F, diferença esta não observada em indivíduos HIV-positivos.

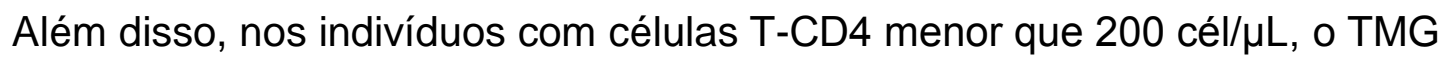
do sorotipo $19 \mathrm{~F}$ foi menor no grupo que recebeu a vacina conjugada ${ }^{66}$. Observaram também que nos adultos HIV positivos com células T-CD4 superiores a 500 cél/ $/ \mathrm{L}$ a resposta à vacina polissacarídica foi similar aos indivíduos não infectados pelo HIV.

No estudo conduzido por Feikin et al, a imunogenicidade com uma dose da vacina PP23V foi similar a uma dose da vacina PC7V para sorotipos 4, 6B, 9V, 14 e 23F, em adultos infectados pelo $\mathrm{HIV}^{67}$.

French et al avaliaram a eficácia da vacina PC7V na prevenção da recorrência de doença pneumocócica invasiva em adultos infectados por HIV $^{68}$. Observaram eficácia vacinal de $74 \%$ quando consideradas doenças pneumocócicas invasivas causadas pelos sete sorotipos presentes na vacina e sorotipo $6 \mathrm{~A}$. 


\subsection{Esquemas combinados da vacinação antipneumocócica}

Devido à ausência da resposta de memória e à queda dos níveis de anticorpo 3 a 5 anos após aplicação da vacina polissacarídica, várias combinações distintas foram testadas em adultos idosos e em algumas populações específicas.

\subsubsection{Combinação de vacinas polissacarídicas}

Em 1997, o CDC propôs a revacinação com vacina PP23V em idosos acima de 65 anos de idade, 5 anos após a vacinação anterior, desde que a primeira dose tivesse sido aplicada antes de 65 anos de idade ${ }^{69}$. Entretanto, estudos evidenciaram que os títulos médios geométricos das concentrações de anticorpos na revacinação eram inferiores aqueles alcançados após a primeira vacinação ${ }^{70,71}$. Esta observação foi atribuída ao fenômeno de hiporresponsividade ou tolerância imunológica.

Hiporresponsividade refere-se à incapacidade do sistema imunológico de montar uma resposta de magnitude igual ou superior após doses de reforço àquela induzida na primeira vacinação ${ }^{72}$. Os mecanismos envolvidos nesse fenômeno à ausência da resposta vacina às doses subsequentes das vacinas polissacarídicas ainda não estão esclarecidos. Brynjolfsson et $\mathrm{al}^{73}$ demonstraram que a apoptose dos linfócitos B de memória polissacáride específica poderia ser uma das causas relacionadas a este fenômeno. Além disso, Granoff et $\mathrm{al}^{74}$ também propuseram que a exposição às vacinas 
polissacarídicas induz uma resposta imune linfócito $\mathrm{T}$ independente onde as células $B$ de memória são estimuladas mas não repostas, resultando em completa depleção do pool de células de memória e uma resposta atenuada na reexposição ao mesmo polissacarídeo. Além disso, como o fenômeno de hiporresponsividade é polissacarídeo-específico, mecanismos regulatórios também não estão afastados ${ }^{72}$.

Outra questão que envolve o fenômeno de hiporresponsividade é se esse efeito é tempo dependente. Davidson et $\mathrm{al}^{75}$ não observaram diferença na resposta anticórpica entre primeira ou segunda dose da PPV23, esta aplicada pelo menos 6 anos após a primeira dose, em adultos residentes da Alaska, portadores de doenças crônicas. Esta observação sugere que o fenômeno da hiporresponsividade a PPV23 pode ser tempo-limitado ${ }^{76}$.

\subsubsection{Combinação de vacina polissacarídica com vacina conjugada}

O benefício de esquemas combinados compostos por vacinas antipneumocócicas polissacarídicas e vacinas conjugadas com intuito de incrementar a resposta anticórpica é discutido por diversos autores.

Kroon et al observaram que o booster com vacina PP23V administrada nove meses após vacinação prévia com duas doses da vacina antipneumocócica tetravalente aplicadas com intervalo de um mês promoveu um aumento dos títulos de anticorpo para sorotipos 6B, 14, 19F e 23F em adultos infectados pelo $\mathrm{HIV}^{77}$. 
Jackson et al avaliaram resposta anticórpica à vacina PP23V ou a diferentes volumes da vacina PC7V $(0,1 ; 0,5 ; 1$ ou $2 \mathrm{~mL})$ em idosos saudáveis de 70 a 79 anos idade, previamente vacinados com PP23V. Observaram maiores títulos médios geométricos das concentrações dos anticorpos dos sorotipos 4, 9V, 18C e $23 \mathrm{~F}$ nos indivíduos vacinados com $1 \mathrm{~mL}$ de $\mathrm{PC} 7 \mathrm{~V}^{78}$. Não houve diferença entre aqueles vacinados com $1 \mathrm{~mL}$ da PC7V em relação àqueles vacinados com $2 \mathrm{~mL}$ da PC7V.

Goldblatt et $\mathrm{al}^{64}$ avaliaram a resposta anticórpica do booster com PC7V ou PP23V em indivíduos de 50 a 80 anos de idade, 6 meses após aplicação da vacina PC7V. Não observaram diferenças estatisticamente significantes nos títulos médios geométricos das concentrações de anticorpo entre as duas estratégias nem em relação à dose única com PC7V.

Feikin et al não observaram diferença estatisticamente significante na concentração de anticorpos em adultos HIV infectados vacinados com booster de PC7V ou PP23V aplicadas 8 semanas após vacinação prévia com PC7V, quando comparada aos níveis após única dose da PC7V. As concentrações de anticorpos em ambos os grupos foram significantemente superior à pré-vacinal ${ }^{67}$. Além disso, também não foi observada diferença estatística na concentração de anticorpos entre esquemas PC7V+PC7V e $P C 7 V+P P 23 V$.

Lesprit et al observaram incremento no título de anticorpos no reforço com vacina PP23V quatro semanas após aplicação da PC7V em indivíduos infectados pelo HIV com contagens de células T-CD4 entre 200 a 500 cél $/ \mathrm{mm}^{3} 79$. 


\section{4 - Estado de colonização de S. pneumoniae após a vacinação}

Sabe-se que o principal reservatório de $S$. pneumoniae é a nasofaringe. Taxas de colonização variam de acordo com a idade e estimase que 30 a $70 \%$ das crianças e menos que $10 \%$ dos adultos são colonizados pelo S. pneumoniae ${ }^{80}$.

Nicoletti et $a^{81}$ observaram que na Cidade de São Paulo, indivíduos infectados pelo HIV apresentavam uma prevalência de colonização de nasofaringe por S. pneumoniae de $17 \%$, sendo que os sorotipos mais prevalentes foram $14(29,7 \%), 6 \mathrm{~B}(10,9 \%), 9 \mathrm{~V}(9,4 \%), 10 \mathrm{~A}(7,8 \%), 23 \mathrm{~F}, 19 \mathrm{~F}$ e 18C (6,3\% cada). Todos esses sorotipos estão representados na vacina conjugada heptavalente, exceto o $10 \mathrm{~A}$.

O impacto da vacina antipneumocócica sobre a colonização da nasofaringe por S. pneumoniae foi avaliado em diversos estudos. Durante a Segunda Guerra Mundial, MacLeod et al observaram uma redução de 50\% no estado do portador de pneumococo em voluntários vacinados com uma vacina experimental ${ }^{82}$.

Dagan et al realizaram um estudo comparativo entre as vacinas polissacarídica e conjugada na redução do estado de portador de nasofaringe nas crianças abaixo de 2 anos de idade ${ }^{83}$. Observaram que um ano após a vacinação, nos grupos que receberam uma ou duas doses (segunda dose aplicada 3 meses após a primeira) de PC7V, a prevalência de portadores de pneumococos com os sorotipos incluídos na vacina reduziu de $21 \%$ para $14 \%$, e de $25 \%$ para $11 \%$, respectivamente. Em contraste, 
essa redução não foi observada no grupo que recebeu PP23V (28\% versus $25 \%$ após a imunização).

Em relação à possível mudança de sorotipos de pneumococo induzido após a vacinação, esse mesmo estudo observou que um ano após a vacinação, houve aumento da prevalência de portadores de sorotipos não incluídos na vacina conjugada, independentemente da vacina aplicada ${ }^{83}$. Não se observou a alteração de perfil de resistência antimicrobiana com a vacinação. $\mathrm{Na}$ análise da relação de nível de anticorpo pós-vacinal com o estado de portador, não se observou nenhuma correlação entre eles para todos os sorotipos analisados.

A redução da colonização de orofaringe após a vacinação também foi observada por Obaro et al com a vacina antipneumocócica conjugada pentavalente ${ }^{84}$. Na análise de 6 meses após a vacinação, notou-se uma redução significativa da colonização por pneumococos, tanto nas crianças que receberam duas doses quanto nas que foram vacinadas com três doses.

O efeito da imunização antipneumocócica na colonização de orofaringe por pneumococos em adultos HIV infectados foi avaliado por Rodriguez-Barradas et al com vacinas polissacarídica 23-valente e conjugada pentavalente ${ }^{85}$. Estes autores observaram que não houve redução do estado de portador com nenhuma das vacinas. Neste estudo, os sorogrupos mais freqüentemente encontrados em indivíduos norteamericanos infectados por HIV foram 6, 14, 8, 19, 22 e 18. 
Lo et al também não observaram influência da vacina PP23V no estado de portador de pneumococo entre indivíduos acima de 15 anos de idade, infectados pelo HIV ${ }^{86}$.

Os dados disponíveis sugerem que a vacina conjugada influencia no estado de portador de nasofaringe, diferentemente do que é observado com a vacina polissacarídica.

\subsection{Justificativa}

Alguns dados disponíveis na literatura até o momento apresentam resultados conflitantes em relação ao efeito das vacinas antipneumocócicas em adultos infectados por HIV. O uso da vacina antipneumocócica polissacarídica 23 valente tem mostrado resultado insatisfatório tanto em relação à imunogenicidade sorotipo específico quanto em relação à eficácia clínica nesta população.

Em relação às vacinas antipneumocócicas conjugadas, que interferem no estado de colonização, alguns estudos observaram melhor resposta anticórpica para alguns sorotipos quando comparada à vacina polissacarídica, porém, outros estudos observaram resultados distintos.

Ainda é controverso, também, na literatura, o efeito da revacinação tanto com vacina antipneumocócica polissacarídica quanto com as conjugadas. 
Em decorrência de todas essas controvérsias, propõe-se este ensaio clínico, com diferentes esquemas vacinais antipneumocócicos, para investigar a resposta de anticorpos pós-vacinal em uma população de adultos infectados pelo HIV. 
Objetivos $\mid \mathbf{2 3}$

\section{OBJETIVOS}


Objetivo primário:

Comparar a resposta sorológica de anticorpos, 60 e 180 dias após vacinação contra S.pneumoniae em adultos infectados pelo HIV, com três diferentes esquemas:

- vacina antipneumocócica polissacarídica 23 valente (PP23V) e após 60 dias, placebo (soro fisiológico);

- vacina antipneumocócica conjugada 7 valente (PC7V) e após 60 dias, placebo (soro fisiológico);

- vacina antipneumocócica conjugada 7 valente e, após 60 dias, vacina antipneumocócica polissacarídica 23-valente (PC7V + PP23V)

Objetivo secundário:

> Avaliar os eventos adversos após a vacinação antipneumocócica nesta população.

Avaliar o estado de portador de S. pneumoniae nessa mesma amostra de população estudada. 
Casuística e Métodos|25

3 Casuística e Métodos 
Ensaio clínico, cego e randomizado para testar a resposta sorológica de anticorpos pós-vacinal com três diferentes esquemas vacinais antipneumocócicos em adultos infectados pelo HIV.

\section{1 - Casuística}

Foram recrutados para o estudo os pacientes em acompanhamento no Serviço de Extensão de Atendimento aos Pacientes HIV/AIDS - "Casa da Aids" - Hospital das Clínicas da Faculdade de Medicina da Universidade de São Paulo.

Durante as consultas de rotina, os potenciais candidatos ao estudo foram identificados pelos médicos infectologistas e estes pacientes foram encaminhados ao pesquisador que informava sobre o estudo e esclarecia as dúvidas. Para os pacientes que concordavam em participar do estudo, foi aplicado o termo de consentimento livre e esclarecido (anexo I).

Foram considerados elegíveis para estudo os indivíduos infectados pelo HIV (testes imunoenzimático e Western Blot positivos, e confirmação com teste imunoenzimático na segunda amostra), com 18 a 60 anos de idade no momento da triagem, e que possuíam contagem de linfócitos TCD4 $\geq 200 \mathrm{cél} / \mathrm{mm} 3 \mathrm{em}$ dois testes nos últimos 6 meses antes da randomização. Foram incluídos aqueles que demonstraram capacidade de compreensão e assinaram o termo de consentimento livre e esclarecido (anexo I). 
Critérios de exclusão: a) presença de qualquer doença febril aguda no momento da vacinação; b) vigência de alguma doença definidora de aids (critério CDC 1997), no momento da inclusão; c) imunização prévia contra pneumococo, com vacina polissacarídica 23-valente ou vacina antipneumocócica conjugada; d) ser portador de qualquer neoplasia maligna; e) uso de imunoglobulina ou interferon nos últimos 3 meses; f) gravidez; g) antecedente de reações alérgicas a qualquer componente das vacinas.

Os pacientes foram randomizados em três grupos:

- Grupo A (PP23V) - receberam vacina antipneumocócica polissacarídica 23 valente e, após 60 dias, placebo (soro fisiológico);

- Grupo B (PC7V) - receberam vacina antipneumocócica conjugada 7 valente e, após 60 dias, placebo (soro fisiológico);

- Grupo C (PC7V+PP23V) - receberam vacina antipneumocócica conjugada 7 valente e, após 60 dias, vacina polissacarídica 23 valente.

O cálculo da amostra foi baseado em dados obtidos na literatura do título médio geométrico (TMG) dos níveis de anticorpos para os sorotipos 6B, 9V e 14 após vacinação anti-pneumocócica polissacarídica e conjugada em adultos ${ }^{67}$, com nível de significância de 0,05 , poder de teste de 0,80 e perda de seguimento de $10 \%$, resultando em 140 sujeitos em cada grupo. Assim, programou-se inicialmente amostra de 420 indivíduos.

Para randomização foi utilizado esquema de blocos de três com intuito de alcançar uma distribuição homogênea entre os grupos. A tabela de 
randomização foi obtida através do programa de estatística Epi-Info versão 6.04, com obtenção de 170 números de até três dígitos. Seguindo orientação do profissional estatístico, os números obtidos foram agrupados de tal modo que os números entre 0 e 142 foram denominados 1, entre 143 e 285 foram denominados 2, entre 286 e 428, denominados 3, entre 429 e 571, denominados 4, entre 572 e 714, denominados 5, entre 715 e 856, denominados 6 , e entre 857 e 999, denominados 7 . Todos os números que tiveram denominação 7 foram excluídos, obtendo-se assim 140 casas de número 1 a 6 (anexo II). Cada número de 1 a 6 corresponde a um dos blocos $A C B, B A C, C B A, A B C, B C A$ ou $C A B$. Cada letra corresponde a um dos esquemas vacinais (grupos $\mathrm{A}, \mathrm{B}$ e $\mathrm{C}$ ).

\section{2 - Metodologia}

Após a assinatura do termo, foi realizada, pelo pesquisador, uma entrevista e revisão do prontuário para checagem dos critérios de inclusão e exclusão, obtenção dos dados demográficos (sexo e idade) e informações relacionadas à infecção pelo HIV (tempo da infecção, classificação CDC, último valor de linfócitos T-CD4, última contagem da carga viral plasmática de HIV, terapia antirretroviral e uso recente de antibióticos) (anexo III).

Para efeito da análise, a carga viral plasmática de HIV foi classificada em menor ou igual a 400 cópias $/ \mathrm{mL}$ e maior que 400 cópias $/ \mathrm{mL}$, uma vez que os exames laboratoriais disponíveis no momento do início do estudo tinham o limite inferior de detecção de 400 cópias $/ \mathrm{mL}$. 
A seguir, era realizada a coleta de 10 a $15 \mathrm{~mL}$ de sangue venoso periférico para determinação das concentrações de anticorpos antipneumocócicos para os sorotipos 6B, $9 \mathrm{~V}$ e 14, e contagens de linfócitos T-CD4 e carga viral plasmática de HIV.

Antes da aplicação da primeira dose da vacina foi coletada amostra de esfregaço da nasofaringe para avaliação do estado de colonização. A técnica da coleta de nasofaringe foi realizada conforme a padronização da Organização Mundial da Saúde $(\mathrm{OMS})^{87}$. Foi utilizado swab com alginato de cálcio para obtenção da amostra e a semeadura em placas de agar-sangue carneiro 5\% com gentamicina foi realizada logo após a obtenção da amostra, eliminando a necessidade de swab com meio de transporte.

O procedimento da coleta de sangue foi repetido 60 e 180 dias após a primeira intervenção e a coleta de nasofaringe foi repetida 180 dias após a primeira vacinação.

\subsubsection{Vacinação}

A vacina foi aplicada logo após os procedimentos da coleta. Apenas o profissional que realizou a aplicação da vacina conhecia qual número (de 1 a 6) correspondia a qual bloco, assim como o grupo para o qual o paciente foi alocado. Os pesquisadores e os pacientes desconheciam qual esquema estava sendo seguido.

Para vacina PP23V foi utilizada a Vacina Antipneumocócica Polissacarídica 23 valente da Aventis Pasteur, dose de 0,5mL, composta por 
polissacarídeos purificados de $S$. pneumoniae dos sorotipos 1, 2, 3, 4, 5, 6B, 7F, 8, 9N, 9V, 10A, 11A, 12F, 14, 15B, 17F, 18C, 19A, 19F, 20, 22F, 23F e 33F.

A vacina PC7V utilizada no estudo foi a vacina Antipneumocócica Conjugada sete valente da Wyeth, dose de $0,5 \mathrm{~mL}$, contendo polissacarideos de sorotipos 4, 6B, 9V, 14, 18C, 19F e 23F, conjugados individualmente à proteína diftérica $\mathrm{CRM}_{197}$.

\subsubsection{Avaliação das concentrações de anticorpos antipneumocócicos}

Para avaliação da concentração de anticorpos antipneumocócicos, foram coletadas amostras de sangue imediatamente antes da imunização, 60 dias após (ou seja, imediatamente antes da segunda intervenção) e 180 dias após a primeira vacinação (ou seja, 120 dias após a segunda coleta).

Logo após a coleta as amostras de sangue foram centrifugadas para obtenção do soro. O material obtido foi aliquotado em 5 tubos de Eppendorf de $1 \mathrm{~mL}$ cada, que foram conservados a $-70^{\circ} \mathrm{C}$ de temperatura. Para determinação das concentrações de anticorpos lgG contra os sorotipos 6B, 9V e 14 foi realizado ensaio imunoenzimático (ELISA).

Tomando como base o estudo de Nicoletti ${ }^{81}$, único com análise de prevalência dos sorotipos mais importantes na colonização de pacientes HIV positivos no nosso meio, as amostras de sangue foram utilizadas para determinação das concentrações de anticorpos contra pneumococos dos sorotipos 6B, 9V e 14 . 
As amostras de soro foram adsorvidas polissacáride da parede celular a $5 \mu \mathrm{g} / \mathrm{mL}$ e com antígeno polissacarídeo $22 \mathrm{~F}$ a $5 \mu \mathrm{g} / \mathrm{mL}$, e realizado ensaio imunoenzimático seguindo as recomendações padronizadas pela $\mathrm{OMS}^{88}$. As reações foram consideradas adequadas quando apresentavam coeficiente de variação de até $30 \%$. Todos os resultados com título de concentração abaixo de $0,1 \mu \mathrm{g} / \mathrm{mL}$ ou acima de $100 \mu \mathrm{g} / \mathrm{mL}$ foram repetidos para conferência.

Para evitar as variações interplacas, as reações de todas as amostras do mesmo paciente foram executadas na mesma placa de ELISA. Todas as placas utilizadas no projeto foram do mesmo lote, eliminando o risco de variabilidade entre diferentes lotes de placa. Para evitar as interferências dos reagentes, todos os reagentes utilizados foram de acordo com as recomendações do protocolo e foi utilizada água apirogênica da Baxter $\AA^{\circledR}$ em todas as etapas da reação.

As reações de ELISA foram realizadas inicialmente no Laboratório de Bacteriologia do Instituto Adolfo Lutz - São Paulo e, posteriormente, no Laboratório de Investigação Médica de Bacteriologia (LIM-54) do Hospital das Clínicas da Faculdade de Medicina USP.

Para comparar a resposta anticórpica pós-vacinal, os seguintes critérios foram analisados: a) proporção de indivíduos com concentrações de anticorpos contra pneumococos dos sorotipos $6 \mathrm{~B}, 9 \mathrm{~V}$ e $14 \geq 0,35 \mu \mathrm{g} / \mathrm{mL}$ e $\geq$ $1,0 \mu \mathrm{g} / \mathrm{mL}$ b) proporção de indivíduos com aumento dessas concentrações maior que 4 vezes em relação à concentração basal, e c) diferença entre 
concentrações de anticorpo de um mesmo indivíduo antes e após a intervenção.

\subsubsection{Colonização da nasofaringe}

Para avaliação da colonização da nasofaringe, as placas de cultura semeadas com material obtido do esfregaço de nasofaringe foram encaminhadas ao Laboratório de Bacteriologia do Instituto Adolfo Lutz - São Paulo, onde foram incubadas em estufa com tensão de 5 a $7 \%$ de $\mathrm{CO}_{2}$, à temperatura de $37^{\circ} \mathrm{C}$, por 24 horas. A identificação de S.pneumoniae seguiu a recomendação da $\mathrm{OMS}^{89}$, através da identificação da zona de alfahemólise, coloração de Gram, teste da Optoquina e teste de solubilidade em bile. A identificação do sorotipo foi realizada através das técnicas de Quelung e da Reação de polimerase em cadeia.

\subsubsection{Avaliação dos eventos adversos}

Os eventos adversos pós-vacinais foram avaliados através de questionário padrão (anexo IV). Todos os pacientes foram contactados pela pesquisadora e alguns por aluna de iniciação científica participante deste projeto, a partir do sétimo dia após cada aplicação (vacina ou placebo). Para aqueles que não foram localizados no primeiro contato telefônico, tentativas sucessivas foram realizadas até 30 dias após a vacinação. 
Para avaliação de eventos adversos pós-vacinação, os eventos locais (dor, calor, eritema e enduração) foram classificados em "presente" ou "ausente", assim como os eventos sistêmicos (febre, mialgia e astenia).

\subsection{Aspectos Éticos}

Este estudo foi aprovado pelo Comitê de Ética em Pesquisa do Hospital das Clínicas da Faculdade de Medicina da Universidade de São Paulo, sob registro número 047/04 (anexo V), e recebeu financiamento da Fundação de Amparo à Pesquisa do Estado de São Paulo, processo número 2005/01414-7.

\subsection{Análise Estatística}

Para as comparações de proporção entre os grupos, foram utilizados testes $x^{2}$ ou testes de Fisher quando apropriado. Para comparação das médias das variáveis quantitativas, foram utilizados teste ANOVA ou Kruskal-Wallis quando a variável não apresentava adesão de normalidade. Todos os valores de $p$ foram bicaudais e considerou-se estatisticamente significante valores de $p \leq 0,05$.

Para avaliação das concentrações dos anticorpos antes e após as intervenções, as concentrações dos anticorpos foram transformadas em seu logaritmo natural (base e) com intuito de obter a normalidade na distribuição 
e foram expressa em títulos médios geométricos (TMG) com intervalo de confiança de $95 \%$.

Para análise dos eventos adversos, foram utilizados testes $x^{2}$.

Para a avaliação da colonização de nasofaringe, foi feita uma análise descritiva da taxa de colonização pelos sorotipos de S.pneumoniae, de $S$. grupo viridans ou outros agentes. Para análise comparativa da colonização nos momentos pré-vacinal e 180 dias após a primeira vacinação, foram utilizados testes $x^{2}$ e teste exato de Fisher quando apropriado.

Todos os dados foram coletados em planilhas de Microsoft Office Excel 2003 e as análises estatísticas foram feitos com programa EPI-Info versão 3.5.1. 
R e s u 1 t a d o s $\mid \mathbf{3 5}$

4 RESULTADOS 
No período de 01/10/2005 a 30/05/2009, foram incluídos 331 voluntários. A inclusão dos pacientes foi interrompida em 30/05/2009 devido às dificuldades de recrutamento.

Após os procedimentos da primeira visita, o primeiro retorno foi agendado para 60 dias após a primeira vacinação e o segundo retorno para 120 dias após a segunda intervenção.

Os voluntários que não compareceram na data agendada foram contactados e reagendados, até período máximo de 30 dias em relação à data inicialmente programada. Após esse limite, foram considerados como perda da amostra. Não houve diferenças estatisticamente significativas nas perdas entre os três grupos, tanto na primeira coleta pós-vacinal quanto na última visita (Figura1).

Assim, para análise pré-vacinal, havia 111 amostras do grupo A, 109 do grupo B e 110 do grupo C; para análise de 60 dias, havia 100 amostras do grupo A, 100 amostras do grupo B e 105 amostras do grupo C; para análise da última coleta, havia 89 amostras do grupo A, 91 amostras do grupo B e 91 amostras do grupo C. 


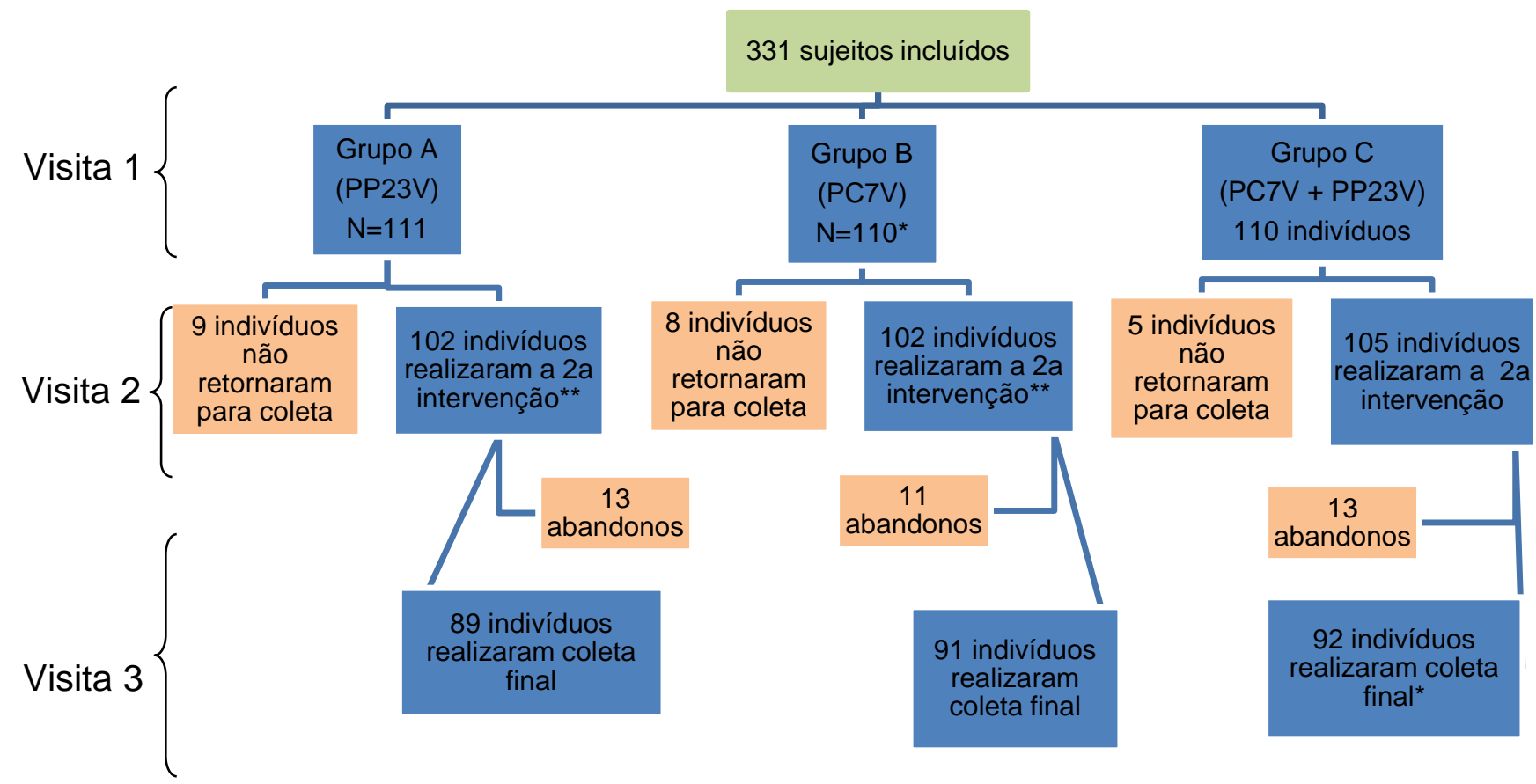

Figura 1 - Diagrama da inclusão dos pacientes em cada visita programada, para os três grupos ( $\mathrm{A}=\mathrm{PP23V}, \mathrm{B}=\mathrm{PC7V}, \mathrm{C}=\mathrm{PC} 7 \mathrm{~V}+\mathrm{PP} 23 \mathrm{~V}$ ) no estudo conduzido no SEAP-Casa da Aids, HC-FMUSP, de 10/2005 a 05/2009

* Perda acidental de uma amostra

${ }^{\star *}$ Perda acidental duas amostras

Dos 331 voluntários incluídos, $74,6 \%$ eram do sexo masculino, idade média de 40,6 anos de idade, tempo médio da infecção pelo HIV de 6,7 anos e $60,1 \%$ possuíam critério aids de acordo com a definição $C^{2} C^{16}$, ou seja, presença de doenças definidoras de aids ou contagem de células T-CD4 abaixo de $200 \mathrm{cél} / \mathrm{mm}^{3}$.

No momento da triagem, a média de linfócitos T-CD4 foi de 525 cél $/ \mathrm{mm}^{3}$ e $67,3 \%$ tinham carga viral de HIV abaixo de 400 cópias $/ \mathrm{mm}^{3}$. A maioria dos pacientes $(76,7 \%)$ estava em uso de terapia antirretroviral altamente potente.

Não foram observadas diferenças estatisticamente significativas nas características demográficas e nas variáveis relacionadas à infecção pelo 
HIV entre os indivíduos dos três grupos no momento da primeira vacinação (tabela 1).

Tabela 1 - Características demográficas e relacionadas à infecção pelo HIV dos indivíduos incluídos nos três grupos $(A=P P 23 V, B=P C 7 V$, $\mathrm{C}=\mathrm{PC7V}+\mathrm{PP23V}$ ) no momento da aplicação da primeira dose da vacina - SEAP-Casa da Aids, HC-FMUSP, de 10/2005 a 05/2009

\begin{tabular}{|c|c|c|c|c|}
\hline & $\begin{array}{c}\text { A } \\
(\mathrm{PP} 23 \mathrm{~V}) \\
\mathrm{N}=111\end{array}$ & $\begin{array}{c}\text { GRUPO } \\
\text { B } \\
(P C 7 V) \\
N=110\end{array}$ & $\begin{array}{c}C \\
(P C 7 V+P P 23 V) \\
N=110\end{array}$ & $p$ \\
\hline$\overline{\text { Sexo }}$ & $\mathrm{n}(\%)$ & $\mathrm{n}(\%)$ & $\mathrm{n}(\%)$ & \\
\hline Masculino & $77(69,5)$ & $86(78,2)$ & $84(76.4)$ & $0,282^{\mathrm{a}}$ \\
\hline Idade* & $\begin{array}{l}\text { Média }(\mathrm{dP}) \\
40,16(9,41)\end{array}$ & $\begin{array}{c}\text { Média(dP) } \\
40,12(8,51)\end{array}$ & $\begin{array}{c}\text { Média(dP) } \\
41,55(7,76)\end{array}$ & $0,370^{b}$ \\
\hline Classificação CDC & n (\%) & n (\%) & $\mathrm{n}(\%)$ & \\
\hline Aids & $65(58,6)$ & $65(59,1 \%)$ & $69(62,7 \%)$ & $0,790^{\mathrm{a}}$ \\
\hline $\begin{array}{l}\text { Contagem de } \\
\text { linfócitosT-CD4* }\end{array}$ & $\begin{array}{c}\text { Média (dP) } \\
548.42(303.92)\end{array}$ & $\begin{array}{c}\text { Média (dP) } \\
54451(23774)\end{array}$ & $\begin{array}{c}\text { Média }(\mathrm{dP}) \\
492.14(269.34)\end{array}$ & $0,067^{\circ}$ \\
\hline $\begin{array}{l}\text { Intocitos I-CD4 } \\
\text { Carga Viral }\end{array}$ & & & $492,14(269,34)$ & \\
\hline $\begin{array}{l}\text { Plasmática de HIV } \\
<400 \text { cópias } / \mathrm{mL}\end{array}$ & $\begin{array}{c}n(\%) \\
71(64)\end{array}$ & $\begin{array}{c}n(\%) \\
74(67,3)\end{array}$ & $\begin{array}{c}n(\%) \\
79(72,5)\end{array}$ & $0,395^{\mathrm{a}}$ \\
\hline $\begin{array}{l}\text { Uso de HAART } \\
\text { Sim }\end{array}$ & $\begin{array}{c}n(\%) \\
81(73)\end{array}$ & $\begin{array}{c}n(\%) \\
84(76,4)\end{array}$ & $\begin{array}{c}n(\%) \\
89(80,9)\end{array}$ & $0,375^{a}$ \\
\hline $\begin{array}{l}\text { a Teste Qui-quadrado } \\
\text { dP = Desvio padrão } \\
\text { Aids = Presença da co } \\
\text { em algum momento da } \\
\text { HAART = Terapia antir } \\
\text { *Apresenta adesão à c c } \\
\text { *A Não apresenta ades }\end{array}$ & $\begin{array}{l}\text { liagnóstico de } 1 \\
\text { amente potente } \\
\text { de normalidade } \\
\text { icão de normali }\end{array}$ & $\begin{array}{l}\text { Jallis } \\
\text { xo de } 200 \text { cél } / \mathrm{mL} \\
\text { sitivo }\end{array}$ & s & \\
\hline
\end{tabular}




\subsection{Imunogenicidade}

\subsubsection{Avaliação anticórpica pré-vacinal}

A tabela 2 mostra os resultados da comparação entre os três grupos das concentrações de anticorpos contra pneumococos sorotipo-específicos maiores ou iguais a $0,35 \mu \mathrm{g} / \mathrm{mL}$ e $1,0 \mu \mathrm{g} / \mathrm{mL}$, e dos títulos médios geométricos dos anticorpos antes da primeira vacinação. Não foram observadas diferenças estatisticamente significativas nessas análises entre os indivíduos dos três grupos.

Tabela 2 - Concentrações de anticorpos e títulos médios geométricos das concentrações dos anticorpos em adultos infectados pelo HIV incluídos nos três grupos (A=PP23V, $B=P C 7 V$, $\mathrm{C}=\mathrm{PC} 7 \mathrm{~V}+\mathrm{PP} 23 \mathrm{~V})$ antes da administração da $1^{\mathrm{a}}$ dose da vacina SEAP- Casa da Aids, HC-FMUSP, de 10/2005 a 05/2009

\begin{tabular}{|c|c|c|c|c|c|}
\hline & \multicolumn{3}{|c|}{ GRUPOS } & \multirow[b]{2}{*}{$p$} \\
\hline & & $\begin{array}{c}\text { A } \\
(\text { PP23V) } \\
N=111\end{array}$ & $\begin{array}{c}B \\
(P C 7 V) \\
N=109\end{array}$ & $\begin{array}{c}C \\
(P C 7 V+P P 23 V) \\
N=110\end{array}$ & \\
\hline \multicolumn{6}{|c|}{ Sorotipos } \\
\hline & Conc $\geq 0,35 \mu \mathrm{g} / \mathrm{mL}-\mathrm{n}(\%)$ & $76(68,5)$ & $68(62,4)$ & $70(63,6)$ & $0,607^{\mathrm{a}}$ \\
\hline \multirow[t]{3}{*}{ 6B } & Conc $\geq 1,00 \mu \mathrm{g} / \mathrm{mL}-\mathrm{n}(\%)$ & $46(41,4)$ & $29(26,6)$ & $40(36,4)$ & $0,064^{a}$ \\
\hline & TMG $(\mathrm{dP})$ & $0,73(4,03)$ & $0,51(3,89)$ & $0,57(4,00)$ & $0,144^{b}$ \\
\hline & Conc $\geq 0,35 \mu \mathrm{g} / \mathrm{mL}-\mathrm{n}(\%)$ & $75(67,9)$ & $59(54,1)$ & $64(58,2)$ & $0,113^{\mathrm{a}}$ \\
\hline \multirow[t]{3}{*}{$9 \mathrm{~V}$} & Conc $\geq 1,00 \mu \mathrm{g} / \mathrm{mL}-\mathrm{n}(\%)$ & $29(26,1)$ & $32(29,4)$ & $25(22,7)$ & $0,535^{\mathrm{a}}$ \\
\hline & $\mathrm{TMG}(\mathrm{dP})$ & $0,55(3,60)$ & $0,43(3,80)$ & $0,47(3,09)$ & $0,347^{b}$ \\
\hline & Conc $\geq 0,35 \mu \mathrm{g} / \mathrm{mL}-\mathrm{n}(\%)$ & $95(85,6)$ & $86(78,9)$ & $84(76,4)$ & $0,200^{a}$ \\
\hline \multirow[t]{2}{*}{14} & Conc $\geq 1,00 \mu \mathrm{g} / \mathrm{mL}-\mathrm{n}(\%)$ & $70(63,1)$ & $64(58,7)$ & $60(54,5)$ & $0,437^{\mathrm{a}}$ \\
\hline & TMG $(\mathrm{dP})$ & $1,82(4,68)$ & $1,52(6,02)$ & $1,39(5,46)$ & $0,488^{b}$ \\
\hline
\end{tabular}

a Qui-quadrado

${ }^{\mathrm{D}}$ ANOVA

$\mathrm{dP}=$ Desvio padrão

$\mathrm{N}=$ número total de indivíduos em cada grupo

$\mathrm{n}$ = número de indivíduos que satisfazem a condição descrita

Conc $=$ Concentração dos anticorpos $\quad$ TMG = Título médio geométrico 


\subsubsection{Avaliação anticórpica 60 dias após a primeira vacinação}

Para esta avaliação, tivemos 100 amostras dos sujeitos do grupo $\mathrm{A}$ (PP23V), 100 amostras do grupo B (PC7V) e 105 amostras do grupo C (PC7V+PP23V).

Os resultados das concentrações de anticorpos contra pneumococos sorotipo-específicos maiores ou iguais a $0,35 \mu \mathrm{g} / \mathrm{mL}$ e $1,0 \mu \mathrm{g} / \mathrm{mL}$, dos títulos médios geométricos dos anticorpos e da proporção de indivíduos com aumento das concentrações de anticorpos sorotipo-específicos maior ou igual a quatro vezes em relação às concentrações basais, 60 dias após a primeira vacinação, estão descritas na tabela 3.

Não foi observada diferença estatisticamente significativa entre os três grupos analisados, 60 dias após a primeira vacinação, em relação à proporção de indivíduos com concentração de anticorpos maior ou igual a $0,35 \mu \mathrm{g} / \mathrm{mL}$ ou a $1,0 \mu \mathrm{g} / \mathrm{mL}$, para os três sorotipos analisados, assim como para os títulos médios geométricos das concentrações de anticorpos (tabela 3).

A proporção de indivíduos com aumento da concentração de anticorpos sorotipos-específicos, em relação às concentrações basais, maior ou igual a quatro vezes, 60 dias após a primeira vacinação foi significativamente menor no grupo PP23V para os sorotipos 6B e 9V (tabela $3)$. 
Tabela 3 - Concentrações de anticorpos, títulos médios geométricos das concentrações dos anticorpos e proporção de indivíduos com aumento da concentração de anticorpos sorotipo-específicos maior ou igual a quatro vezes em relação às concentrações basais, em adultos infectados pelo HIV incluídos nos três grupos $(A=P P 23 V, B=P C 7 V, \quad C=P C 7 V+P P 23 V) 60$ dias após a administração da $1^{1}$ dose da vacina - SEAP-Casa da Aids, HC-FMUSP, de 10/2005 a 05/2009

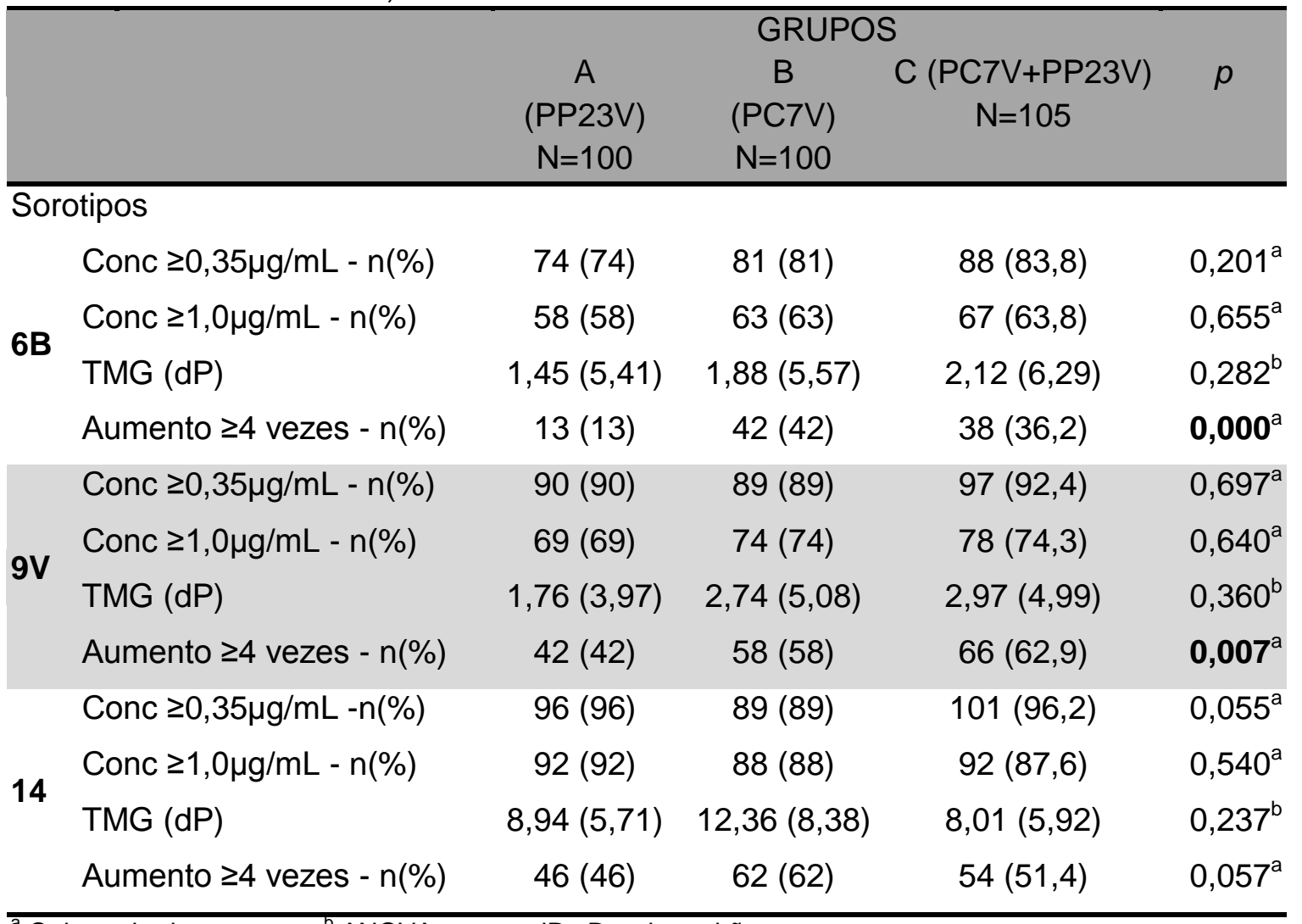

a Qui-quadrado $\quad{ }^{b}$ ANOVA $\mathrm{dP}=$ Desvio padrão

$\mathrm{N}=$ número total de indivíduos em cada grupo

$\mathrm{n}$ = número de indivíduos que satisfazem a condição descrita

Conc $=$ Concentração dos anticorpos $\quad T M G=$ Título médio geométrico

\subsubsection{Avaliação anticórpica 180 dias pós a primeira vacinação}

A análise das concentrações de anticorpos 180 dias após a primeira vacinação, para os três grupos de voluntários, foi realizada com 89 amostras 
do grupo PP23V, 91 amostras do grupo PC7V e 91 amostras do grupo PC7V+PP23V.

Os resultados das concentrações de anticorpos contra pneumococos sorotipo-específicos maiores ou iguais a $0,35 \mu \mathrm{g} / \mathrm{mL}$ e $1,0 \mu \mathrm{g} / \mathrm{mL}$, dos títulos médios geométricos dos anticorpos e da proporção de indivíduos com aumento das concentrações de anticorpos sorotipo-específicos maior ou igual a quatro vezes em relação às concentrações basais, 180 dias após a primeira vacinação, estão descritos na tabela 4 .

Não foram observadas diferenças estatisticamente significativas nas concentrações de anticorpos acima de $0,35 \mu \mathrm{g} / \mathrm{mL}$ ou de $1,0 \mu \mathrm{g} / \mathrm{mL}$, assim como nos títulos médios geométricos 180 dias após a primeira vacinação, entre os três grupos, para nenhum dos sorotipos avaliados (tabela 4).

A proporção de indivíduos com aumento da concentração de anticorpos sorotipos-específicos, em relação às concentrações basais, maior ou igual a quatro vezes, 180 dias após a primeira vacinação foi significativamente menor no grupo PP23V para os sorotipos 6B e 9V (tabela $4)$. 
Tabela 4 - Concentrações de anticorpos, títulos médios geométricos das concentrações dos anticorpos e proporção de indivíduos com aumento da concentração de anticorpos sorotipo-específicos maior ou igual a quatro vezes em relação às concentrações basais, em adultos infectados pelo HIV incluídos nos três grupos $(A=P P 23 V, B=P C 7 V, C=P C 7 V+P P 23 V) 180$ dias após a administração da $1^{a}$ dose da vacina - SEAP-Casa da Aids, HC-FMUSP, de 10/2005 a 05/2009

\begin{tabular}{|c|c|c|c|c|c|}
\hline & \multicolumn{3}{|c|}{ GRUPO } & \multirow{3}{*}{$p$} \\
\hline & & $\begin{array}{c}\text { A } \\
(P P ? 3 y /\end{array}$ & B & 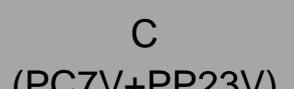 & \\
\hline & & $\mathrm{N}=89$ & $\mathrm{~N}=91$ & $N=91$ & \\
\hline \multicolumn{6}{|c|}{ Sorotipo } \\
\hline \multirow{4}{*}{$6 B$} & Conc $\geq 0,35 \mu \mathrm{g} / \mathrm{mL}-\mathrm{n}(\%)$ & $67(75,3)$ & $74(81,3)$ & $76(83,5)$ & $0,360^{a}$ \\
\hline & Conc $\geq 1,0 \mu \mathrm{g} / \mathrm{mL}-\mathrm{n}(\%)$ & $47(52,8)$ & $45(49,5)$ & $54(59,3)$ & $0,396^{a}$ \\
\hline & TMG (dP) & $1,02(4,93)$ & $1,24(5,40)$ & $1,76(5,50)$ & $0,083^{b}$ \\
\hline & Aumento $\geq 4$ vezes $-\mathrm{n}(\%)$ & $7(7,9)$ & $27(30)$ & $27(29,7)$ & $0,000^{a}$ \\
\hline \multirow{4}{*}{$9 \mathrm{~V}$} & Conc $\geq 0,35 \mu \mathrm{g} / \mathrm{mL}-\mathrm{n}(\%)$ & $79(88,8)$ & $77(84,6)$ & $81(89,0)$ & $0,604^{a}$ \\
\hline & Conc $\geq 1,0 \mu \mathrm{g} / \mathrm{mL}-\mathrm{n}(\%)$ & $56(62,9)$ & $55(60,4)$ & $60(65,9)$ & $0,744^{a}$ \\
\hline & TMG (dP) & $1,37(3,96)$ & $1,68(4,68)$ & $2,13(4,34)$ & $0,132^{b}$ \\
\hline & Aumento $\geq 4$ vezes $-\mathrm{n}(\%)$ & $25(28,1)$ & $41(45,6)$ & $41(45,1)$ & $0,025^{a}$ \\
\hline \multirow[t]{4}{*}{14} & Conc $\geq 0,35 \mu \mathrm{g} / \mathrm{mL}-\mathrm{n}(\%)$ & $86(96,6)$ & $81(89)$ & $86(94,5)$ & $0,105^{\mathrm{a}}$ \\
\hline & Conc $\geq 1,0 \mu \mathrm{g} / \mathrm{mL}-\mathrm{n}(\%)$ & $79(88,8)$ & $76(83,5)$ & $77(84,6)$ & $0,573^{a}$ \\
\hline & TMG (dP) & $6,72(5,91)$ & $9,32(8,27)$ & $6,35(6,27)$ & $0,348^{\mathrm{b}}$ \\
\hline & Aumento $\geq 4$ vezes $-\mathrm{n}(\%)$ & $35(39,3)$ & $50(55,6)$ & $42(46,2)$ & $0,092^{a}$ \\
\hline
\end{tabular}

Foram realizadas curvas evolutivas dos títulos médios geométricos das concentrações dos anticorpos obtidos com os três esquemas vacinais, ao longo do período do estudo, para os três sorotipos testados (gráficos 1, 2 e 3). 
Gráfico 1- Evolução dos títulos médios geométricos das concentrações dos anticorpos contra sorotipo 6B dos indivíduos dos três diferentes esquemas de vacinação. SEAP-Casa da Aids, HC-FMUSP

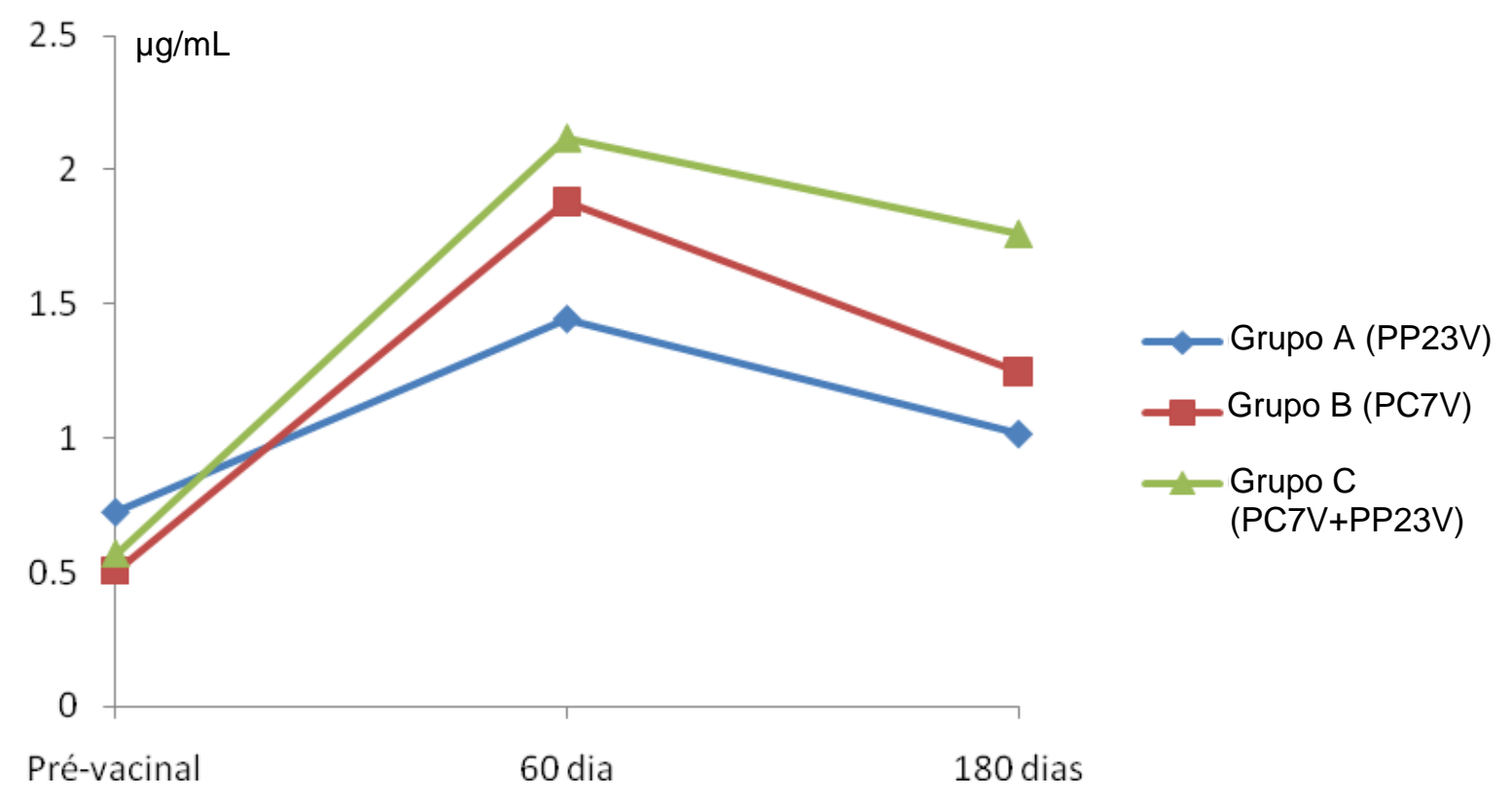

Gráfico 2 - Evolução dos títulos médios geométricos das concentrações dos anticorpos contra sorotipo $9 \mathrm{~V}$ dos indivíduos dos três diferentes esquemas de vacinação. SEAP-Casa da Aids, HC-FMUSP

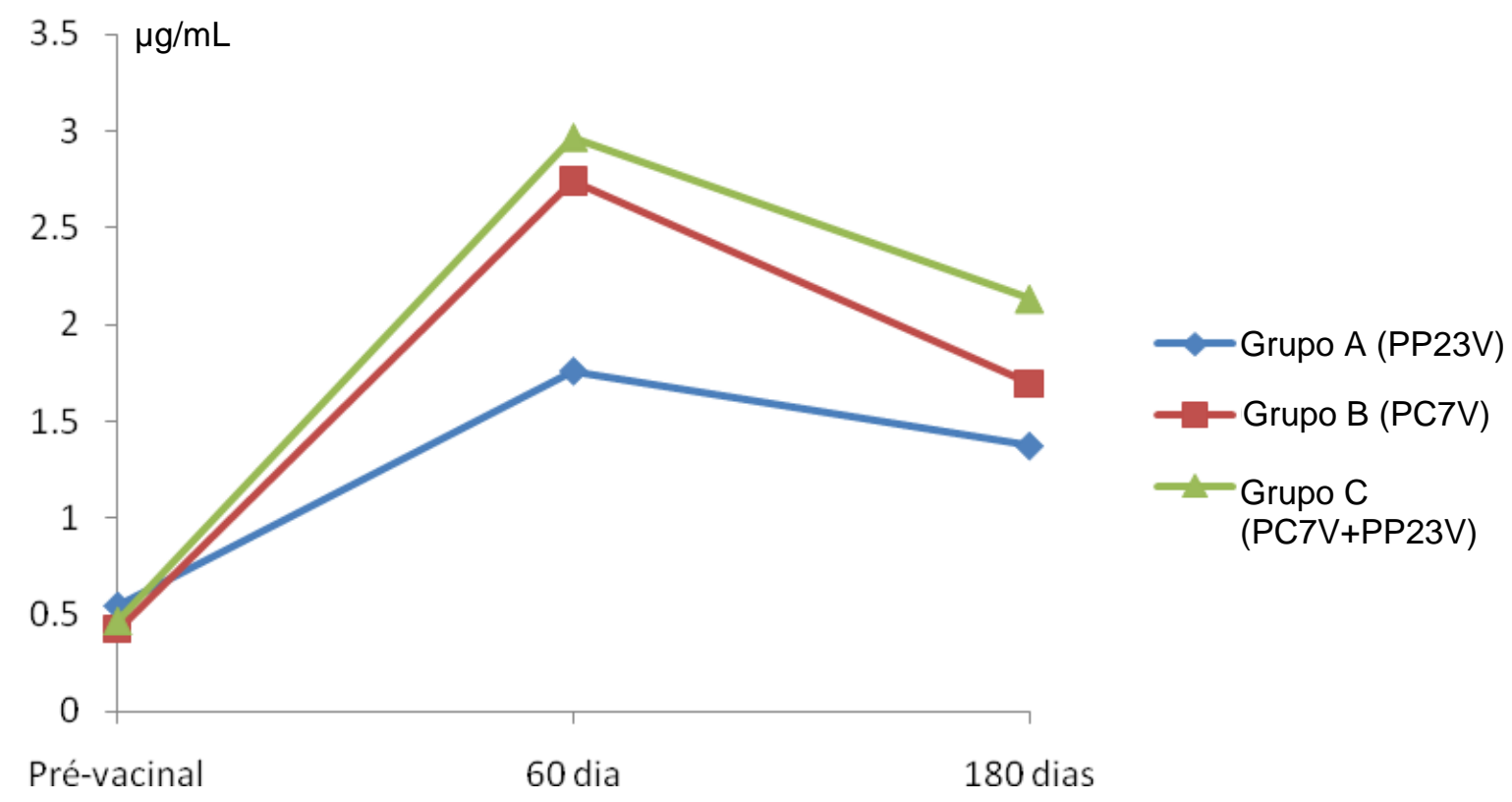


Gráfico 3 - Evolução dos títulos médios geométricos das concentrações dos anticorpos contra sorotipo 14 dos indivíduos dos três diferentes esquemas de vacinação. SEAP-Casa da Aids, HC-FMUSP

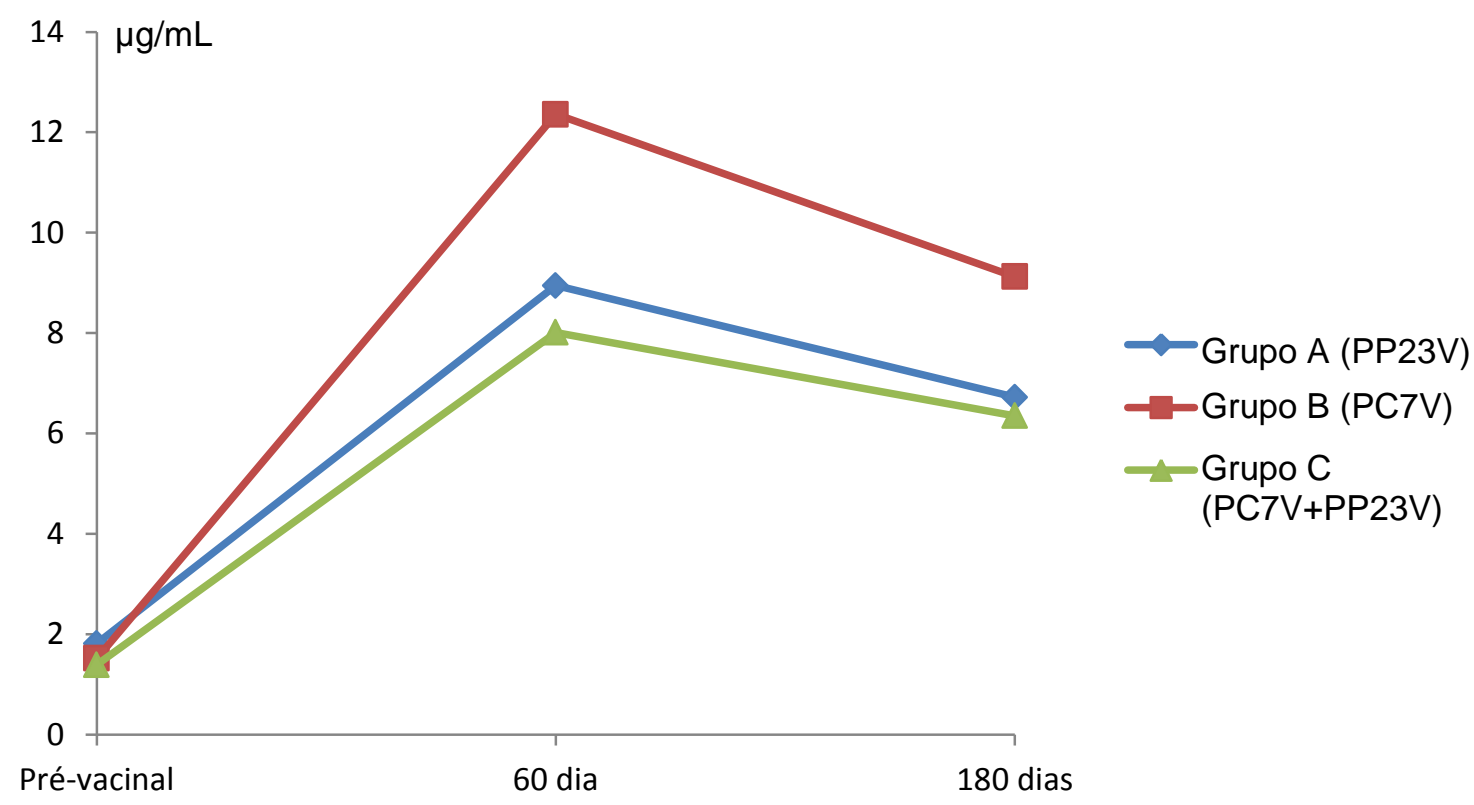

\subsubsection{Avaliação do efeito do booster com PP23V após PC7V na resposta anticórpica}

Para esta análise, foram disponíveis 91 amostras do grupo B (PC7V+placebo) e 91 amostras do grupo C (PC7V+PP23V). Foram comparados a proporção de indivíduos com concentração maior ou igual a 0,35 $\mu \mathrm{g} / \mathrm{mL}$, o título médio geométrico das concentrações dos anticorpos contra os sorotipos 6B, $9 \mathrm{~V}$ e 14 e a proporção de indivíduos com aumento na concentração de anticorpos maior ou igual a quatro vezes para cada sorotipo 120 dias após a vacinação em relação à concentração basal.

Não houve diferença estatisticamente significante entre os indivíduos que receberam reforço vacinal com PP23V em relação aos que receberam 
placebo na segunda intervenção, tanto na proporção dos indivíduos com concentração maior ou igual a 0,35 e $1,0 \mu \mathrm{g} / \mathrm{mL}$ quanto no título médio geométrico dos anticorpos, assim como na proporção de indivíduos com concentração de anticorpos maior ou igual a quatro vezes, 120 dias após a vacinação, em relação à concentração basal para todos os três sorotipos avaliados (tabela 5).

Tabela 5 - Concentrações de anticorpos, títulos médios geométricos das concentrações dos anticorpos e proporção de indivíduos com aumento da concentração de anticorpos sorotipo-específicos maior ou igual a quatro vezes em relação às concentrações basais, em adultos infectados pelo HIV dos grupos B (PC7V) e C (PC7V+PP23V) 120 dias após a administração da $1^{\mathrm{a}}$ dose da vacina - SEAP-Casa da Aids, HC-FMUSP, de 10/2005 a 05/2009

\begin{tabular}{|c|c|c|c|c|}
\hline & & & rupo & \\
\hline & & $\begin{array}{c}B \\
(P C 7 V) \\
N=91\end{array}$ & $\begin{array}{c}C \\
(\mathrm{PC} 7 \mathrm{~V}+\mathrm{PP} 23 \mathrm{~V}) \\
\mathrm{N}=91\end{array}$ & $p$ \\
\hline Sor & tipo & & & \\
\hline & Conc $\geq 0,35 \mu \mathrm{g} / \mathrm{mL}-\mathrm{n}(\%)$ & $74(81,3)$ & $76(83,5)$ & $0,697^{a}$ \\
\hline$C D$ & Conc $\geq 1,0 \mu \mathrm{g} / \mathrm{mL}-\mathrm{n}(\%)$ & $45(49,5)$ & $54(59,3)$ & $0,181^{a}$ \\
\hline $6 B$ & TMG (dP) & $1,24(5,40)$ & $1,76(5,50)$ & $0,174^{b}$ \\
\hline & Aumento $\geq 4$ vezes $-\mathrm{n}(\%)$ & $27(30)$ & $27(29,7)$ & $0,961^{\mathrm{a}}$ \\
\hline & Conc $\geq 0,35 \mu \mathrm{g} / \mathrm{mL}-\mathrm{n}(\%)$ & $77(84,6)$ & $81(89,0)$ & $0,381^{a}$ \\
\hline & Conc $\geq 1,0 \mu \mathrm{g} / \mathrm{mL}-\mathrm{n}(\%)$ & $55(60,4)$ & $60(65,9)$ & $0,443^{\mathrm{a}}$ \\
\hline $9 \mathrm{~V}$ & $\mathrm{TMG}(\mathrm{dP})$ & $1,68(4,68)$ & $2,13(4,34)$ & $0,305^{\mathrm{b}}$ \\
\hline & Aumento $\geq 4$ vezes $-\mathrm{n}(\%)$ & $41(45,6)$ & $41(45,1)$ & $0,946^{\mathrm{a}}$ \\
\hline 14 & Conc $\geq 0,35 \mu \mathrm{g} / \mathrm{mL}-\mathrm{n}(\%)$ & $81(89)$ & $86(94,5)$ & $0,178^{a}$ \\
\hline & Conc $\geq 1,0 \mu \mathrm{g} / \mathrm{mL}-\mathrm{n}(\%)$ & $76(83,5)$ & $77(84,6)$ & $0,839^{\mathrm{a}}$ \\
\hline & TMG (dP) & $9,32(8,27)$ & $6,35(6,27)$ & $0,193^{b}$ \\
\hline & Aumento $\geq 4$ vezes $-\mathrm{n}(\%)$ & $50(55,6)$ & $42(46,2)$ & $0,206^{a}$ \\
\hline
\end{tabular}




\subsection{Eventos adversos}

Foram avaliados os eventos adversos após a primeira e a segunda intervenção (tabela 6).

Para avaliação dos eventos após a primeira vacinação, foram obtidas 110 respostas dos indivíduos do grupo A (PP23V), 110 respostas do grupo B (PC7V) e 108 respostas do grupo C (PC7V+PP23V).

Para avaliação dos eventos após a segunda intervenção, foram obtidas 100 respostas dos indivíduos do grupo A (PP23V), 100 respostas do grupo B (PC7V) e 103 respostas do grupo C (PC7V+PP23V).

Tabela 6 - Eventos adversos locais e sistêmicos, em adultos infectados pelo HIV incluídos nos três grupos ( $A=P P 23 \mathrm{~V}, \quad B=P C 7 V$, $\mathrm{C}=\mathrm{PC7V}+\mathrm{PP} 23 \mathrm{~V})$ após a administração da $1^{\underline{a}}$ e $2^{\underline{a}}$ dose da vacina - SEAP-Casa da Aids, HC-FMUSP, 10/2005 a 05/2009

\begin{tabular}{|c|c|c|c|c|}
\hline & \multicolumn{3}{|c|}{ GRUPOS } & \multirow[b]{2}{*}{$p$} \\
\hline & $\begin{array}{c}\text { A } \\
(\text { PP23V) }\end{array}$ & $\begin{array}{c}\mathrm{B} \\
(\mathrm{PC} 7 \mathrm{~V})\end{array}$ & $\begin{array}{c}C \\
(P C 7 V+P P 23 V)\end{array}$ & \\
\hline \multirow[t]{2}{*}{ Após 1a. vacinação } & $\mathrm{N}=110$ & $\mathrm{~N}=110$ & $\mathrm{~N}=108$ & \\
\hline & n (\%) & $\mathrm{n}(\%)$ & $\mathrm{n}(\%)$ & \\
\hline Eventos locais & $43(39,1)$ & $46(41,8)$ & $44(40,7)$ & 0,917 \\
\hline Eventos sistêmicos & $27(24,5)$ & $36(32,7)$ & $41(38,0)$ & 0,100 \\
\hline \multirow[t]{2}{*}{ Após $2^{\mathrm{a}}$. vacinação } & $\mathrm{N}=100$ & $N=100$ & $\mathrm{~N}=103$ & \\
\hline & $\mathrm{n}(\%)$ & n (\%) & n (\%) & \\
\hline Eventos locais & $17(17)$ & $17(17)$ & $29(28,2)$ & 0,077 \\
\hline Eventos sistêmicos & $7(7)$ & $13(13)$ & $18(17,3)$ & 0,078 \\
\hline
\end{tabular}

a Qui-quadrado

$\mathrm{N}=$ número total de indivíduos em cada grupo

$\mathrm{n}=$ número de indivíduos que satisfazem a condição descrita 
Não foram observadas diferenças estatisticamente significativas tantos nos eventos adversos locais quanto nos sistêmicos entre os indivíduos vacinados com os três diferentes esquemas nos dois momentos da intervenção (tabela 6).

Entre os eventos adversos locais após a primeira vacinação, a dor no local da aplicação foi a queixa mais relatada nos três grupos $(36 \%, 41,8 \%$ e $40,7 \%$, respectivamente), sendo a maioria de leve intensidade. Quanto aos eventos adversos sistêmicos, a astenia foi a queixa mais relatada entre os indivíduos dos três grupos (19,8\%, 20\% e 23,1\%, respectivamente).

Para comparar a ocorrência de eventos adversos após uma única dose da vacina PP23V e da vacina PC7V, os indivíduos dos grupos B e C foram agrupados uma vez que ambos os grupos receberam PC7V na primeira intervenção.

Para esta análise, 110 respostas foram obtidas nos indivíduos vacinados com PP23V e 218 nos indivíduos com PC7V.

Não houve diferença estatisticamente significante nos eventos adversos locais entre os indivíduos vacinados com PP23V e PC7V, entretanto, os indivíduos vacinados com PC7V tiveram mais eventos sistêmicos $(p 0,048)$ (tabela 7$)$. 
Tabela 7 - Eventos adversos locais e sistêmicos após a primeira vacinação (PP23V e PC7V). SEAP-Casa da Aids, HC-FMUSP - 10/2005 a $05 / 2009$

\begin{tabular}{|c|c|c|c|c|}
\hline & & & \multicolumn{2}{|c|}{ EVENTO ADVERSO } \\
\hline & & & Local & Sistêmico \\
\hline \multirow[t]{3}{*}{ Vacina } & PP23V & $\mathrm{n}(\%)$ & $43(39,1)$ & $27(24,5)$ \\
\hline & PC7V & n (\%) & $90(41,3)$ & $77(35,3)$ \\
\hline & & $p$ & 0,702 & 0,048 \\
\hline
\end{tabular}

Com objetivo de avaliar se a exposição prévia à vacina antipneumocócica conjugada 7 valente altera a reatogenicidade da vacina antipneumocócica polissacarídica 23 valente, foi comparada a ocorrência dos eventos adversos após aplicação das vacinas antipneumocócica polissacarídica 23 valente, nos indivíduos do grupo A (aplicada na primeira intervenção) e do grupo C (aplicada na segunda intervenção, com exposição prévia à $\mathrm{PC7V}$ ).

Para esta análise, foram obtidas 110 respostas dos voluntários do grupo A e 103 do grupo B.

Não foram observadas diferenças estatisticamente significantes entre os grupos, tanto em eventos locais quanto eventos sistêmicos (tabela 8). 
Tabela 8 - Eventos adversos locais e sistêmicos após aplicação da vacina PP23V em indivíduos dos grupos A e C. SEAP-Casa da Aids, HC-FMUSP - 10/2005 a 05/2009

\begin{tabular}{ccccc} 
& & & \multicolumn{2}{c}{ EVENTO ADVERSO } \\
& & & Local & Sistêmico \\
\hline Grupo & $\mathrm{A}(\mathrm{PP} 23 \mathrm{~V})$ & $\mathrm{n}(\%)$ & $43(39,1)$ & $27(24,5)$ \\
& $\mathrm{C}(\mathrm{PC7V}+\mathrm{PP} 23 \mathrm{~V})$ & $\mathrm{n}(\%)$ & $29(28,3)$ & $18(17,5)$ \\
& & $p^{a}$ & 0,09 & 0,21
\end{tabular}

a teste do qui-quadrado

Grupo A - vacina antipneumocócica polissacarídica 23 valente na primeira aplicação

Grupo C - vacina antipneumocócica polissacarídica 23 valente na segunda aplicação, após exposição prévia com vacina conjugada sete valente

$\mathrm{n}=$ número de indivíduos

\subsection{Colonização da nasofaringe}

A coleta do material de nasofaringe foi realizada pré-vacinação em 274 dos 331 pacientes incluídos no estudo. A colonização pelo $S$. pneumoniae foi identificada em $8 \%$ dos indivíduos (tabela 9).

Das 22 culturas positivas para S. pneumoniae, foram identificados os seguintes sorogrupos:

- Sorogrupo 6 - quatro amostras;

- Sorogrupo 19 - três amostras;

- Sorogrupos 7 e 10 - duas amostras cada;

- Sorogrupos 4, 14, 16, 22 - uma amostra cada.

Houve crescimento de cepas não tipáveis em sete amostras.

A coleta da amostra de nasofaringe 180 dias após a primeira vacinação foi realizada em 197 pacientes, representando $70,61 \%$ da amostra total dos indivíduos que realizaram as três visitas programadas. 
Foi observada uma redução significativa da colonização de nasofaringe por S.pneumoniae entre o momento pré-vacinal e 180 dias após a primeira vacinação, independentemente do esquema vacinal adotado (Tabela 9).

Tabela 9 - Colonização da nasofaringe antes e 180 dias após a vacinação nos pacientes infectados pelo HIV - SEAP - Casa da Aids, HCFMUSP - 10/2005 a 05/2009

\begin{tabular}{lccc}
\hline & \multicolumn{3}{c}{ COLONIZAÇÃO } \\
Agente & Pré-vacinal & 180 dias após 1a dose & \\
\hline S. pneumoniae & $22(8,0 / 5,1 \sim 11,9)$ & $6(3,0 / 1,1 \sim 6,5)$ & $\mathbf{0 , 0 2 3}$ \\
S. grupo viridans & $64(23,4 / 18,5 \sim 28,8)$ & $33(16,8 / 11,8 \sim 22,7)$ & 0,080 \\
Outros agentes & $67(24,5 / 19,5 \sim 30)$ & $60(30,5 / 24,1 \sim 37,4)$ & 0,147 \\
Sem crescimento & $121(44,2 / 38,2 \sim 50,3)$ & $98(49,7 / 42,6 \sim 56,9)$ & 0,230 \\
\hline \multicolumn{1}{c}{ Total } & $274(100)$ & $197(100)$ & \\
\hline
\end{tabular}

${ }^{a}$ teste do qui-quadrado

n - número de indivíduos

IC $95 \%$ - intervalo de confiança 95\%

Dos 22 indivíduos que tiveram isolamento de S.pneumoniae na primeira coleta, 14 realizaram também a segunda coleta. Seis desses indivíduos apresentaram colonização da nasofaringe por S.pneumoniae, sendo identificadas uma amostra para cada um dos os sorotipos 3, 9N, 19A e 23F, e duas amostras não tipáveis.

Apenas um indivíduo teve pneumococo identificado tanto na primeira quanto na segunda coleta. Entretanto, na primeira amostra foi identificado sorotipo 19A e na segunda amostra, sorotipo 9N, ambos não contidos na vacina conjugada administrada. 
Foi analisada separadamente a influência do uso de vacina polissacarídica ou conjugada na colonização de nasofaringe 180 dias após a vacinação inicial. Para tanto, foram comparados o esquemas vacinais $A$ (PP23V) com esquemas vacinais $B+C$ (ambos receberam vacina conjugada na primeira intervenção). Não foi observada diferença estatística entre eles (tabela 10).

Tabela 10 - Colonização da nasofaringe antes e 180 dias após, de acordo com a vacina recebida na primeira intervenção (PP23V ou PC7V) nos indivíduos infectados pelo HIV - SEAP - Casa da Aids, HC-FMUSP - 10/2005 a 05/2009

\begin{tabular}{lcccc}
\hline \multirow{4}{*}{ Agente } & \multicolumn{4}{c}{ COLONIZAÇÃO } \\
\hline \multirow{4}{*}{ S. pneumoniae } & $\mathrm{n}(\%)$ & $\mathrm{n}(\%)$ & \\
& PP23V & $11(12,1)$ & $4(6,2)$ & $0,336^{\mathrm{b}}$ \\
& PC7V & $11(6,0)$ & $2(1,5)$ & $0,0811^{\mathrm{b}}$ \\
S. grupo & $p$ & $0,0812^{\mathrm{a}}$ & $0,187^{\mathrm{b}}$ & \\
viridans & PP23V & $20(22,0)$ & $13(20,0)$ & $0,766^{\mathrm{b}}$ \\
& & & & \\
& PC7V & $44(24,0)$ & $20(15,2)$ & $0,053^{\mathrm{a}}$ \\
Outros agentes & PP23V & $15(16,5)$ & $14(21,5)$ & $0,424^{\mathrm{a}}$ \\
& PC7V & $52(28,4)$ & $46(34,8)$ & $0,224^{\mathrm{a}}$ \\
Sem & $p$ & $0,035^{\mathrm{a}}$ & $0,056^{\mathrm{a}}$ & \\
crescimento & PP23V & $45(49,5)$ & $34(52,3)$ & $0,725^{\mathrm{a}}$ \\
& & & & \\
& PC7V & $76(41,5)$ & $64(48,5)$ & $0,221^{\mathrm{a}}$ \\
& $p$ & $0,214^{\mathrm{a}}$ & $0,613^{\mathrm{a}}$ & \\
\hline
\end{tabular}

a teste do qui-quadrado

${ }^{\mathrm{b}}$ teste exato de Fisher

$\mathrm{n}$ - número de indivíduos 
D i s c u s são $\mathbf{5 3}$

5 Discussão 
As infecções pneumocócicas são muito frequentes em todas as regiões do mundo. $\mathrm{O}$ agente causal coloniza a nasofaringe e é transmitido predominantemente por gotículas respiratórias. O risco da doença é maior em indivíduos com condições médicas crônicas e em indivíduos com comprometimento do sistema imune, tais como infecção pelo HIV ${ }^{90}$.

As vacinas antipneumocócicas têm sido usadas para prevenção da doença pneumocócica há mais de 30 anos. A vacina polissacarídica 23 valente está disponível desde o início dos anos 1980 e as vacinas conjugadas, desde o início dos anos 2000. Contudo, muitos estudos não demonstraram a eficácia da vacina PP23V na prevenção da doença pneumocócica em populações com doenças crônicas e indivíduos imunocomprometidos de qualquer faixa etária, de alto risco para doença pneumocócica $^{30,90}$. Por outro lado, o uso rotineiro em alguns países das vacinas antipneumocócicas conjugadas em crianças reduziu drasticamente a incidência da doença pneumocócica invasiva, de tal forma que as doenças causadas por sorotipos presentes na vacina conjugada virtualmente desapareceram em alguns países ${ }^{90,91}$.

Este resultado estimulou a investigação do uso das vacinas conjugadas em adultos com condições predisponentes que aumentam o risco de doença pneumocócica, tais como os indivíduos infectados pelo HIV. Neste ensaio clínico foram comparados três diferentes esquemas vacinais.

A população estudada pode ser considerada representativa embora tenham sido incluídos 331 voluntários, representando $78,89 \%$ da amostra 
inicialmente estimada. Com a amostra atingida, mantendo o nível de significância de 0,05 , o poder do teste passou para 0,73.

A amostra incluída apresenta distribuição similar ao perfil da população adulta infectada pelo HIV/aids no Brasil passado os 30 anos da pandemia ${ }^{92}$, com predomínio do sexo masculino e maior incidência na faixa etária de 25 a 49 anos de idade. Podemos observar ainda a presença de uma grande proporção de pacientes que possuíram algum critério definidor de aids de acordo com a definição do $\operatorname{CDC}(60,1 \%)$. O mesmo padrão é observado em todo o país, corroborando com a dificuldade de diagnóstico nas fases precoces da infecção pelo HIV no nosso meio, sendo uma das principais barreiras para redução de taxa de óbito por aids no nosso país ${ }^{93}$.

$\mathrm{Na}$ população incluída no estudo, apesar do relativo longo tempo médio da infecção por HIV (6,7 anos), a maior proporção dos indivíduos apresenta carga viral abaixo de 400 cópias $/ \mathrm{mm}^{3}$ podendo traduzir uma boa adesão à terapia antirretroviral (76,7\% estavam em uso de HAART) e boa qualidade do atendimento do serviço.

Por outro lado, chama atenção o fato de que essa mesma população, apesar do relativo longo tempo da infecção pelo HIV, não ter sido vacinada previamente contra pneumococo apesar da recomendação do Ministério da Saúde. Resultado similar foi descrito anteriormente em outro estudo ${ }^{94}$, onde aproximadamente $50 \%$ dos pacientes infectados pelo HIV não eram vacinados contra $S$. pneumoniae. Os autores atribuíram esta baixa adesão dos médicos em encaminhar os pacientes à vacinação contra pneumococo 
devido às incertezas quanto a sua imunogenicidade, o que corrobora a importância desta investigação.

$\mathrm{Na}$ população estudada, os pacientes incluídos nos três grupos apresentaram os níveis de anticorpo pré-vacinal similares entre si para os três sorotipos avaliados, evidenciando a homogeneidade destes grupos. Além disso, uma grande proporção dos indivíduos apresentou níveis de títulos de anticorpos acima de $0,35 \mu \mathrm{g} / \mathrm{mL}$ no momento antes da vacinação, especialmente para sorotipo 14. Proporção significante desses indivíduos também tinham títulos de anticorpos acima de 1,0 $\mathrm{gg} / \mathrm{mL}$ para o sorotipo 14 . Isso pode ser consequente à exposição prévia aos pneumococos nessa população, principalmente ao sorotipo 14, um dos sorotipos mais frequentes na população adulta ${ }^{20}$.

A ausência da definição dos títulos de anticorpo protetor contra os diferentes sorotipos de pneumococo em adultos tem sido uma das dificuldades nos estudos clínicos da vacina antipneumocócica em adultos. A OMS adota como correlato de proteção contra doença invasiva em crianças níveis de anticorpo acima de 0,35 $\mu \mathrm{g} / \mathrm{mL}$. Já Esposito et al observaram que, em crianças, títulos de anticorpo acima de $1,0 \mu \mathrm{g} / \mathrm{mL}$ são necessários para conferir proteção contra a maioria dos sorotipos ${ }^{95}$. Entretanto, estes níveis não estão definidos para adultos. Além disso, não há consenso entre os especialistas em relação ao número de vezes de aumento nos níveis de anticorpo para definição de soroconversão. Alguns autores têm adotado aumento de duas vezes ${ }^{41,64,67,78,96}$ em relação aos níveis basais, enquanto outros têm adotado aumento de quatro vezes ${ }^{52,97,98}$. 
Por todas estas razões, para efeito de comparação entre os esquemas vacinais propostos no estudo, utilizamos concentrações acima de $0,35 \mu \mathrm{g} / \mathrm{mL}$ e acima de $1,0 \mu \mathrm{g} / \mathrm{mL}$, e aumento de quatro vezes ou mais no título de anticorpos medidos por ELISA.

$\mathrm{Na}$ avaliação 60 dias após a primeira vacinação, observamos que tanto a vacina PP23V quanto a vacina PC7V promoveram um aumento dos títulos de anticorpo para os três sorotipos avaliados, demonstrando a boa imunogenicidade de ambas as vacinas nesta população infectada pelo HIV. Não houve diferença estatisticamente significativa na proporção de indivíduos com concentração de anticorpos acima de $0,35 \mu \mathrm{g} / \mathrm{mL}$ e acima de $1,0 \mathrm{ug} / \mathrm{mL}$, e nos títulos médios geométricos entre os três grupos após a primeira vacinação. Entretanto, a proporção de indivíduos com aumento de 4 vezes ou mais na concentração de anticorpos foi menor no grupo PP23V para sorotipos $6 \mathrm{~B}$ e $9 \mathrm{~V}$.

Se adotarmos o número de vezes de aumento de anticorpo em relação aos níveis pré-vacinais como determinação de resposta ideal à vacinação, esse resultado poderia representar uma resposta superior com uma dose da PC7V em relação à PP23V para sorotipos $6 \mathrm{~B}$ e 9V, diferente do resultado encontrado por Penaranda et $\mathrm{al}^{99}$. Em um estudo com desenho diferente do empregado nesta tese, não observaram diferença estatística no aumento de duas vezes nos títulos de anticorpo em relação aos níveis basais entre ambas vacinas.

Apesar de termos estabelecido como critério de inclusão no estudo indivíduos com nível de células T-CD4 acima de 200 cél $/ \mathrm{mm}^{3}$, alguns 
estudos não observaram influência do nível de T-CD4 na resposta vacinal, mas sim, da carga viral do HIV no momento da vacinação ${ }^{43,44,100}$ e do uso da terapia antirretroviral ${ }^{101}$. Os indivíduos dos três grupos analisados eram similares quanto ao uso de HAART e carga viral do HIV, sendo que a maioria apresentava carga viral abaixo de 400 cópias $/ \mathrm{mL}$.

Na análise de 180 dias, observamos que houve um declínio em todos os grupos na concentração de anticorpos, para os três sorotipos, comparados aos níveis observados 60 dias após a primeira vacinação. Entretanto, em todos os grupos, os níveis se mantiveram acima da concentração pré-vacinal.

Não foi observada diferença estatisticamente significativa na proporção dos indivíduos com concentração de anticorpos acima de 0,35 $\mu \mathrm{g} / \mathrm{mL}$ e 1,0 $\mu \mathrm{g} / \mathrm{mL}$, independente do esquema vacinal utilizado, assim como nos títulos médios geométricos, ao final de 180 dias. Entretanto, foi observada uma maior proporção de indivíduos que sustentaram aumento de quatro vezes ou mais na concentração de anticorpos para os sorotipos $6 \mathrm{~B}$ e 9V nos grupos que receberam PC7V na primeira vacinação. Interroga-se se esses dados provavelmente representam reflexos da resposta de memória anticórpica célula T-dependente induzida pela vacina conjugada, o que poderia ter preservado maior capacidade da produção dos anticorpos em longo prazo.

Estudos recentes demonstraram que as vacinas polissacarídica e conjugada promovem estimulação de linfócitos $\mathrm{B}$ em diferentes áreas do baço. Enquanto a exposição antigênica direta do polissacáride estimula 
células B da zona marginal esplênica, o conjunto proteína carreadorapolissacáride é processado pelos linfócitos $B$ do centro germinativo ${ }^{102,103}$.

Clutterbuck et al $^{104}$ demonstraram em adultos saudáveis que uma única dose da vacina PC7V induziu um aumento significativo da população de linfócitos B de memória sorotipo específico no sangue periférico, indicando a presença de resposta T-dependente. Inversamente, o estímulo com vacina PP23V resultou na redução da frequência de células $B$ de memória além de promover uma atenuação da resposta na vacinação subsequente com PC7V. Esses dados poderiam ser interpretados como vantagem imunológica da vacina conjugada sobre a polissacarídica em adultos.

A proposta de criar um grupo com booster com vacina polissacarídica 23-valente após exposição inicial com vacina conjugada 7-valente baseou-se no suposto de que a imunização prévia com a vacina conjugada induziria resposta de memória linfócito T-dependente e a exposição posterior a uma vacina polissacarídica 23-valente aumentaria esta resposta anticórpica além de ampliar a cobertura para outros sorotipos.

Entretanto, observamos que o "reforço" com vacina PP23V, 60 dias após aplicação da vacina PC7V, não alterou a imunogenicidade para nenhum dos sorotipos analisados. Estes resultados são consistentes aos achados de estudos prévios que não observaram benefício da administração de vacina PP23V após exposição à vacina $P C 7 V^{67,99}$, em contraste aos resultados de Lesprit et $\mathrm{al}^{79}$. Em um estudo de indivíduos infectados pelo HIV com níveis de linfócitos T-CD4 entre 200 a $500 \mathrm{cel} / \mu \mathrm{L}$, esses autores 
observaram maior proporção de indivíduos que alcançou títulos de anticorpos maior que duas vezes em relação à situação pré-vacinal para os sorotipos 14, 18C, 19F e 23F nos voluntários que receberam vacina PP23V quatro semanas após aplicação da PC7V, quando comparados aos que receberam apenas vacina PP23V. Os autores atribuíram este aumento como efeito booster da vacina PP23V.

A razão da ausência do aumento da resposta anticórpica com booster de vacina polissacarídica após vacina conjugada ainda não está bem esclarecida na literatura. Algumas hipóteses são utilizadas para explicar o fenômeno: primeiramente, a colonização do pneumococo na nasofaringe pode induzir algum grau de resposta anticórpica através dos linfócitos B semelhante à resposta anticórpica induzida pela vacina polissacarídica ${ }^{105}, 0$ que poderia limitar a resposta a doses subsequentes. Outra hipótese é que a resposta anticórpica induzida pela vacina conjugada 7 -valente teria expandido ao máximo a população desses linfócitos B, limitando o aumento adicional com dose subsequente da vacina polissacarídica 23 -valente ${ }^{65}$.

Outra hipótese ainda é que os altos títulos de anticorpo induzidos pela primeira dose da vacina PC7V possam inibir a produção adicional de anticorpo através de um mecanismo de feedback negativo ou neutralização de antígeno vacinal ${ }^{65,97,106}$.

Toda a análise deste estudo baseou-se na determinação dos níveis de anticorpo por ELISA para três sorotipos. Nos últimos anos, ensaio de opsonofagocitose em conjunto com determinação dos níveis de anticorpo por ELISA tem sido utilizado para avaliação da resposta vacinal. Entretanto, 
estudos demonstraram que ensaios com reação de ELISA que incluem absorção de polissacáride heterólogo $22 \mathrm{~F}$, técnica utilizada nesta tese, promove uma boa correlação entre resultados de ELISA e da atividade de opsonofagocitose $\mathrm{e}^{107-109}$. Por limitações financeiras, foram analisados apenas três sorotipos, tendo sido selecionados os mais frequentes em adultos no nosso meio $^{13}$

Os resultados encontrados sugerem que a resposta sorológica para os sorotipos $6 \mathrm{~B}$ e $9 \mathrm{~V}$ foi melhor com a vacina $\mathrm{PC7V}$, e o reforço com vacina PP23V, 60 dias após aplicação da vacina PC7V, não alterou a imunogenicidade para nenhum dos sorotipos analisados.

Similar ao observado em outros estudos, ambas as vacinas foram bem toleradas nessa população e as reações no local da vacinação foram mais frequentes que as reações sistêmicas. A ocorrência de eventos adversos locais e sistêmicos foi semelhante às observadas na literatura, tanto em adultos idosos quanto em adultos infectados pelo HIV ${ }^{63,64,68,79,96,99}$. Entretanto, observamos uma diferença estatisticamente significante na ocorrência de eventos sistêmicos, sendo mais frequentes em indivíduos vacinados com PC7V na primeira intervenção. A queixa de astenia foi o relato mais comum.

Diferentemente ao observado por Miernyk et $\mathrm{al}^{110}$, não observamos diferenças estatísticas na ocorrência de eventos adversos entre a vacinação PP23V após exposição prévia a PC7V e PP23V isoladamente. Resultado semelhante aos nossos foram observados por Kroon et $\mathrm{al}^{77}$. Esses dados evidenciam a segurança do uso da vacina PP23V após uso prévio da PC7V, 
embora não tenhamos notado vantagem do seu uso em relação à resposta de anticorpos.

A taxa de colonização de $8 \%$ encontrada nesse estudo foi similar aos dados da literatura para população HIV adulta, embora menor que encontrada anteriormente em estudo realizado no Brasil $^{81}$. Estudos realizados em diversas regiões do mundo, na população adulta infectada pelo HIV, observaram taxa de colonização variando entre $3,4 \%$ a $18 \%{ }^{85,111-}$ ${ }^{113}$, sendo maior em países onde a política de vacinação não é adotada para esta população como Uganda.

A coleta das amostras de nasofaringe 180 dias após a vacinação foi realizada em 197 indivíduos. Este procedimento foi suspenso devido à queixa de desconforto, o que estava prejudicando a adesão ao retorno da terceira visita, inclusive a coleta da terceira amostra de sangue.

Nessas amostras de nasofaringe 180 dias após a vacinação, foi observada uma redução estatisticamente significativa da colonização por $S$. pneumoniae, passando de $8 \%$ para $3 \%$. Não conseguimos observar a diferença do efeito dos diferentes esquemas vacinais na colonização da nasofaringe.

A redução das taxas de colonização de pneumococo na nasofaringe após a introdução das vacinas antipneumocócicas conjugadas foi relatada em vários estudos ${ }^{83,84,114,115}$, fato que não ocorre com uso das vacinas polissacarídicas. Estas observações ocorreram principalmente em crianças, tanto pela ação direta da vacina quanto pelo efeito rebanho da vacinação ${ }^{83,114-116}$. Além do efeito sobre as crianças, a redução da 
colonização de nasofaringe por pneumococos dos sorotipos vacinais também foi observada em adultos em países onde a vacina PC7V foi implantada ${ }^{117,118}$. Entretanto, estudo conduzido pelo Kuo et al em Taiwan não observou este comportamento três anos após a introdução da vacina PC7V no calendário vacinal ${ }^{119}$.

Onwubiko et al também observou a redução da colonização da nasofaringe em pacientes infectados pelo HIV nos EUA após a implantação da vacina antipneumocócica conjugada 7 -valente em crianças ${ }^{111}$. No estudo avaliando o impacto da vacina PP23V, Lo et $a^{113}$ não observaram o efeito da vacina PP23V na colonização da nasofaringe em adultos infectados pelo HIV, como observado previamente por Rodriguez-Barradas et al ${ }^{85}$.

Nosso estudo foi realizado na fase pré implantação da vacina antipneumocócica no calendário vacinal das crianças abaixo de 2 anos de idade no Brasil, portanto, não houve o "efeito rebanho" nos nossos resultados. Observamos uma redução da taxa de colonização na população estudada, independentemente da vacina aplicada.

Além disso, observamos colonização, tanto no momento pré-vacinal quanto no pós-vacinal, em apenas um indivíduo, por pneumococos de sorotipos distintos. Como as taxas de colonização foram baixas, não foi possível calcular a influência do esquema vacinal no estado de colonização.

Apesar de todas as questões que envolvem o melhor esquema vacinal antipneumocócico em adultos infectados pelo HIV, a importância da vacinação é inquestionável. S. pneumoniae inclui mais de 90 sorotipos, com distribuição variável em diferentes faixas etárias, regiões geográficas e 
gravidade da doença. O uso cada vez mais amplo dos antimicrobianos tem contribuído para aumento da resistência dos pneumococos. Alguns sorotipos como 6B, 9V, 14, 19A e 23F estão relacionados a maior desenvolvimento da resistência do que outros sorotipos ${ }^{57}$. A introdução da vacinação antipneumocócica em grande escala poderia ajudar a reduzir a circulação das cepas resistentes ${ }^{90}$.

O presente trabalho de imunogenicidade e de segurança da vacina antipneumocócica conjugada ganha importância neste momento em que a Agência Americana do Controle de Alimentos e Drogas (FDA) acelerou a liberação da vacina antipneumocócica 13-valente (PC13V) em indivíduos imunocomprometidos ${ }^{120}$. Esta liberação baseou-se em dados limitados de imunogenicidade dos estudos com vacina PC7V em adultos imunocomprometidos, uma vez que não há estudos com estas características com vacina PC13V.

Este estudo, apesar das limitações já citadas, acrescenta dados à investigação da resposta de adultos às vacinas antipneumocócicas conjugadas, particularmente de adultos imunocomprometidos, uma vez que este entendimento não está completamente esclarecido. 
Conclus ões $\mid \mathbf{6 5}$

6 Conclusões 
Baseados nos resultados observados, concluímos que:

1. Tanto a vacina PP23V quanto a vacina PC7V promoveram um aumento dos títulos de anticorpo para os três sorotipos avaliados, demonstrando a boa imunogenicidade de ambas as vacinas nesta população infectada pelo HIV.

2. Não houve diferença estatisticamente significativa na proporção de indivíduos com concentração de anticorpos acima de $0,35 \mu \mathrm{g} / \mathrm{mL}$ e acima de 1,0 ug/mL, e nos títulos médios geométricos entre os três grupos após a primeira vacinação e ao final de 180 dias.

3. A proporção de indivíduos com aumento de 4 vezes ou mais na concentração de anticorpos foi menor no grupo PP23V para sorotipos 6B e $9 \mathrm{~V}$ após a primeira vacinação e ao final de 180 dias.

4. O "reforço" com vacina polissacarídica 23-valente 60 dias após a aplicação da vacina conjugada 7-valente não alterou os títulos de anticorpos para nenhum dos sorotipos analisados.

5. Não foi observada diferença estatisticamente significativa na reatogenicidade à vacina $\mathrm{PP23V}$ e à $\mathrm{PC7V}$, em relação aos eventos locais. A vacina PC7V foi mais reatogênica em relação aos eventos sistêmicos.

6. A exposição prévia à vacina $P C 7 V$ não aumentou a reatogenicidade à vacina PP23V.

7. Foi observada redução estatisticamente significativa da colonização de nasofaringe por S.pneumoniae 180 dias após a vacinação, embora não tenha sido observada diferença do efeito dos diferentes esquemas vacinais. 


\section{Anexos}




\section{TERMO DE CONSENTIMENTO LIVRE E ESCLARECIDO}

(Instruções para preenchimento no verso)

\section{I - DADOS DE IDENTIFICAÇÃO DO SUJEITO DA PESQUISA OU RESPONSÁVEL LEGAL}

1. NOME DO PACIENTE .

DOCUMENTO DE IDENTIDADE № :

DATA NASCIMENTO:

№

APTO:

ENDEREÇO CIDADE

BAIRRO: ...)

CEP:. TELEFONE: DDD

2.RESPONSÁVEL LEGAL

NATUREZA (grau de parentesco, tutor, curador etc.)

DOCUMENTO DE IDENTIDADE : SEXO: M Ž F Ž

DATA NASCIMENTO. ............

ENDEREÇO: № APTO: ....

BAIRRO: CIDADE:

CEP: TELEFONE: DDD ..)........

\section{II - DADOS SOBRE A PESQUISA CIENTÍFICA}

1. TÍTULO DO PROTOCOLO DE PESQUISA: COMPARAÇÃO DE RESPOSTA À VACINAÇÃO COM TRÊS ESQUEMAS DIFERENTES DE VACINA ANTI-PNEUMOCÓCCICA EM INDIVÍDUOS INFECTADOS PELO VÍRUS DA IMUNODEFICIÊNCIA HUMANA

2. PESQUISADOR: Ho Yeh Li

CARGO/FUNÇÃO: Médica Assistente INSCRIÇÃO CONSELHO REGIONAL № 90806 UNIDADE DO HCFMUSP: Departamento de Moléstias Infecciosas e Parasitárias

3. AVALIAÇÃO DO RISCO DA PESQUISA:

\begin{tabular}{|c|c|c|}
\hline EM RISCO & Ž & RISCO MÍNIMO \\
\hline RISCO BAIXO & $\check{Z}$ & RISC \\
\hline
\end{tabular}

(probabilidade de que o indivíduo sofra algum dano como conseqüência imediata ou tardia do estudo) 4.DURAÇÃO DA PESQUISA : 4 anos 


\section{III - REGISTRO DAS EXPLICAÇÕES DO PESQUISADOR AO PACIENTE OU SEU REPRESENTANTE LEGAL SOBRE A PESQUISA CONSIGNANDO:}

O(a) senhor(a) está sendo convidado(a) a participar desse estudo que avalia a vacinação contra pneumococo em pacientes infectados pelo HIV/AIDS. O pneumococo é uma bactéria que habitualmente fica no nariz e na garganta (nasofaringe) das pessoas. Entretanto, algumas vezes invade o sangue e pode causar doenças graves como a pneumonia, a meningite e outras. Isto ocorre mais freqüentemente em pessoas com infecção por HIV/Aids. Por este motivo o Ministério da Saúde recomenda a vacinação contra o pneumococo para indivíduos infectados pelo HIV/Aids (Manual dos Centros de Referência de Imunobiológicos Especiais - Fundação Nacional de Saúde, Ministério da Saúde. 2001).

Existem atualmente disponíveis dois tipos de vacina contra pneumococo (polissacarídica e conjugada). A vacina polissacarídica é feita com pedaços da bactéria, com eficácia comprovada em adultos. A vacina conjugada, além dos pedaços da bactéria, está ligada a uma proteína que acreditase estimular a duração e a intensidade da resposta à vacina, resultado observado em crianças.

Este estudo tem como objetivo investigar em pacientes adultos com infecção pelo HIV/Aids duas situações: a - a quantidade de anticorpos que aparecem no sangue após a vacinação contra pneumococo; b - se há alteração, após a vacinação, das bactérias que habitualmente ficam no nariz e na garganta das pessoas.

Para fazer esta investigação serão utilizados três diferentes esquemas de vacinação:

- Um grupo de pacientes HIV/Aids receberá a vacina polissacarídica. Após dois meses receberá vacinação só com soro fisiológico

- Um grupo de pacientes receberá a vacina conjugada. Após dois meses receberá a vacina só com soro fisiológico

- Um grupo de pacientes receberá a vacina conjugada. Após dois meses, receberá a vacina polissacarídica

A participação dos pacientes em cada um dos grupos será por sorteio.

Se concordar em participar do projeto, o(a) senhor(a) será submetido(a) a uma pequena entrevista e a uma análise de seu prontuário para verificar se já usou as vacinas contra pneumococo e como está sua situação em relação à infecção por HIV. Caso não tenha utilizado a vacina, o(a) senhor(a) será sorteado(a) para receber um dos esquemas acima citados. Até o final do estudo nem 0 senhor nem o médico saberão qual o esquema de vacinação que foi aplicado. Serão tirados 10 a 15 $\mathrm{mL}$ de sangue logo antes da cada vacinação, e 6 meses após a data da primeira vacina, para medir: os anticorpos contra pneumococos, a função destes anticorpos, a carga viral de HIV e a contagem de células CD4. Antes da primeira vacina e 6 meses após será colhida secreção de dentro do nariz, com um cotonete, para fazer a cultura de bactérias, e verificar se houve alteração, após a vacinação, das bactérias que habitualmente ficam no nariz. 
Ao todo, participarão desse projeto 420 pacientes com infecção pelo HIV/AIDS atendidos na "Casa da AIDS", sendo 140 pacientes em cada grupo.

Pode haver desconforto no momento de tirar sangue (dor local e raramente mal estar por reação emocional). A secreção do nariz é obtida com um cotonete e pode haver um pequeno desconforto na coleta.

Não há contra-indicação a vacinação antipneumocóccica, ou seja, qualquer pessoa pode tomar estas vacinas.

Podem apresentar reações no local da vacinação como vermelhidão, inchaço e dor, aproximadamente 30 a $50 \%$ das pessoas que recebem estas vacinas. Essas reações podem durar de 1 a 3 dias e são leves. Reações mais importantes e febre de mais de $39,5^{\circ} \mathrm{C}$ são raras.

Apesar da vacinação pneumocóccica em pacientes HIV positivos poder levar a aumento passageiro de carga viral de HIV, assim como ocorre com outras vacinas, não foi observado risco relacionado a esse fato.

Benefícios que poderão ser obtidos:

A infecção por pneumococos em pessoas infectadas por HIV/Aids é uma das primeiras causas de pneumonias podendo trazer complicações.

Uma vez que a pessoa carrega esta bactéria, às vezes por um longo período, o risco da bactéria desenvolver resistência a antibióticos é maior, principalmente nas pessoas que fazem uso de profilaxias (medicações que previnem o adoecimento) como sulfametoxazol-trimetoprim (popularmente conhecido como Bactrim $\AA$ ). Infecções por bactérias resistentes a antibióticos são mais difíceis de serem tratadas.

A vacinação promove uma melhor defesa contra o pneumococo reduzindo o risco de adoecimento e das complicações relacionadas à pneumonia.

Atualmente não há nenhum remédio que seja recomendado para prevenir a pneumonia por pneumococo.

\section{IV - ESCLARECIMENTOS DADOS PELO PESQUISADOR SOBRE GARANTIAS DO SUJEITO DA PESQUISA CONSIGNANDO:}

1. $O(A)$ senhor(a) tem garantida a resposta a qualquer pergunta ou esclarecimento a qualquer dúvida acerca dos procedimentos, riscos, benefícios, e outros assuntos relacionados com a pesquisa.

2. $\mathrm{O}$ (a) senhor(a) pode retirar seu consentimento a qualquer momento e deixar de participar do estudo, sem que isso traga prejuízo à continuação do seu cuidado e tratamento

3. A sua identificação não será revelada, mantendo-se confidenciais as informações.

4. Não são esperados danos à sua saúde. A assistência na "Casa da AIDS" seguirá a rotina normal de atendimento. As urgências são atendidas em consultas extras na "Casa da AIDS" como habitualmente funciona a rotina de atendimento ao paciente com infecção pelo HIV/AIDS.

5. Não há indenização prevista pelo projeto, uma vez que não são previstos danos pela pesquisa.

\section{INFORMAÇÕES DE NOMES, ENDEREÇOS E TELEFONES DOS RESPONSÁVEIS PELO ACOMPANHAMENTO DA PESQUISA, PARA CONTATO EM CASO DE INTERCORRÊNCIAS CLÍNICAS E REAÇÕES ADVERSAS.}


- As urgências serão atendidas em consultas extras no Núcleo de Extensão ao Atendimento de Pacientes com Infecção pelo HIVIAIDS ("Casa da AIDS", Rua Frei Caneca, 557) como normalmente funciona a rotina de atendimento ao paciente com infecção pelo HIV/AIDS, das 8:00 às 20:00, de segunda a sexta-feira, ou no Pronto Atendimento da Divisão de Moléstias Infecciosas e Parasitárias do Hospital das Clínicas (Entrada pelo Pronto Socorro do Hospital das Clínicas - Av. Dr. Enéas Carvalho de Aguiar,255), das 20:00 às 8:00 de segunda a sexta-feira e nos feriados e fins de semana.

- Em caso de necessidade de esclarecimento sobre quaisquer aspectos da pesquisa ou resultados de exames, o médico responsável pelo paciente poderá entrar em contato com a Dra. Ho Yeh Li no Núcleo de Extensão ao Atendimento de Pacientes com Infecção pelo HIVIAIDS ("Casa da AIDS"), no telefone 3120-5290, de segunda à sexta-feira, das 12 às 16 horas ou pelo telefone 3069-6413 à noite, feriados e fins de semana.

\section{OBSERVAÇÕES COMPLEMENTARES:}

\section{VII - CONSENTIMENTO PÓS-ESCLARECIDO}

Declaro que, após convenientemente esclarecido pelo pesquisador e ter entendido o que me foi explicado, consinto em participar do presente Protocolo de Pesquisa.

São Paulo,

de

de 20

assinatura do sujeito da pesquisa ou responsável legal

assinatura do pesquisador (carimbo ou nome Legível) 
Anexos II - Tabela de Randomização

\begin{tabular}{|l|l|l|l|l|l|l|l|l|l|}
\hline 3 & 2 & 3 & 4 & 3 & 3 & 6 & 1 & 4 & 1 \\
\hline 6 & 1 & 1 & 4 & 1 & 3 & 4 & 2 & 3 & 2 \\
\hline 4 & 2 & 2 & 2 & 3 & 5 & 3 & 2 & 3 & 3 \\
\hline 5 & 1 & 3 & 6 & 1 & 1 & 6 & 5 & 1 & 6 \\
\hline 1 & 1 & 5 & 3 & 3 & 6 & 3 & 5 & 2 & 2 \\
\hline 4 & 2 & 5 & 1 & 4 & 2 & 6 & 6 & 6 & 4 \\
\hline 3 & 5 & 4 & 6 & 6 & 2 & 3 & 5 & 4 & 3 \\
\hline 2 & 5 & 4 & 4 & 5 & 5 & 5 & 3 & 6 & 5 \\
\hline 3 & 6 & 5 & 1 & 2 & 6 & 3 & 4 & 4 & 2 \\
\hline 4 & 3 & 4 & 1 & 5 & 5 & 5 & 4 & 2 & 2 \\
\hline 1 & 2 & 1 & 6 & 4 & 4 & 2 & 1 & 1 & 4 \\
\hline 5 & 3 & 5 & 1 & 3 & 2 & 4 & 3 & 5 & 2 \\
\hline 2 & 2 & 4 & 2 & 3 & 1 & 5 & 5 & 1 & 2 \\
\hline 4 & 5 & 1 & 6 & 3 & 4 & 4 & 1 & 4 & 4 \\
\hline
\end{tabular}

Cada número corresponde a um bloco abaixo descrito:

1- $A-C-B$

2- $B-C-A$

3- $C-B-A$

4- $A-B-C$

5- $B-A-C$

6- $C-A-B$

Cada letra corresponde a um esquema vacinal:

A - Polissacarídica 23 valente seguida de placebo;

B - Conjugada 7 valente seguida de placebo;

C - Conjugada 7 valente seguida de polissacarídica 23 valente. 
Anexo III - Questionário demográfico, epidemiológico, imunológico, virológico e de uso de antimicrobianos.

Número paciente:

Data:

Nome (iniciais):

RGHC:

Critérios de inclusão:

- Soropotivitidade para HIV

- Contagem de linfócitos T CD4 $\geq 200 \mathrm{cé} / \mathrm{mm}^{3}$ em dois testes nos últimos 6 meses antes da randomização

- Entre 18 a 60 anos de idade

- Assinatura do termo de consentimento livre e esclarecido

Critérios de exclusão:

- Presença de qualquer doença febril aguda no momento da vacinação

- Em vigência de alguma doença definidora de Aids (critério CDC 1997)

- Imunização prévia contra pneumococo, com vacina polissacarídica 23-valente ou vacina pneumocóccica conjugada independente do tempo

- Portadores de qualquer doença maligna que requeira quimioterapia ou radioterapia

- Uso de imunoglobulina ou interferon nos últimos 3 meses

- Gravidez

- História prévia de reação alérgica à vacina com componente de toxóide de difteria

- Antecedente de reações alérgicas a qualquer componente das vacinas 


\begin{tabular}{|l|l|l|}
\hline Identificação: & & \\
\hline Variável & Resposta & Codificação \\
\hline 1. Sexo & & $\mathrm{M}=1 \quad \mathrm{~F}=2$ \\
\hline 2. Idade & & \\
\cline { 2 - 3 } & anos & $\leq 12$ meses $=1$ \\
3. Tempo de diagnóstico de & & $\begin{array}{l}1 \text { a } 4 \text { anos }=2 \\
5 \text { a } 10 \text { anos }=3 \\
\text { HIV }\end{array}$ \\
& & $>10$ anos $=4$ \\
\hline
\end{tabular}

\section{Situação HIV/Aids}

\begin{tabular}{|c|c|c|}
\hline Variável & Resposta & Codificação \\
\hline \multicolumn{3}{|l|}{ Contagem de CD4 } \\
\hline 4. Classificação CDC & & $\begin{array}{lll}\mathrm{A} 1=1 & \mathrm{~A} 2=2 & \mathrm{~A} 3=3 \\
\mathrm{~B} 1=4 & \mathrm{~B} 2=5 & \mathrm{~B} 3=6 \\
\mathrm{C} 1=7 & \mathrm{C} 2=8 & \mathrm{C} 3=9\end{array}$ \\
\hline 5. Último CD4 (data & & $\begin{array}{l}\leq 200 \mathrm{cé} l / \mathrm{mm}^{3}=1 \\
200 \sim 500 \mathrm{cél} / \mathrm{mm}^{3}=2 \\
>500 \mathrm{cél} / \mathrm{mm}^{3}=3 \\
\text { sem dados = 999 }\end{array}$ \\
\hline \multicolumn{3}{|l|}{ Carga Plasmáticade RNA do HIV } \\
\hline 6. Última CV (data & & $\begin{array}{l}<10.000 \text { cópias } / \mathrm{mL}=1 \\
10.000 \text { a } 99.999 \text { cópias } / \mathrm{mL}= \\
2 \\
\geq 100.000=3 \\
\text { sem dados }=999\end{array}$ \\
\hline $\begin{array}{l}\text { 7. Uso atual de profilaxia contra } \\
\text { infecções oportunistas }\end{array}$ & & $\begin{array}{l}\text { Sim }=1 \\
\text { Não }=2\end{array}$ \\
\hline $\begin{array}{l}\text { 8. Uso de terapia antiretroviral } \\
\text { (ARV) atual }\end{array}$ & & $\begin{array}{l}\text { Sim }=1 \\
\text { Não }=2\end{array}$ \\
\hline 9. Esquema ARV atual & & $\begin{array}{l}\text { HAART }=1 \\
\text { Não HAART = } 2 \\
\text { Não se aplica = } 999\end{array}$ \\
\hline $\begin{array}{l}\text { 10. Uso prévio de terapia ARV } \\
\text { (só se atualmente sem ARV) }\end{array}$ & & $\begin{array}{l}\text { Sim }=1 \\
\text { Não }=2 \\
\text { Não se aplica = } 999\end{array}$ \\
\hline 11. Esquema ARV prévia & & $\begin{array}{l}\text { HAART }=1 \\
\text { Não HAART }=2 \\
\text { Não se aplica }=999\end{array}$ \\
\hline
\end{tabular}


Vigilância quanto ao uso sistêmico de antibióticos (iv ou vo)

Em uso de antimicrobianos

\begin{tabular}{|l|l|l|}
\hline Variável & Resposta & Codificação \\
\hline 12. SMX/TMP & & Sim $=1$ \\
& & Não $=2$ \\
\hline 13. Azitromicina/Claritromicina & & Sim $=1$ \\
& & Não $=2$ \\
\hline 14. Outros & Sim $=1$ \\
& & Não $=2$ \\
\hline
\end{tabular}

\begin{tabular}{|l|l|}
\hline $\begin{array}{l}\text { 15. Uso de antibióticos nos } \\
\text { ultimos } 7 \text { dias }\end{array}$ & $\begin{array}{l}\text { Sim }=1 \\
\text { Não }=2\end{array}$ \\
\hline 16. Motivo do uso de antibiótico & $\begin{array}{l}\text { Infecção de vias aéreas altas }= \\
1 \\
\text { Infecção de vias aéreas baixas } \\
=2 \\
\text { Infecções abdominais }=3 \\
\text { Infecções urinárias }=4 \\
\text { Infecções cutâneas }=5 \\
\text { Profilaxia de DO }=6 \\
\text { Outros }=7\end{array}$ \\
& \begin{tabular}{l} 
Não se aplica $=999$ \\
\hline
\end{tabular} \\
\hline
\end{tabular}


Anexo IV - Questionário de Eventos Adversos pós-vacinação.

Número paciente:

Data:

Nome (iniciais):

RGHC:

\begin{tabular}{|l|l|l|}
\hline Dados da Vacinação & & \\
\hline Variável & Resposta & Codificação \\
\hline Data de vacinação & $/$ & $\mathrm{dd} / \mathrm{mm} / \mathrm{aaaa}$ \\
\hline & & \\
\hline
\end{tabular}

\begin{tabular}{|c|c|c|}
\hline Eventos adversos & & \\
\hline Variável & Resposta & Codificação \\
\hline Dor Local & & $\begin{array}{l}\text { Leve }=1 \\
\text { Moderada = } 2 \\
\text { Intensa }=3 \\
\text { Ausente }=4\end{array}$ \\
\hline Eritema Local & & $\begin{array}{l}\text { Leve }=1 \\
\text { Moderada = } 2 \\
\text { Intensa }=3 \\
\text { Ausente }=4\end{array}$ \\
\hline Enduração & & $\begin{array}{l}<1 \mathrm{~cm}=1 \\
1 \sim 5 \mathrm{~cm}=2 \\
>5 \mathrm{~cm}=3 \\
\text { Ausente }=4\end{array}$ \\
\hline Calor local & & $\begin{array}{l}\operatorname{Sim}=1 \\
\text { Não }=2\end{array}$ \\
\hline Febre & & $\begin{array}{l}<380 C=1 \\
38 \sim 390 C=2 \\
>390 C=3 \\
\text { não aferida }=4 \\
\text { Ausente }=5\end{array}$ \\
\hline Mialgia & & $\begin{array}{l}\text { Sim }=1 \\
\text { Não }=2\end{array}$ \\
\hline Astenia & & $\begin{array}{l}\text { Leve }=1 \\
\text { Moderada }=2 \\
\text { Intensa }=3 \\
\text { Ausente }=4\end{array}$ \\
\hline \multirow[t]{2}{*}{ Outros sintomas } & & Sim =1 Qual: \\
\hline & & $\overline{\text { Não }}=2$ \\
\hline
\end{tabular}


Anexo V - Aprovação CAPPESq

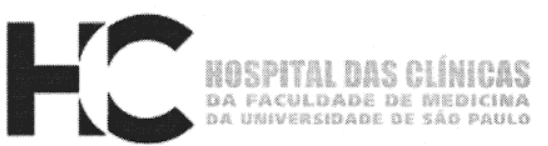

DIRETORIA CLÍNICA

\section{Comissão de Ética para Análise de Projetos de Pesquisa}

\section{APROVAÇÃO}

A Comissão de Ética para Análise de Projetos de Pesquisa - CAPPesq da Diretoria Clínica do Hospital das Clínicas e da Faculdade de Medicina da Universidade de São Paulo, em sessão de 14.07.04, APROVOU o Protocolo de Pesquisa $n^{\circ}$ 047/04, intitulado: "Comparação de Resposta à Vacinação com Três Esquemas Diferentes de Vacinação Anti-pneumocóccia em Indivíduos Infectados por Vírus de Imunodeficiência Humana" apresentado pelo Departamento de MOLÉSTIAS INFECCIOSAS E PARASITÁRIAS, inclusive o Termo de Consentimento Livre e Esclarecido.

Pesquisador(a) Responsável: Dra. Marta Heloisa Lopes

Pesquisador(a) Executante: Dra. Ho Yeh Li

CAPPesq, 14 de Julho de 2004.

PROF. DR. CLAUDIO LEONE

Vice-Presidente da Comissão de Ética para Análise de Projetos de Pesquisa

\footnotetext{
OBSERVAÇÃO: Cabe ao pesquisador elaborar e apresentar à CAPPesq, os relatórios parciais e final sobre a pesquisa (Resolução do Conselho Nacional de Saúde $n^{\circ} 196$, de 10.10.1996, inciso IX.2, letra "c")
} 


\section{Anexo VI - Tabela com dados demográficos e os resultados dos títulos médios geométricos dos anticorpos}

\begin{tabular}{|c|c|c|c|c|c|c|c|c|c|c|c|c|c|c|}
\hline NO & IDADE & THIV & ARV & Grupo & CD4 & TMG6B1 & MG6B2 & TMG6B3 & TMG9V1 & TMG9V2 & TMG9V3 & ГMG14 & 1G14B & TM \\
\hline 1 & 39 & 11 & Sim & A & 418 & 0,52 & & 1,27 & 1,99 & & 1,73 & 2,93 & & 14,99 \\
\hline 2 & 43 & 17 & Não & C & 788 & 0,09 & 0,49 & 0,24 & 0,09 & 2,90 & 0,73 & 2,46 & 3,45 & 2,11 \\
\hline 3 & 58 & 7 & Sim & B & 509 & 0,53 & 10,01 & 7,92 & 1,28 & 14,12 & 8,43 & 5,25 & 19,26 & 12,41 \\
\hline 4 & 44 & 10 & Sim & B & 674 & 0,40 & 1,83 & 1,67 & 0,50 & 1,54 & 1,09 & 3,03 & 6,87 & 4,92 \\
\hline 5 & 35 & 9 & Sim & C & 764 & 0,13 & 0,87 & 0,30 & 0,21 & 1,49 & 0,65 & 1,70 & 2,52 & 1,83 \\
\hline 6 & 48 & 12 & Sim & A & 585 & 0,24 & 0,17 & 0,20 & 0,60 & 1,27 & 1,31 & 0,79 & 15,67 & 13,60 \\
\hline 7 & 39 & 11 & Não & C & 572 & 0,12 & 0,54 & 0,23 & 1,80 & 1,10 & 0,50 & 1,08 & 3,65 & 2,39 \\
\hline 8 & 53 & 2 & Sim & B & 536 & 0,24 & 1,20 & 1,02 & 0,31 & 1,33 & 0,87 & 3,44 & 13,55 & 10,20 \\
\hline 9 & 31 & 6 & Sim & A & 477 & 0,35 & 0,70 & 0,37 & 0,54 & 1,86 & 1,24 & 0,97 & 8,82 & 7,33 \\
\hline 10 & 35 & 3 & Não & C & 402 & 0,23 & 1,01 & 0,49 & 0,25 & 1,32 & 0,66 & 3,36 & 11,15 & 8,63 \\
\hline 11 & 45 & 9 & Sim & A & 507 & 0,51 & 0,95 & 0,46 & 0,74 & 1,68 & 1,18 & 1,19 & 5,33 & 4,95 \\
\hline 12 & 35 & 7 & Sim & B & 277 & 0,20 & 0,67 & 0,53 & 0,26 & 1,14 & 0,63 & 1,49 & 4,86 & 4,00 \\
\hline 13 & 28 & 3 & Sim & B & 722 & 0,19 & 0,76 & 0,56 & 0,22 & 1,50 & 0,69 & 1,19 & 8,07 & 6,88 \\
\hline 14 & 36 & 7 & Não & C & 480 & 0,20 & 0,76 & 0,49 & 0,20 & 1,27 & 0,65 & 3,52 & 9,89 & 7,75 \\
\hline 15 & 40 & 5 & Sim & A & 1070 & 0,42 & 0,63 & 0,36 & 0,73 & 1,93 & 1,27 & 1,39 & 5,86 & 4,77 \\
\hline 16 & 47 & 8 & Não & A & 564 & 0,39 & 0,60 & & 0,80 & 1,91 & & 1,69 & 5,80 & \\
\hline 17 & 45 & 8 & Sim & B & 872 & 0,19 & 0,80 & 0,59 & 0,20 & 1,43 & 0,71 & 0,85 & 6,25 & 4,99 \\
\hline 18 & 48 & 7 & Sim & C & 869 & 0,24 & 0,80 & 0,53 & 0,22 & 1,37 & 0,72 & 2,29 & 6,54 & 5,26 \\
\hline 19 & 49 & 4 & Sim & C & 389 & 0,22 & 0,64 & & 0,19 & 1,35 & & 1,47 & 5,52 & \\
\hline 20 & 55 & 6 & Sim & B & 278 & 0,23 & 1,71 & 1,23 & 0,20 & 2,15 & 1,00 & 0,74 & 6,49 & 4,88 \\
\hline 21 & 30 & 1 & Sim & A & 369 & 0,49 & 0,72 & 0,45 & 0,75 & 1,78 & 1,23 & 1,47 & 4,58 & 3,83 \\
\hline 22 & 45 & 7 & Não & B & 569 & 0,24 & 1,91 & 1,30 & 0,25 & 2,84 & 1,31 & 0,93 & 8,60 & 6,03 \\
\hline 23 & 58 & 7 & Sim & A & 883 & 0,62 & 1,18 & 0,77 & 0,91 & 2,10 & 1,47 & 1,82 & 5,64 & 4,92 \\
\hline 24 & 39 & 1 & Sim & C & 569 & 0,29 & 1,13 & 0,97 & 0,18 & 1,31 & 0,69 & 1,00 & 4,67 & 3,98 \\
\hline 25 & 48 & 5 & Sim & B & 714 & 0,29 & 2,75 & 1,91 & 0,25 & 4,46 & 2,14 & 1,23 & 11,82 & 8,36 \\
\hline 26 & 41 & 12 & Sim & C & 448 & 0,28 & 1,21 & 1,03 & 0,18 & 1,41 & 0,74 & 1,10 & 5,98 & 4,64 \\
\hline 27 & 49 & 12 & Sim & A & 270 & 0,80 & 1,50 & 0,96 & 0,98 & 2,25 & 1,59 & 1,69 & 4,75 & 4,04 \\
\hline 28 & 46 & 15 & Sim & B & 739 & 0,29 & 2,36 & 1,57 & 0,22 & 3,06 & 1,54 & 1,14 & 8,72 & 6,42 \\
\hline 29 & 53 & 4 & Sim & C & 681 & 0,27 & 1,67 & 1,30 & 0,24 & 2,10 & 1,17 & 1,21 & 8,22 & 6,19 \\
\hline 30 & 50 & 21 & Sim & A & 134 & 0,70 & 1,59 & 1,22 & 0,82 & 2,14 & 1,60 & 2,08 & 5,34 & 5,30 \\
\hline 31 & 46 & 1 & Sim & A & 335 & 0,70 & & & 0,90 & & & 1,81 & & \\
\hline 32 & 31 & 10 & Sim & B & 1367 & 0,30 & 2,98 & 1,99 & 0,22 & 3,95 & 2,04 & 1,10 & 8,44 & 6,24 \\
\hline 33 & 39 & 10 & Sim & C & 974 & 0,31 & 2,48 & 1,83 & 0,25 & 1,98 & 1,14 & 1,11 & 8,87 & 6,46 \\
\hline 34 & 42 & 13 & Sim & B & 794 & 0,29 & 2,88 & 1,96 & 0,25 & 4,03 & 2,19 & 1,11 & 10,73 & 7,98 \\
\hline 35 & 39 & 3 & Sim & C & 579 & 0,33 & 2,49 & 1,82 & 0,25 & 1,86 & 1,09 & 1,56 & 11,82 & 8,58 \\
\hline 36 & 52 & 11 & Não & A & 1176 & 0,76 & 1,70 & 1,31 & 0,88 & 2,29 & 1,80 & 2,07 & 5,68 & 5,67 \\
\hline 37 & 50 & 11 & Sim & B & 586 & 0,30 & 2,86 & 1,88 & 0,26 & 4,48 & 2,43 & 1,17 & 13,00 & 9,32 \\
\hline 38 & 35 & 9 & Sim & C & 1269 & 0,35 & 2,36 & 1,48 & 0,26 & 1,93 & 0,98 & 1,34 & 10,00 & 6,80 \\
\hline 39 & 51 & 14 & Sim & A & 422 & 0,72 & 1,44 & 1,29 & 0,77 & 1,80 & 1,84 & 1,87 & 4,42 & 5,18 \\
\hline 40 & 47 & 15 & Sim & A & 249 & 0,64 & 1,23 & 1,03 & 0,65 & 1,43 & 1,37 & 1,89 & 4,32 & 5,02 \\
\hline 41 & 41 & 15 & Sim & B & 462 & 0,31 & 2,86 & 1,78 & 0,27 & 4,32 & 2,21 & 1,14 & 13,85 & 9,40 \\
\hline 42 & 55 & 10 & Sim & C & 462 & 0,37 & 2,29 & 1,34 & 0,26 & 1,95 & 0,87 & 1,18 & 8,10 & 5,87 \\
\hline 43 & 37 & 2 & Sim & A & 289 & 0,62 & 1,45 & 1,16 & 0,59 & 1,59 & 1,40 & 2,11 & 5,34 & 5,44 \\
\hline 44 & 28 & 7 & Não & B & 685 & 0,32 & & 1,75 & 0,27 & & 2,07 & 1,18 & & 10,68 \\
\hline 45 & 33 & 12 & Sim & C & 807 & 0,33 & 2,19 & & 0,24 & 1,82 & & 1,01 & 8,73 & \\
\hline 46 & 45 & 6 & Sim & C & 277 & 0,34 & 2,08 & 1,26 & 0,24 & 1,80 & 0,84 & 1,14 & 10,27 & 6,87 \\
\hline 47 & 30 & 7 & Sim & B & 925 & 0,32 & 3,03 & 1,72 & 0,27 & 4,37 & 1,97 & 1,14 & 13,58 & 10,12 \\
\hline 48 & 36 & 6 & Sim & A & 288 & 0,67 & 1,47 & 1,07 & 0,59 & 1,49 & 1,19 & 2,12 & 5,63 & 5,05 \\
\hline 49 & 51 & 11 & $\operatorname{Sim}$ & C & 384 & 0,32 & 1,93 & 1,22 & 0,22 & 1,60 & 0,79 & 1,10 & 10,74 & 6,94 \\
\hline 50 & 50 & 10 & Não & B & 519 & 0,32 & 2,55 & 1,61 & 0,28 & 3,80 & 2,01 & 1,13 & 12,03 & 8,49 \\
\hline 51 & 52 & 11 & Sim & A & 472 & 0,63 & 1,30 & 0,95 & 0,59 & 1,48 & 1,16 & 1,95 & 6,06 & 5,33 \\
\hline 52 & 47 & 5 & Sim & C & 604 & 0,34 & 2,38 & 1,52 & 0,25 & 1,93 & 1,00 & 1,07 & 11,40 & 7,63 \\
\hline
\end{tabular}




\begin{tabular}{|c|c|c|c|c|c|c|c|c|c|c|c|c|c|c|}
\hline 53 & 39 & 3 & Sim & B & 127 & 0,33 & & & 0,28 & & & 1,26 & & \\
\hline 54 & 35 & 9 & Sim & A & 396 & 0,57 & 1,10 & 0,82 & 0,56 & 1,36 & 1,07 & 1,82 & 5,46 & 4,83 \\
\hline 55 & 36 & 1 & Não & A & 379 & 0,59 & 1,11 & 0,83 & 0,60 & 1,60 & 1,31 & 1,75 & 6,14 & 5,25 \\
\hline 56 & 27 & 7 & Sim & B & 1162 & 0,30 & & & 0,28 & & & 1,28 & & \\
\hline 57 & 27 & 5 & Sim & C & 339 & 0,34 & 2,30 & 1,49 & 0,24 & 1,77 & 0,93 & 1,07 & 10,45 & 7,06 \\
\hline 58 & 36 & 12 & Sim & B & 960 & 0,31 & 2,38 & 1,50 & 0,28 & 3,31 & 1,84 & 1,26 & 12,44 & 7,94 \\
\hline 59 & 39 & 1 & Sim & C & 189 & 0,35 & 2,26 & 1,46 & 0,24 & 1,63 & 0,86 & 1,07 & 11,29 & 7,45 \\
\hline 60 & 45 & 9 & Sim & A & 658 & 0,60 & 1,15 & 0,85 & 0,60 & 1,77 & 1,41 & 1,83 & 7,15 & 5,86 \\
\hline 61 & 33 & 4 & Sim & C & 388 & 0,35 & 2,07 & 1,39 & 0,24 & 1,55 & 0,86 & 1,01 & 10,08 & 7,04 \\
\hline 62 & 40 & 9 & Sim & A & 739 & 0,60 & & & 0,62 & & & 1,91 & & \\
\hline 63 & 45 & 1 & Não & B & 522 & 0,36 & 2,46 & 1,59 & 0,26 & 3,16 & 1,77 & 1,37 & 13,57 & 8,92 \\
\hline 64 & 41 & 11 & Sim & A & 1549 & 0,66 & 1,21 & 0,90 & 0,63 & 1,74 & 1,37 & 1,98 & 6,84 & 5,66 \\
\hline 65 & 56 & 12 & Sim & B & 517 & 0,39 & 2,51 & 1,64 & 0,29 & 3,13 & 1,79 & 1,26 & 11,19 & 7,63 \\
\hline 66 & 46 & 1 & Sim & C & 308 & 0,38 & 2,11 & 1,47 & 0,25 & 1,51 & 0,87 & 0,96 & 8,79 & 6,18 \\
\hline 67 & 44 & 7 & Sim & C & 856 & 0,40 & 2,13 & 1,55 & 0,26 & 1,62 & 0,93 & 1,03 & 9,27 & 6,74 \\
\hline 68 & 51 & 14 & Sim & A & 531 & 0,72 & 1,31 & 1,00 & 0,67 & 1,92 & 1,47 & 2,12 & 7,20 & 5,88 \\
\hline 69 & 34 & 13 & Sim & B & 573 & 0,44 & 2,66 & 1,71 & 0,30 & 3,20 & 1,78 & 1,33 & 10,83 & 7,59 \\
\hline 70 & 45 & 12 & Sim & A & 311 & 0,76 & 1,39 & 1,08 & 0,68 & 1,98 & 1,50 & 2,41 & 8,00 & 6,61 \\
\hline 71 & 41 & 11 & Sim & B & 350 & 0,48 & 2,77 & 1,80 & 0,36 & 3,69 & 2,08 & 1,43 & 11,11 & 7,84 \\
\hline 72 & 47 & 4 & Sim & C & 142 & 0,41 & 1,21 & 1,55 & 0,27 & 1,79 & 1,02 & 1,20 & 10,38 & 7,65 \\
\hline 73 & 37 & 2 & Sim & B & 314 & 0,54 & 3,20 & 2,08 & 0,39 & 4,11 & 2,29 & 1,62 & 13,46 & 9,39 \\
\hline 74 & 40 & 8 & Sim & C & 502 & 0,43 & 2,11 & 1,55 & 0,27 & 1,86 & 1,05 & 1,25 & 10,26 & 7,63 \\
\hline 75 & 42 & 9 & Sim & A & 929 & 0,76 & 1,48 & 1,12 & 0,68 & 2,07 & 1,60 & 2,33 & 8,64 & 7,31 \\
\hline 76 & 53 & 11 & Sim & A & 588 & 0,77 & 1,80 & 1,32 & 0,66 & 2,16 & 1,68 & 2,49 & 9,52 & 8,05 \\
\hline 77 & 54 & 8 & Sim & C & 405 & 0,42 & 1,99 & 1,44 & 0,27 & 2,01 & 1,14 & 1,20 & 10,90 & 8,07 \\
\hline 78 & 52 & 10 & Sim & B & 821 & 0,51 & 2,79 & 1,84 & 0,38 & 3,74 & 2,12 & 1,73 & 13,45 & 9,45 \\
\hline 79 & 41 & 9 & Sim & B & 598 & 0,51 & 2,64 & 1,81 & 0,37 & 3,70 & 2,14 & 1,75 & 14,04 & 9,71 \\
\hline 80 & 39 & 3 & Sim & A & 1142 & 0,78 & 1,87 & 1,27 & 0,64 & 2,01 & 1,62 & 2,70 & 10,15 & 9,50 \\
\hline 81 & 47 & 2 & Sim & C & 252 & 0,41 & 1,85 & 1,31 & 0,27 & 1,82 & 1,04 & 1,19 & 10,05 & 7,52 \\
\hline 82 & 41 & 13 & Sim & A & 329 & 0,79 & 1,85 & 1,27 & 0,67 & 2,10 & 1,68 & 2,76 & 10,36 & 9,67 \\
\hline 83 & 42 & 7 & Sim & C & 400 & 0,41 & 2,01 & 0,14 & 0,27 & 1,81 & 1,05 & 1,24 & 10,60 & 7,96 \\
\hline 84 & 56 & 11 & Não & B & 760 & & 2,62 & 1,77 & & 3,52 & 2,07 & & 15,29 & 10,42 \\
\hline 85 & 55 & 1 & Sim & A & 248 & 0,81 & 1,89 & 1,30 & 0,72 & 2,21 & 1,78 & 2,94 & 10,59 & 9,83 \\
\hline 86 & 41 & 5 & Sim & B & 419 & 0,52 & & & 0,41 & & & 1,82 & & \\
\hline 87 & 44 & 6 & Sim & C & 211 & 0,45 & 2,41 & 1,71 & 0,27 & 1,87 & 1,08 & 1,24 & 9,94 & 7,67 \\
\hline 88 & 39 & 10 & Sim & A & 192 & 0,79 & 1,79 & 1,24 & 0,70 & 2,14 & 1,70 & 2,85 & 10,61 & 9,70 \\
\hline 89 & 39 & 2 & Sim & C & 404 & 0,45 & 2,39 & 1,72 & 0,27 & 1,96 & 1,14 & 1,30 & 10,04 & 7,77 \\
\hline 90 & 38 & 4 & Sim & B & 490 & 0,52 & 2,58 & 1,75 & 0,42 & 3,54 & 2,09 & 1,81 & 15,72 & 10,66 \\
\hline 91 & 22 & 1 & Não & B & 538 & 0,58 & 2,83 & 1,89 & 0,48 & 3,74 & 2,22 & 1,95 & 15,69 & 10,64 \\
\hline 92 & 43 & 8 & Não & C & 906 & 0,45 & 2,45 & 1,72 & 0,26 & 1,94 & 1,14 & 1,43 & 10,92 & 8,37 \\
\hline 93 & 51 & 11 & Não & A & 537 & 0,78 & 1,80 & 1,22 & 0,68 & 2,02 & 1,61 & 2,81 & 10,44 & 9,24 \\
\hline 94 & 40 & 1 & Não & B & 553 & 0,57 & 2,82 & 1,84 & 0,48 & 3,65 & 2,17 & 1,85 & 16,32 & 10,67 \\
\hline 95 & 59 & 16 & Sim & C & 504 & 0,45 & 2,36 & 1,66 & 0,26 & 1,96 & 1,16 & 1,38 & 10,55 & 8,17 \\
\hline 96 & 26 & 1 & Não & A & 1038 & 0,79 & 1,76 & 1,20 & 0,68 & 1,95 & 1,56 & 2,74 & 11,01 & 9,42 \\
\hline 97 & 34 & 8 & Sim & B & 822 & 0,57 & 2,93 & 1,86 & 0,49 & 3,85 & 2,27 & 1,81 & 17,46 & 11,35 \\
\hline 98 & 25 & 1 & Sim & A & 852 & 0,76 & 1,66 & 1,15 & 0,68 & 1,99 & 1,59 & 2,88 & 11,53 & 9,33 \\
\hline 99 & 36 & 10 & Sim & C & 410 & 0,45 & 2,24 & 1,59 & 0,27 & 2,11 & 1,27 & 1,39 & 10,19 & 7,74 \\
\hline 100 & 38 & 7 & Sim & B & 764 & 0,57 & 3,03 & 1,92 & 0,50 & 3,75 & 2,25 & 1,91 & 18,70 & 12,26 \\
\hline 101 & 43 & 7 & Sim & A & 454 & 0,79 & 1,69 & 1,18 & 0,68 & 2,14 & 1,69 & 2,76 & 11,52 & 9,11 \\
\hline 102 & 45 & 13 & Sim & C & 503 & 0,47 & 2,28 & 1,61 & 0,28 & 2,08 & 1,28 & 1,37 & 9,55 & 7,30 \\
\hline 103 & 28 & 5 & Sim & A & 852 & 0,79 & 1,81 & 1,30 & 0,65 & 2,10 & 1,64 & 2,62 & 12,60 & 9,74 \\
\hline 104 & 55 & 8 & Sim & C & 158 & 0,47 & 2,19 & & 0,28 & 1,97 & & 1,32 & 9,48 & \\
\hline 105 & 41 & 7 & Sim & B & 843 & 0,60 & 3,31 & 2,11 & 0,50 & 4,04 & 2,41 & 1,88 & 20,05 & 13,18 \\
\hline 106 & 57 & 7 & Sim & B & 573 & 0,61 & 3,03 & & 0,52 & 4,33 & & 1,92 & 18,35 & \\
\hline 107 & 43 & 12 & Sim & A & 421 & 0,79 & 2,01 & 1,43 & 0,64 & 2,17 & 1,67 & 2,56 & 13,04 & 10,08 \\
\hline 108 & 34 & 6 & Sim & C & 376 & 0,49 & 2,14 & 1,57 & 0,29 & 1,90 & 1,23 & 1,39 & 10,14 & 7,71 \\
\hline 109 & 42 & 10 & Sim & B & 797 & 0,65 & 3,12 & 2,14 & 0,54 & 4,47 & 2,47 & 1,99 & 19,39 & 13,98 \\
\hline 110 & 31 & 5 & Sim & A & 296 & 0,81 & 2,03 & 1,45 & 0,65 & 2,19 & 1,68 & 2,65 & 13,91 & 10,57 \\
\hline 111 & 43 & 17 & Sim & C & 477 & 0,48 & 2,04 & 1,49 & 0,29 & 1,83 & 1,20 & 1,36 & 9,78 & 7,40 \\
\hline
\end{tabular}




\begin{tabular}{|c|c|c|c|c|c|c|c|c|c|c|c|c|c|c|}
\hline 112 & 39 & 11 & Sim & C & 459 & 0,48 & 1,95 & 1,44 & 0,29 & 1,87 & 1,25 & 1,50 & 10,31 & 7,92 \\
\hline 113 & 27 & 10 & Não & B & 344 & 0,70 & 3,39 & 2,32 & 0,54 & 4,39 & 2,52 & 2,20 & 20,23 & 14,76 \\
\hline 114 & 52 & 3 & Sim & A & 305 & 0,81 & 2,03 & 1,42 & 0,65 & 2,15 & 1,67 & 2,53 & 13,70 & 10,39 \\
\hline 115 & 45 & 12 & Sim & A & 499 & 0,80 & 1,93 & 1,34 & 0,63 & 2,11 & 1,61 & 2,33 & 12,84 & 9,58 \\
\hline 116 & 43 & 6 & Sim & B & 539 & 0,70 & 3,39 & 2,33 & 0,54 & 4,29 & 2,53 & 2,35 & 20,43 & 14,94 \\
\hline 117 & 47 & 8 & Sim & C & 266 & 0,51 & 2,03 & 1,52 & 0,30 & 1,93 & 1,31 & 1,61 & 10,54 & 8,16 \\
\hline 118 & 44 & 4 & Sim & A & 250 & 0,77 & 1,83 & 1,30 & 0,62 & 2,24 & 1,72 & 2,41 & 13,70 & 10,30 \\
\hline 119 & 38 & 9 & Não & B & 482 & 0,67 & 3,32 & 2,25 & 0,51 & 4,00 & 2,35 & 2,21 & 18,90 & 13,81 \\
\hline 120 & 54 & 9 & Sim & C & 169 & 0,51 & 1,98 & 1,49 & 0,30 & 1,93 & 1,32 & 1,50 & 9,53 & 7,27 \\
\hline 121 & 25 & 1 & Não & A & 723 & 0,79 & 1,88 & 1,33 & 0,62 & 2,22 & 1,70 & 2,40 & 13,54 & 10,01 \\
\hline 122 & 55 & 7 & Sim & C & 932 & 0,51 & 1,91 & 1,47 & 0,31 & 2,08 & 1,43 & 1,44 & 9,68 & 7,32 \\
\hline 123 & 43 & 10 & Sim & B & 445 & 0,67 & 3,38 & 2,28 & 0,52 & 3,89 & 2,33 & 2,12 & 18,46 & 13,05 \\
\hline 124 & 27 & 1 & Não & C & 408 & 0,56 & 2,18 & 1,66 & 0,32 & 2,23 & 1,55 & 1,45 & 9,93 & 7,34 \\
\hline 125 & 43 & 7 & Sim & B & 622 & 0,67 & 3,61 & 2,42 & 0,50 & 3,56 & 2,14 & 2,20 & 18,13 & 12,41 \\
\hline 126 & 27 & 4 & Sim & A & 465 & 0,80 & 1,94 & 1,35 & 0,62 & 2,17 & 1,65 & 2,33 & 13,17 & 9,65 \\
\hline 127 & 28 & 4 & Sim & B & 616 & 0,72 & 3,76 & 2,54 & 0,53 & 3,59 & 2,19 & 2,24 & 18,00 & 12,39 \\
\hline 128 & 59 & 6 & Sim & A & 830 & 0,84 & 2,00 & 1,39 & 0,64 & 2,27 & 1,70 & 2,41 & 13,82 & 10,26 \\
\hline 129 & 50 & 22 & Sim & C & 703 & 0,55 & 2,34 & 1,78 & 0,32 & 2,34 & 1,62 & 1,35 & 9,83 & 7,17 \\
\hline 130 & 59 & 12 & Sim & A & 399 & 0,85 & 2,00 & 1,40 & 0,64 & 2,28 & 1,69 & 2,36 & 13,25 & 9,84 \\
\hline 131 & 39 & 11 & Sim & A & 810 & 0,83 & 1,94 & 1,36 & 0,63 & 2,25 & 1,69 & 2,25 & 13,30 & 9,67 \\
\hline 132 & 52 & 10 & Sim & C & 357 & 0,54 & 2,28 & 1,70 & 0,32 & 2,21 & 1,56 & 1,36 & 9,99 & 7,60 \\
\hline 133 & 42 & 7 & Sim & B & 373 & 0,70 & 3,51 & 2,40 & 0,52 & 3,45 & 2,11 & 2,19 & 16,85 & 11,77 \\
\hline 134 & 27 & 2 & Sim & C & 398 & 0,56 & 2,39 & 1,76 & 0,32 & 2,22 & 1,59 & 1,39 & 9,80 & 7,35 \\
\hline 135 & 35 & 14 & Sim & B & 555 & 0,69 & 3,32 & 2,29 & 0,51 & 3,36 & 2,06 & 2,19 & 16,30 & 11,46 \\
\hline 136 & 27 & 1 & Não & A & 480 & 0,87 & 2,11 & & 0,65 & 2,25 & & 2,28 & 13,31 & \\
\hline 137 & 55 & 8 & Sim & B & 471 & 0,68 & 3,13 & 2,18 & 0,52 & 3,61 & 2,23 & 2,15 & 15,90 & 11,14 \\
\hline 138 & 41 & 8 & Sim & C & 896 & 0,56 & 2,31 & & 0,33 & 2,26 & & 1,46 & 9,91 & \\
\hline 139 & 53 & 11 & Sim & C & 270 & 0,57 & 2,28 & 1,73 & 0,34 & 2,34 & 1,64 & 1,57 & 10,51 & 7,75 \\
\hline 140 & 41 & 7 & Não & B & 422 & 0,67 & 3,11 & 2,11 & 0,54 & 3,76 & 2,28 & 2,20 & 16,26 & 11,27 \\
\hline 141 & 38 & 9 & Sim & A & 418 & 0,86 & 2,06 & 1,35 & 0,64 & 2,16 & 1,63 & 2,33 & 13,25 & 9,72 \\
\hline 142 & 52 & 1 & Sim & C & 305 & 0,55 & 2,23 & 1,68 & 0,34 & 2,28 & 1,60 & 1,49 & 9,61 & 7,12 \\
\hline 143 & 42 & 4 & Sim & A & 562 & 0,86 & 2,01 & 1,33 & 0,66 & 2,18 & 1,65 & 2,27 & 12,94 & 9,50 \\
\hline 144 & 45 & 8 & Sim & B & 277 & 0,68 & 3,03 & 2,06 & 0,55 & 3,62 & 2,20 & 2,06 & 14,45 & 10,13 \\
\hline 145 & 47 & 7 & Sim & C & 935 & 0,55 & 2,19 & 1,68 & 0,35 & 2,28 & 1,60 & 1,49 & 9,45 & 7,04 \\
\hline 146 & 44 & 11 & Sim & B & 282 & 0,67 & 2,87 & 1,97 & 0,54 & 3,41 & 2,09 & 1,94 & 12,95 & 9,14 \\
\hline 147 & 51 & 7 & Não & A & 587 & 0,87 & 2,00 & 1,33 & 0,66 & 2,15 & 1,63 & 2,26 & 12,36 & 9,18 \\
\hline 148 & 47 & 1 & Não & C & 384 & 0,56 & 2,24 & 1,71 & 0,35 & 2,42 & 1,70 & 1,55 & 9,86 & 7,37 \\
\hline 149 & 35 & 2 & Não & A & 621 & 0,85 & 1,94 & 1,29 & 0,65 & 2,13 & 1,61 & 2,21 & 11,97 & 8,80 \\
\hline 150 & 36 & 1 & Não & B & 506 & 0,68 & 2,91 & 1,97 & 0,53 & 3,27 & 1,99 & 1,98 & 12,82 & 9,02 \\
\hline 151 & 38 & 6 & Sim & C & 888 & 0,57 & 2,27 & 1,73 & 0,36 & 2,43 & 1,71 & 1,51 & 9,78 & 7,28 \\
\hline 152 & 30 & 1 & Não & B & 745 & 0,70 & 2,94 & 1,99 & 0,55 & 3,30 & 2,01 & 2,07 & 12,91 & 9,10 \\
\hline 153 & 39 & 14 & Sim & A & 692 & 0,83 & 1,86 & 1,24 & 0,65 & 2,22 & 1,67 & 2,15 & 11,91 & 8,65 \\
\hline 154 & 37 & 8 & Sim & B & 767 & 0,70 & 2,90 & 1,94 & 0,55 & 3,39 & 2,02 & 1,94 & 12,36 & 8,45 \\
\hline 155 & 45 & 10 & Sim & A & 387 & 0,84 & 1,89 & 1,26 & 0,68 & 2,38 & 1,80 & 2,31 & 12,47 & 9,12 \\
\hline 156 & 41 & 1 & Sim & C & 276 & 0,58 & 2,24 & 1,74 & 0,37 & 2,44 & 1,73 & 1,51 & 9,37 & 7,00 \\
\hline 157 & 42 & 12 & Sim & C & 271 & 0,60 & 2,38 & 1,82 & 0,39 & 2,50 & 1,77 & 1,56 & 9,57 & 7,08 \\
\hline 158 & 39 & 11 & Sim & B & 553 & 0,72 & 2,93 & 1,98 & 0,57 & 3,40 & 2,05 & 1,97 & 12,24 & 8,38 \\
\hline 159 & 33 & 3 & Sim & A & 878 & 0,89 & 1,97 & 1,33 & 0,74 & 2,53 & 1,93 & 2,44 & 12,74 & 9,40 \\
\hline 160 & 38 & 9 & Sim & B & 931 & 0,73 & 2,87 & 1,95 & 0,57 & 3,32 & 2,02 & 2,00 & 12,69 & 8,66 \\
\hline 161 & 31 & 3 & Não & A & 356 & 0,92 & 2,00 & 1,36 & 0,76 & 2,54 & 1,93 & 2,41 & 12,17 & 8,99 \\
\hline 162 & 39 & 5 & Sim & C & 524 & 0,61 & 2,51 & 1,92 & 0,40 & 2,63 & 1,87 & 1,69 & 10,02 & 7,50 \\
\hline 163 & 29 & 1 & Não & B & 527 & 0,70 & 2,78 & 1,89 & 0,56 & 3,38 & 2,04 & 2,03 & 13,13 & 8,97 \\
\hline 164 & 36 & 3 & Sim & C & 378 & 0,61 & 2,53 & 1,95 & 0,41 & 2,66 & 1,89 & 1,73 & 10,24 & 7,61 \\
\hline 165 & 37 & 8 & Sim & A & 628 & 0,91 & 1,96 & & 0,74 & 2,43 & & 2,31 & 11,40 & \\
\hline 166 & 36 & 8 & Sim & A & 590 & 0,93 & 1,98 & 1,38 & 0,74 & 2,40 & 1,91 & 2,28 & 11,15 & 8,77 \\
\hline 167 & 54 & 5 & Sim & B & 504 & 0,73 & 2,80 & 1,93 & 0,57 & 3,46 & 2,08 & 1,97 & 13,01 & 8,87 \\
\hline 168 & 51 & 6 & Sim & C & 873 & 0,61 & 2,51 & 1,93 & 0,42 & 2,76 & 1,94 & 1,67 & 9,88 & 7,23 \\
\hline 169 & 34 & 5 & Sim & B & 663 & 0,71 & 2,71 & 1,88 & 0,58 & 3,51 & 2,12 & 2,01 & 13,10 & 9,00 \\
\hline 170 & 38 & 2 & Sim & A & 658 & 0,95 & 1,95 & 1,38 & 0,76 & 2,41 & 1,94 & 2,31 & 11,02 & 8,73 \\
\hline
\end{tabular}




\begin{tabular}{|c|c|c|c|c|c|c|c|c|c|c|c|c|c|c|}
\hline 171 & 34 & 1 & Não & C & 326 & 0,62 & 2,55 & 1,96 & 0,44 & 2,82 & 1,97 & 1,71 & 9,85 & 7,21 \\
\hline 172 & 55 & 9 & Sim & A & 205 & 0,91 & & & 0,74 & & & 2,24 & & \\
\hline 173 & 52 & 6 & Sim & B & 310 & 0,68 & 2,56 & 1,78 & 0,58 & 3,43 & 2,07 & 1,92 & 12,21 & 8,41 \\
\hline 174 & 27 & 9 & Não & C & 299 & 0,62 & 2,44 & 1,85 & 0,44 & 2,76 & 1,93 & 1,67 & 9,31 & 6,75 \\
\hline 175 & 43 & 1 & Sim & C & 756 & 0,61 & 2,49 & 1,89 & 0,45 & 2,90 & 2,02 & 1,65 & 9,76 & 7,01 \\
\hline 176 & 23 & 1 & Sim & B & 404 & 0,67 & 2,59 & 1,77 & 0,57 & 3,47 & 2,09 & 1,81 & 11,32 & 7,90 \\
\hline 177 & 28 & 2 & Sim & A & 447 & 0,92 & 1,95 & 1,38 & 0,75 & 2,44 & 1,97 & 2,15 & 10,57 & 8,36 \\
\hline 178 & 42 & 15 & Sim & C & 439 & 0,62 & 2,55 & 1,94 & 0,46 & 2,88 & 2,02 & 1,73 & 9,93 & 7,47 \\
\hline 179 & 36 & 1 & Não & B & 323 & 0,67 & 2,52 & 1,75 & 0,59 & 3,50 & 2,10 & 1,78 & 11,10 & 7,78 \\
\hline 180 & 36 & 7 & Sim & A & 393 & 0,92 & 1,98 & 1,41 & 0,74 & 2,45 & 1,95 & 2,29 & 11,00 & 8,74 \\
\hline 181 & 40 & 8 & Sim & B & 384 & 0,66 & 2,47 & 1,72 & 0,57 & 3,33 & 2,01 & 1,70 & 10,21 & 7,18 \\
\hline 182 & 27 & 3 & Sim & A & 634 & 0,90 & 1,94 & 1,38 & 0,72 & 2,47 & 1,97 & 2,32 & 11,54 & 9,19 \\
\hline 183 & 39 & 16 & Sim & C & 500 & 0,62 & 2,55 & 1,93 & 0,46 & 2,90 & 2,02 & 1,68 & 9,81 & 7,24 \\
\hline 184 & 52 & 10 & Sim & A & 774 & 0,95 & 2,02 & 1,45 & 0,72 & 2,46 & 1,96 & 2,37 & 11,93 & 9,44 \\
\hline 185 & 37 & 10 & Sim & C & 1903 & 0,61 & 2,47 & 1,89 & 0,46 & 2,86 & 2,00 & 1,63 & 9,33 & 6,88 \\
\hline 186 & 48 & 6 & Sim & B & 614 & 0,64 & 2,34 & 1,62 & 0,54 & 3,19 & 1,91 & 1,66 & 10,48 & 7,35 \\
\hline 187 & 43 & 1 & Sim & C & 171 & 0,61 & 2,56 & 1,94 & 0,45 & 2,93 & 2,05 & 1,61 & 9,42 & 6,99 \\
\hline 188 & 30 & 1 & Não & A & 432 & 0,95 & & 1,45 & 0,72 & & 1,95 & 2,40 & & 9,35 \\
\hline 189 & 39 & 12 & Não & B & 369 & 0,61 & 2,20 & 1,53 & 0,52 & 2,99 & 1,78 & 1,58 & 9,61 & 6,76 \\
\hline 190 & 45 & 7 & Sim & B & 377 & 0,62 & 2,21 & 1,56 & 0,53 & 2,96 & 1,78 & 1,61 & 9,73 & 6,83 \\
\hline 191 & 39 & 1 & Sim & C & 541 & 0,61 & 2,55 & 1,93 & 0,46 & 3,01 & 2,11 & 1,57 & 9,41 & 6,95 \\
\hline 192 & 32 & 2 & Sim & A & 520 & 0,95 & 1,93 & & 0,71 & 2,50 & & 2,37 & 12,10 & \\
\hline 193 & 40 & 8 & Sim & B & 627 & 0,61 & 2,18 & 1,57 & 0,54 & 3,03 & 1,83 & 1,61 & 9,79 & 6,91 \\
\hline 194 & 54 & 10 & Não & C & 530 & 0,61 & 2,54 & 1,92 & 0,48 & 3,04 & 2,15 & 1,60 & 9,38 & 6,96 \\
\hline 195 & 45 & 9 & Sim & A & 1492 & 0,95 & 1,92 & 1,45 & 0,72 & 2,46 & 1,94 & 2,37 & 11,88 & 9,21 \\
\hline 196 & 45 & 1 & Sim & B & 215 & 0,62 & 2,19 & 1,57 & 0,54 & 3,10 & 1,86 & 1,64 & 10,09 & 7,11 \\
\hline 197 & 34 & 1 & Não & C & 391 & 0,63 & 2,58 & & 0,48 & 2,95 & & 1,65 & 9,42 & \\
\hline 198 & 41 & 3 & Sim & A & 376 & 0,92 & 1,85 & 1,42 & 0,70 & 2,39 & 1,88 & 2,32 & 12,25 & 9,51 \\
\hline 199 & 44 & 10 & Sim & B & 784 & 0,61 & 2,11 & 1,51 & 0,53 & 3,04 & 1,83 & 1,65 & 10,37 & 7,34 \\
\hline 200 & 59 & 3 & Sim & A & 420 & 0,92 & 1,89 & 1,45 & 0,72 & 2,48 & 1,94 & 2,35 & 12,57 & 9,93 \\
\hline 201 & 36 & 10 & Não & C & 293 & 0,63 & 2,58 & 1,91 & 0,47 & 2,96 & 2,14 & 1,63 & 9,51 & 6,94 \\
\hline 202 & 26 & 7 & Sim & C & 759 & 0,64 & 2,55 & 1,96 & 0,48 & 2,95 & 2,16 & 1,63 & 9,39 & 6,90 \\
\hline 203 & 49 & 1 & Não & A & 353 & 0,89 & 1,82 & 1,39 & 0,72 & 2,41 & 1,87 & 2,35 & 12,68 & 9,93 \\
\hline 204 & 42 & 9 & Sim & B & 816 & 0,61 & 2,21 & 1,58 & 0,54 & 3,01 & 1,82 & 1,69 & 10,50 & 7,49 \\
\hline 205 & 31 & 9 & Sim & B & 363 & 0,60 & & & 0,53 & & & 1,64 & & \\
\hline 206 & 34 & 11 & Sim & A & 492 & 0,87 & 1,76 & 1,37 & 0,70 & 2,37 & 1,83 & 2,23 & 11,76 & 9,16 \\
\hline 207 & 39 & 14 & Sim & C & 715 & 0,64 & 2,58 & 1,97 & 0,48 & 3,03 & 2,20 & 1,61 & 9,35 & 6,84 \\
\hline 208 & 42 & 1 & Não & A & 2239 & 0,87 & 1,79 & 1,38 & 0,70 & 2,40 & 1,84 & 2,20 & 11,89 & 9,29 \\
\hline 209 & 42 & 13 & Sim & B & 738 & 0,60 & 2,21 & 1,60 & 0,54 & 3,10 & 1,86 & 1,67 & 10,90 & 7,66 \\
\hline 210 & 54 & 11 & Sim & C & 287 & 0,63 & 2,54 & 1,93 & 0,48 & 3,06 & 2,21 & 1,56 & 8,99 & 6,56 \\
\hline 211 & 36 & 8 & Sim & B & 282 & 0,59 & 2,17 & 1,57 & 0,53 & 3,12 & 1,87 & 1,67 & 11,16 & 7,86 \\
\hline 212 & 31 & 4 & Sim & C & 730 & 0,63 & 2,50 & 1,88 & 0,48 & 2,99 & 2,14 & 1,57 & 9,15 & 6,71 \\
\hline 213 & 37 & 1 & Não & A & 885 & 0,85 & & & 0,68 & & & 2,18 & & \\
\hline 214 & 45 & 10 & Sim & A & 585 & 0,86 & 1,80 & 1,38 & 0,69 & 2,42 & 1,86 & 2,23 & 11,95 & 9,42 \\
\hline 215 & 41 & 7 & Sim & C & 268 & 0,63 & 2,47 & 1,85 & 0,47 & 2,96 & 2,12 & 1,58 & 9,28 & 6,84 \\
\hline 216 & 37 & 6 & Sim & B & 538 & 0,60 & 2,24 & 1,59 & 0,53 & 3,15 & 1,89 & 1,71 & 11,21 & 7,92 \\
\hline 217 & 28 & 1 & Não & A & 650 & 0,83 & 1,74 & 1,34 & 0,68 & 2,38 & 1,82 & 2,26 & 11,99 & 9,42 \\
\hline 218 & 36 & 11 & Sim & B & 772 & 0,61 & 2,23 & 1,59 & 0,54 & 3,15 & 1,89 & 1,76 & 11,30 & 7,96 \\
\hline 219 & 46 & 8 & Sim & C & 919 & 0,62 & 2,55 & & 0,48 & 3,03 & & 1,54 & 9,20 & \\
\hline 220 & 35 & 7 & Não & C & 433 & 0,61 & & & 0,47 & & & 1,52 & & \\
\hline 221 & 28 & 9 & Sim & B & 942 & 0,63 & 2,26 & 1,61 & 0,54 & 3,21 & 1,91 & 1,78 & 11,68 & 8,42 \\
\hline 222 & 45 & 7 & Sim & A & 554 & 0,87 & 1,81 & 1,40 & 0,68 & 2,42 & 1,84 & 2,38 & 12,27 & 9,93 \\
\hline 223 & 51 & 13 & Não & A & 394 & 0,86 & 1,80 & 1,37 & 0,67 & 2,41 & 1,81 & 2,32 & 11,85 & 9,56 \\
\hline 224 & 36 & 8 & Sim & C & 414 & 0,58 & & & 0,48 & & & 1,45 & & \\
\hline 225 & 43 & 9 & Não & B & 681 & 0,60 & 2,13 & 1,53 & 0,52 & 3,11 & 1,84 & 1,82 & 11,68 & 8,45 \\
\hline 226 & 38 & 9 & Sim & C & 478 & 0,59 & 2,52 & & 0,48 & 3,00 & & 1,41 & 9,15 & \\
\hline 227 & 47 & 12 & Sim & B & 357 & 0,62 & 2,22 & 1,58 & 0,52 & 3,07 & 1,83 & 1,79 & 11,72 & 8,49 \\
\hline 228 & 30 & 1 & Não & A & 458 & 0,86 & 1,77 & & 0,67 & 2,37 & & 2,29 & 11,39 & \\
\hline 229 & 28 & 1 & Não & A & 267 & 0,84 & 1,70 & 1,32 & 0,64 & 2,24 & 1,70 & 2,21 & 10,68 & 8,96 \\
\hline
\end{tabular}




\begin{tabular}{|c|c|c|c|c|c|c|c|c|c|c|c|c|c|c|}
\hline 230 & 39 & 12 & Sim & C & 551 & 0,60 & 2,61 & 1,91 & 0,49 & 3,01 & 2,13 & 1,41 & 9,30 & 6,90 \\
\hline 231 & 43 & 8 & Sim & B & 138 & 0,63 & 2,22 & 1,58 & 0,52 & 3,03 & 1,82 & 1,77 & 11,70 & 8,37 \\
\hline 232 & 38 & 8 & Sim & C & 751 & 0,59 & 2,64 & 1,93 & 0,49 & 3,04 & 2,13 & 1,42 & 9,57 & 7,18 \\
\hline 233 & 35 & 1 & Não & B & 511 & 0,62 & 2,22 & 1,60 & 0,52 & 2,98 & 1,79 & 1,75 & 11,50 & 8,22 \\
\hline 234 & 37 & 1 & Não & A & 248 & 0,83 & & & 0,65 & & & 2,15 & & \\
\hline 235 & 32 & 7 & Sim & A & 656 & 0,87 & 1,77 & 1,37 & 0,65 & 2,19 & 1,66 & 2,19 & 10,64 & 8,89 \\
\hline 236 & 33 & 1 & Não & B & 1119 & 0,63 & & & 0,51 & & & 1,75 & & \\
\hline 237 & 48 & 10 & Sim & C & 655 & 0,58 & 2,55 & 1,86 & 0,47 & 2,99 & 2,08 & 1,42 & 9,48 & 7,09 \\
\hline 238 & 44 & 12 & Sim & C & 234 & 0,59 & 2,58 & 1,85 & 0,47 & 3,00 & 2,08 & 1,39 & 9,17 & 6,83 \\
\hline 239 & 30 & 1 & Não & A & 628 & 0,90 & 1,80 & 1,37 & 0,66 & 2,20 & 1,66 & 2,21 & 10,55 & 8,78 \\
\hline 240 & 42 & 12 & Sim & B & 605 & 0,62 & 2,18 & 1,57 & 0,51 & 3,02 & 1,81 & 1,72 & 11,69 & 8,27 \\
\hline 241 & 36 & 6 & Sim & B & 709 & 0,62 & 2,19 & 1,56 & 0,50 & 2,99 & 1,80 & 1,68 & 11,93 & 8,27 \\
\hline 242 & 43 & 1 & Sim & A & 588 & 0,88 & 1,75 & 1,34 & 0,66 & 2,23 & 1,68 & 2,21 & 10,35 & 8,60 \\
\hline 243 & 31 & 10 & Não & C & 864 & 0,59 & 2,55 & 1,80 & 0,47 & 2,92 & 2,02 & 1,35 & 8,77 & 6,47 \\
\hline 244 & 47 & 11 & Sim & B & 820 & 0,62 & 2,14 & 1,52 & 0,51 & 3,06 & 1,84 & 1,76 & 12,17 & 8,46 \\
\hline 245 & 44 & 11 & Sim & C & 633 & 0,58 & 2,51 & 1,78 & 0,49 & 3,07 & 2,11 & 1,34 & 8,81 & 6,50 \\
\hline 246 & 47 & 1 & Sim & A & 296 & 0,88 & 1,73 & 1,32 & 0,66 & 2,21 & 1,67 & 2,23 & 10,30 & 8,58 \\
\hline 247 & 36 & 20 & Sim & B & 576 & 0,62 & 2,13 & 1,51 & 0,51 & 3,03 & 1,83 & 1,70 & 12,03 & 8,32 \\
\hline 248 & 51 & 9 & Sim & A & 673 & 0,85 & & & 0,66 & & & 2,19 & & \\
\hline 249 & 43 & 1 & Sim & C & 150 & 0,57 & 2,41 & & 0,47 & 2,92 & & 1,32 & 8,44 & \\
\hline 250 & 49 & 13 & Sim & A & 190 & 0,83 & 1,67 & 1,27 & 0,65 & 2,20 & 1,65 & 2,13 & 9,85 & 8,22 \\
\hline 251 & 45 & 2 & Sim & B & 354 & 0,62 & 2,10 & 1,48 & 0,51 & 3,01 & 1,81 & 1,64 & 11,48 & 7,97 \\
\hline 252 & 43 & 10 & Sim & C & 455 & 0,59 & 2,48 & 1,84 & 0,48 & 3,00 & 2,18 & 1,32 & 8,56 & 6,62 \\
\hline 253 & 53 & 8 & Sim & C & 539 & 0,60 & 2,48 & & 0,49 & 3,04 & & 1,33 & 8,43 & \\
\hline 254 & 38 & 10 & Não & B & 746 & 0,60 & 2,04 & 1,44 & 0,49 & 2,96 & 1,78 & 1,56 & 11,22 & 7,79 \\
\hline 255 & 44 & 18 & Sim & A & 468 & 0,81 & 1,63 & 1,24 & 0,62 & 2,08 & 1,58 & 2,10 & 9,72 & 8,12 \\
\hline 256 & 50 & 1 & Sim & C & 310 & 0,59 & 2,47 & 1,80 & 0,50 & 3,13 & 2,23 & 1,30 & 8,28 & 6,51 \\
\hline 257 & 47 & 2 & Sim & B & 173 & 0,59 & 1,98 & 1,38 & 0,50 & 2,90 & 1,76 & 1,63 & 10,94 & 7,96 \\
\hline 258 & 39 & 14 & Sim & A & 359 & 0,80 & 1,63 & & 0,62 & 2,07 & & 2,04 & 9,47 & \\
\hline 259 & 27 & 2 & Sim & C & 367 & 0,57 & & & 0,49 & & & 1,29 & & \\
\hline 260 & 35 & 1 & Não & B & 348 & 0,60 & 1,98 & 1,38 & 0,50 & 2,94 & 1,77 & 1,64 & 11,39 & 8,26 \\
\hline 261 & 55 & 2 & Sim & A & 350 & 0,80 & 1,60 & 1,21 & 0,61 & 2,07 & 1,56 & 2,06 & 9,68 & 8,06 \\
\hline 262 & 48 & 2 & Não & A & 321 & 0,81 & 1,62 & & 0,61 & 2,06 & & 2,03 & 9,44 & \\
\hline 263 & 41 & 2 & Sim & B & 282 & 0,59 & 1,93 & 1,35 & 0,50 & 2,93 & 1,76 & 1,70 & 11,65 & 8,45 \\
\hline 264 & 51 & 6 & Sim & C & 278 & 0,56 & 2,41 & 1,76 & 0,49 & 3,18 & 2,24 & 1,27 & 8,24 & 6,42 \\
\hline 265 & 25 & 6 & Não & A & 703 & 0,80 & 1,61 & & 0,60 & 2,00 & & 2,05 & 9,67 & \\
\hline 266 & 33 & 2 & Sim & B & 283 & 0,59 & 1,92 & 1,34 & 0,49 & 2,95 & 1,76 & 1,75 & 11,97 & 8,58 \\
\hline 267 & 31 & 1 & Não & C & 307 & 0,55 & 2,34 & & 0,48 & 3,23 & & 1,27 & 8,03 & \\
\hline 268 & 29 & 1 & Sim & B & 306 & 0,58 & 1,87 & & 0,48 & 2,93 & & 1,73 & 11,79 & \\
\hline 269 & 42 & 2 & Sim & C & 281 & 0,55 & & & 0,49 & & & 1,30 & & \\
\hline 270 & 25 & 1 & Sim & A & 373 & 0,79 & 1,58 & 1,19 & 0,59 & 1,95 & 1,50 & 2,06 & 9,81 & 8,12 \\
\hline 271 & 42 & 9 & Sim & C & 349 & 0,55 & & & 0,50 & & & 1,32 & & \\
\hline 272 & 52 & 1 & Sim & A & 820 & 0,78 & 1,54 & 1,16 & 0,59 & 1,95 & 1,49 & 2,02 & 9,59 & 7,90 \\
\hline 273 & 25 & 1 & Não & B & 553 & 0,56 & 1,85 & 1,32 & 0,48 & 2,93 & 1,76 & 1,75 & 12,33 & 8,94 \\
\hline 274 & 39 & 15 & Sim & C & 328 & 0,55 & 2,27 & 1,70 & 0,49 & 3,14 & 2,19 & 1,30 & 7,77 & 6,18 \\
\hline 275 & 46 & 1 & Sim & B & 219 & 0,56 & 1,82 & & 0,47 & 2,91 & & 1,72 & 12,21 & \\
\hline 276 & 32 & 1 & Não & A & 546 & 0,77 & & & 0,59 & & & 2,01 & & \\
\hline 277 & 39 & 6 & Sim & A & 449 & 0,75 & 1,49 & 1,12 & 0,59 & 1,95 & 1,49 & 2,02 & 9,73 & 8,00 \\
\hline 278 & 47 & 9 & Sim & C & 865 & 0,54 & 2,21 & & 0,48 & 3,03 & & 1,29 & 7,78 & \\
\hline 279 & 45 & 8 & Sim & B & 370 & 0,55 & 1,81 & 1,31 & 0,48 & 2,96 & 1,80 & 1,71 & 12,62 & 9,22 \\
\hline 280 & 40 & 1 & Não & C & 357 & 0,55 & 2,24 & 1,73 & 0,48 & 3,05 & 2,20 & 1,31 & 7,82 & 6,24 \\
\hline 281 & 59 & 11 & Sim & A & 460 & 0,74 & 1,47 & 1,10 & 0,57 & 1,91 & 1,48 & 1,98 & 9,44 & 7,69 \\
\hline 282 & 40 & 2 & Sim & B & 293 & 0,54 & 1,82 & 1,32 & 0,46 & 2,87 & 1,77 & 1,65 & 11,98 & 8,97 \\
\hline 283 & 29 & 1 & Não & A & 474 & 0,73 & 1,45 & 1,09 & 0,56 & 1,90 & 1,48 & 1,93 & 9,23 & 7,48 \\
\hline 284 & 29 & 1 & Não & B & 288 & 0,53 & 1,77 & 1,28 & 0,45 & 2,78 & 1,73 & 1,58 & 11,46 & 8,64 \\
\hline 285 & 37 & 6 & Sim & C & 345 & 0,55 & 2,26 & 1,74 & 0,48 & 2,98 & 2,15 & 1,32 & 8,04 & 6,42 \\
\hline 286 & 34 & 1 & Sim & A & 396 & 0,73 & 1,44 & & 0,57 & 1,91 & & 1,93 & 9,43 & \\
\hline 287 & 51 & 11 & Sim & C & 921 & 0,54 & 2,22 & 1,70 & 0,47 & 3,05 & 2,18 & 1,29 & 7,91 & 6,24 \\
\hline 288 & 53 & 2 & Sim & B & 226 & 0,53 & 1,78 & & 0,45 & 2,81 & & 1,50 & 11,63 & \\
\hline
\end{tabular}




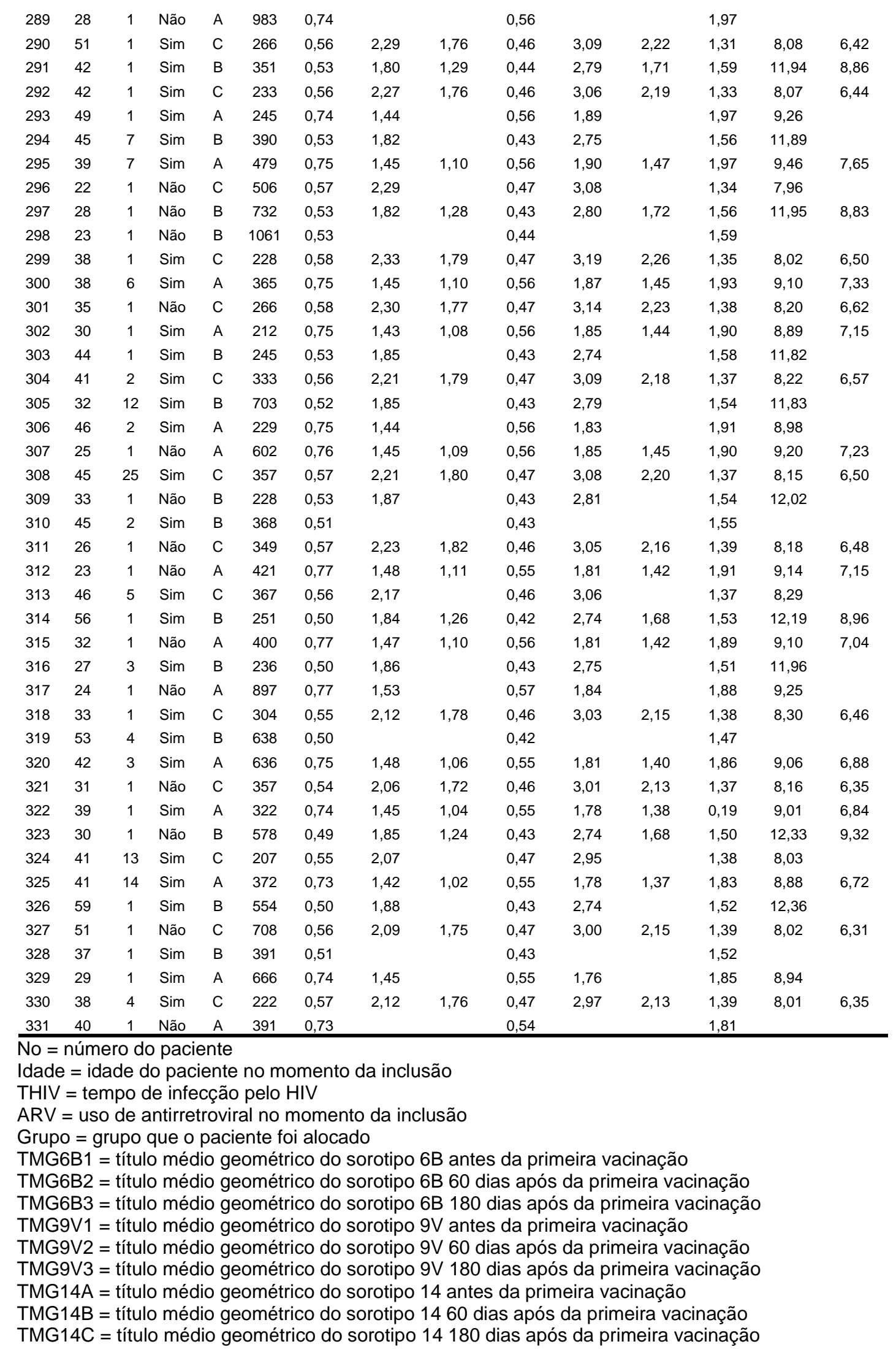




\section{Anexo VII - Tabela da colonização de nasofaringe entre os indivíduos que tiveram identificação de S.pneumoniae em uma das coletas}

\begin{tabular}{|c|c|c|c|c|}
\hline No & Colonização pré & Sorotipo pré & Colonização pós & Sorotipo pós \\
\hline 1 & S. pneumoniae & 4 & Streptococcus grupo viridans & \\
\hline 3 & S. pneumoniae & NT & Outros & \\
\hline 6 & S. pneumoniae & NT & Sem colonização & \\
\hline 9 & S. pneumoniae & NT & Outros & \\
\hline 11 & S. pneumoniae & NT & Sem colonização & \\
\hline 12 & S. pneumoniae & NT & Outros & \\
\hline 15 & S. pneumoniae & $6 B$ & Streptococcus grupo viridans & \\
\hline 30 & S. pneumoniae & $7 \mathrm{~F}$ & & \\
\hline 35 & S. pneumoniae & NT & Sem colonização & \\
\hline 43 & S. pneumoniae & NT & Sem colonização & \\
\hline 79 & Streptococcus grupo viridans & & S. pneumoniae & NT \\
\hline 82 & S. pneumoniae & $10 \mathrm{~A}$ & Sem colonização & \\
\hline 84 & S. pneumoniae & $6 \mathrm{~A}$ & Streptococcus grupo viridans & \\
\hline 110 & Outros agente & & S. pneumoniae & NT \\
\hline 121 & Outros agente & & S. pneumoniae & $23 \mathrm{~F}$ \\
\hline 146 & S. pneumoniae & $7 \mathrm{C}$ & Sem colonização & \\
\hline 154 & S. pneumoniae & $19 A$ & S. pneumoniae & $9 \mathrm{~N}$ \\
\hline 170 & S. pneumoniae & $19 \mathrm{~A}$ & Outros & \\
\hline 176 & S. pneumoniae & $16 \mathrm{~F}$ & & \\
\hline 180 & Streptococcus grupo viridans & & S. pneumoniae & 3 \\
\hline 223 & S. pneumoniae & $19 \mathrm{~F}$ & & \\
\hline 231 & Sem colonização identificada & & S. pneumoniae & $19 \mathrm{~A}$ \\
\hline 236 & S. pneumoniae & $6 \mathrm{~B}$ & & \\
\hline 238 & S. pneumoniae & $22 \mathrm{~F}$ & & \\
\hline 265 & S. pneumoniae & $6 \mathrm{~B}$ & & \\
\hline 268 & S. pneumoniae & 14 & & \\
\hline 270 & S. pneumoniae & $10 \mathrm{~A}$ & & \\
\hline
\end{tabular}

No = número do indivíduo

Colonização pré = agente identificado na nasofaringe antes da primeira vacinação

Sorotipo pré = sorotipo de $S$. pneumoniae identificado na nasofaringe, pré-vacinação Colonização pós = agente isolado na nasofaringe 180 dias após a primeira vacinação Sorotipo pós = sorotipo de $S$. pneumoniae identificado na nasofaringe 180 dias após a primeira vacinação 
Referências $\mid \mathbf{8 5}$

8 Referências 
1. Centers for Disease Control and Prevention (CDC), 2008. Streptococcus pneumoniae Disease (Acessado em 4 abril 2011). disponível em: http://www.cdc.gov/ncidod/dbmd/diseaseinfo /streppneum_t.htm.

2. Huang SS, Johnson KM, Ray GT, Wroe P, Lieu TA, Moore MR, Zell ER, Linder JA, Grijalva CG, Metlay JP, Finkelstein JA. Healthcare utilization and cost of pneumococcal disease in the United States. Vaccine. 2011;29:3398-412.

3. Novaes HM, Sartori AM, Soarez PC. Hospitalization rates for pneumococcal disease in Brazil, 2004 - 2006. Rev Saude Publica. 2011;45:539-47.

4. Akgun KM, Pisani M, Crothers K. The changing epidemiology of HIVinfected patients in the intensive care unit. $J$ Intensive Care Med. 2011;26:151-64.

5. Chiang HH HC, Lee CM, Chen HY, Chen MY, Sheng WH, Hsieh SM, Sun HY, Ho CC, Yu CJ. Admissions to intensive care unit of HIVinfected patients in the era of highly active antiretroviral therapy: etiology and prognostic factors. Crit Care. 2011;14:R202.

6. Hirschtick RE, Glassroth J, Jordan MC, Wilcosky TC, Wallace JM, Kvale PA, Markowitz N, Rosen MJ, Mangura BT, Hopewell PC. Bacterial pneumonia in persons infected with the human immunodeficiency virus. Pulmonary Complications of HIV Infection Study Group. N Engl J Med. 1995;333:845-51.

7. Nuorti JP, Butler JC, Gelling L, Kool JL, Reingold AL, Vugia DJ. Epidemiologic relation between HIV and invasive pneumococcal disease in San Francisco County, California. Ann Intern Med. 2000;132:182-90. 
8. Jordano Q, Falcó V, Almirante B, Planes AM, del Valle O, Ribera E, Len O, Pigrau C, Pahissa A. Invasive pneumococcal disease in patients infected with HIV: still a threat in the era of highly active antiretroviral therapy. Clin Infect Dis. 2004;38:1623-8.

9. Heffernan RT, Barrett NL, Gallagher KM, Hadler JL, Harrison LH, Reingold AL, Khoshnood K, Holford TR, Schuchat A. Declining incidence of invasive Streptococcus pneumoniae infections among persons with AIDS in an era of highly active antiretroviral therapy, 1995-2000. J Infect Dis. 2005;191:2038-45.

10. Cohen AL, Harrison LH, Farley MM, Reingold AL, Hadler J, Schaffner W, Lynfield R, Thomas AR, Campsmith M, Li J, Schuchat A, Moore MR; Active Bacterial Core Surveillance Team. Prevention of invasive pneumococcal disease among HIV-infected adults in the era of childhood pneumococcal immunization. AIDS. 2010;24:2253-62.

11. Kourtis AP, Ellington S, Bansil P, Jamieson DJ, Posner SF. Hospitalizations for invasive pneumococcal disease among HIV-1infected adolescents and adults in the United States in the era of highly active antiretroviral therapy and the conjugate pneumococcal vaccine. J Acquir Immune Defic Syndr. 2010;55:128-31.

12. Klugman KP, Madhi SA, Feldman C. HIV and pneumococcal disease. Curr Opin Infect Dis. 2007;20:11-5.

13. Organização Panamericana de Saúde. Informe Regional de SIREVA II, 2010: datos por país y por grupos de edad sobre las características de los aislamientos de Streptococcus pneumoniae, Haemophilus influenzae y Neisseria meningitidis en procesos invasores. In: Vigilancia Sanitaria PyCdEHRSI, Alerta y Respuesta y Enfermedades Epidémicas (HSD/IR), ed. Washington (DC). 2011. 
14. Crewe-Brown HH, Karstaedt AS, Saunders GL, Khoosal M, Jones N, Wasas A, Klugman KP. Streptococcus pneumoniae blood culture isolates from patients with and without human immunodeficiency virus infection: alterations in penicillin susceptibilities and in serogroups or serotypes. Clin Infect Dis. 1997;25:1165-72.

15. Grau I, Pallares R, Tubau F, Schulze MH, Llopis F, Podzamczer D, Liñares J, Gudiol F; Spanish Pneumococcal Infection Study Network (G03/103). Epidemiologic changes in bacteremic pneumococcal disease in patients with human immunodeficiency virus in the era of highly active antiretroviral therapy. Arch Intern Med. 2005;165:153340.

16. Center for Disease Control and Prevention (CDC). Updated Recommendations for Prevention of Invasive Pneumococcal Disease Among Adults Using the 23-Valent Pneumococcal Polysaccharide Vaccine (PPSV23). MMWR Morb Mortal Wkly Rep. 2010:1102-6.

17. Brasil. Ministério da Saúde. Secretaria de Vigilância à Saúde. Programa Nacional de Imunizações. Manual dos Centros de Referência para Imunobiológicos Especiais. 3a. Edição. Brasília(DF). Ministério da Saúde; 2006.

18. Brasil. Ministério da Saúde. Secretaria de Vigilância à Saúde. Programa Nacional de Imunizações. Proposta para introdução da vacina pneumocócica 10-valente (conjugada) no calendário básico de vacinação da criança - incorporação março - 2010. Brasília(DF). Ministério da Saúde; 2010.

19. Lesinski GB, Westerink MA. Vaccines against polysaccharide antigens. Curr Drug Targets Infect Disord. 2001;1:325-34. 
20. Organização Panamericana de Saúde. Vigilancia Sanitaria, Prevención y Control de Enfermedades (HSD). Informe Regional de SIREVA II, 2009: datos por país y por grupos de edad sobre las características de los aislamientos de Streptococcus pneumoniae, Haemophilus influenzae y Neisseria meningitidis en procesos invasores. Washington (DC); 2010.

21. Robbins JB, Austrian R, Lee CJ, Rastogi SC, Schiffman G, Henrichsen J, Mäkelä PH, Broome CV, Facklam RR, Tiesjema RH, Parke Jr JC. Considerations for formulating the second-generation pneumococcal capsular polysaccharide vaccine with emphasis on the cross-reactive types within groups. J Infect Dis. 1983;148:1136-59.

22. Fry AM, Facklam RR, Whitney CG, Plikaytis BD, Schuchat A. Multistate evaluation of invasive pneumococcal diseases in adults with human immunodeficiency virus infection: serotype and antimicrobial resistance patterns in the United States. J Infect Dis. 2003:643-52.

23. Musher DM, Luchi MJ, Watson DA, Hamilton R, Baughn RE. Pneumococcal polysaccharide vaccine in young adults and older bronchitics: determination of IgG responses by ELISA and the effect of adsorption of serum with non-type-specific cell wall polysaccharide. $J$ Infect Dis. 1990;161:728-35.

24. Musher DM, Watson DA, Baughn RE. Genetic control of the immunologic response to pneumococcal capsular polysaccharides. Vaccine. 2000: 19(6):623-7.

25. Sankilampi U, Honkanen PO, Bloigu A, Leinonen M. Persistence of antibodies to pneumococcal capsular polysaccharide vaccine in the elderly. J Infect Dis. 1997;176:1100-4.

26. Braido F, Bellotti M, De Maria A, Cazzola M, Canonica GW. The role of Pneumococcal vaccine. Pulm Pharmacol Ther. 2008;21:608-15. 
27. Shapiro ED, Berg AT, Austrian R, Schroeder D, Parcells V, Margolis A, Adair RK, Clemens JD. The protective efficacy of polyvalent pneumococcal polysaccharide vaccine. N Engl J Med. 1991;325:145360.

28. Vila-Corcoles A, Salsench E, Rodriguez-Blanco T, Ochoa-Gondar O, de Diego C, Valdivieso A, Hospital I, Gomez-Bertomeu F, Raga X. Clinical effectiveness of 23-valent pneumococcal polysaccharide vaccine against pneumonia in middle-aged and older adults: A matched case-control study. Vaccine. 2009;27:1504-10.

29. Fedson DS. The clinical effectiveness of pneumococcal vaccination: a brief review. Vaccine. 1999;17 Suppl 1:S85-90.

30. Huss A, Scott P, Stuck AE, Trotter C, Egger M. Efficacy of pneumococcal vaccination in adults: a meta-analysis. CMAJ. 2009;180:48-58.

31. Moberley SA, Holden J, Tatham DP, Andrews RM. Vaccines for preventing pneumococcal infection in adults. Cochrane Database Syst Rev. 2008:CD000422.

32. Melegaro A, Edmunds WJ. The 23-valent pneumococcal polysaccharide vaccine. Part I. Efficacy of PPV in the elderly: a comparison of meta-analyses. Eur J Epidemiol. 2004;19:353-63.

33. Conaty S, Watson L, Dinnes J, Waugh N. The effectiveness of pneumococcal polysaccharide vaccines in adults: a systematic review of observational studies and comparison with results from randomised controlled trials. Vaccine. 2004;22:3214-24.

34. Watson L, Wilson BJ, Waugh N. Pneumococcal polysaccharide vaccine: a systematic review of clinical effectiveness in adults. Vaccine. 2002;20:2166-73. 
35. Janoff EN, Douglas JM Jr, Gabriel M, Blaser MJ, Davidson AJ, Cohn DL, Judson FN. Class-specific antibody response to pneumococcal capsular polysaccharides in men infected with human immunodeficiency virus type 1. J Infect Dis. 1988;158:983-90.

36. Rodriguez-Barradas MC, Musher DM, Lahart C, Lacke C, Groover J, Watson D, Baughn R, Cate T, Crofoot G. Antibody to capsular polysaccharides of Streptococcus pneumoniae after vaccination of human immunodeficiency virus-infected subjects with 23-valent pneumococcal vaccine. J Infect Dis. 1992;165:553-6.

37. Mascart-Lemone F, Gérard M, Libin M, Crusiaux A, Franchioly $P$, Lambrechts A, Goldman M, Clumeck N. Differential effect of human immunodeficiency virus infection on the $\operatorname{IgA}$ and $\lg G$ antibody responses to pneumococcal vaccine. J Infect Dis. 1995;172:1253-60.

38. Kroon FP, van Dissel JT, de Jong JC, van Furth R. Antibody response to influenza, tetanus and pneumococcal vaccines in HIV-seropositive individuals in relation to the number of CD4+ lymphocytes. AIDS. 1994;8:469-76.

39. Gebo KA, Moore RD, Keruly JC, Chaisson RE. Risk factors for pneumococcal disease in human immunodeficiency virus-infected patients. J Infect Dis. 1996;173:857-62.

40. Dworkin MS, Ward JW, Hanson DL, Jones JL, Kaplan JE, Adult and Adolescent Spectrum of HIVDP. Pneumococcal disease among human immunodeficiency virus-infected persons: incidence, risk factors, and impact of vaccination. Clin Infect Dis. 2001;32:794-800.

41. Falcó V, Jordano Q, Cruz MJ, Len O, Ribera E, Campins M, Crespo M, Ocaña I, Rodrigo MJ, Pahissa A. Serological response to pneumococcal vaccination in HAART-treated HIV-infected patients: one year follow-up study. Vaccine. 2006;24:2567-74. 
42. Breiman RF, Keller DW, Phelan MA, Sniadack DH, Stephens DS, Rimland D, Farley MM, Schuchat A, Reingold AL. Evaluation of effectiveness of the 23-valent pneumococcal capsular polysaccharide vaccine for HIV-infected patients. Arch Intern Med. 2000;160:2633-8.

43. Peñaranda $M$, Falco $V$, Payeras $A$, Jordano $Q$, Curran $A$, Pareja $A$, Samperiz G, Dalmau D, Ribera E, Riera M. Effectiveness of polysaccharide pneumococcal vaccine in HIV-infected patients: a case-control study. Clin Infect Dis. 2007;45:e82-7.

44. Teshale EH, Hanson D, Flannery B, Phares C, Wolfe M, Schuchat A, Sullivan P. Effectiveness of 23-valent polysaccharide pneumococcal vaccine on pneumonia in HIV-infected adults in the United States, 1998-2003. Vaccine. 2008;26:5830-4.

45. French N, Nakiyingi J, Carpenter LM, Lugada E, Watera C, Moi K, Moore M, Antvelink D, Mulder D, Janoff EN, Whitworth J, Gilks CF.. 23-valent pneumococcal polysaccharide vaccine in HIV-1-infected Ugandan adults: double-blind, randomised and placebo controlled trial. Lancet. 2000;355:2106-11.

46. Lindberg AA. Glycoprotein conjugate vaccines. Vaccine. 1999;17 Suppl 2:S28-36.

47. Hausdorff WP, Bryant J, Kloek C, Paradiso PR, Siber GR. The contribution of specific pneumococcal serogroups to different disease manifestations: implications for conjugate vaccine formulation and use, part II. Clin Infect Dis. 2000;30:122-40.

48. Hausdorff WP, Bryant J, Paradiso PR, Siber GR. Which pneumococcal serogroups cause the most invasive disease: implications for conjugate vaccine formulation and use, part I. Clin Infect Dis. 2000;30:100-21. 
49. Shinefield HR, Black S, Ray $P$, et al. Safety and immunogenicity of heptavalent pneumococcal CRM197 conjugate vaccine in infants and toddlers. Pediatr Infect Dis J. 1999;18:757-63.

50. Siber GR, Chang I, Baker S, Fernsten P, O'Brien KL, Santosham M, Klugman KP, Madhi SA, Paradiso P, Kohberger R. Estimating the protective concentration of anti-pneumococcal capsular polysaccharide antibodies. Vaccine. 2007;25:3816-26.

51. Organização Mundial da Saúde (WHO). Recommendations for the production and control of pneumococcal conjugate vaccines. WHO Technical Report Series. Genebra: WHO 2005;927.

52. Vieira S, Baldacci ER, Carneiro-Sampaio M, Doria U, Koch VH. Evaluation of antibody response to the heptavalent pneumococcal conjugate vaccine in pediatric chronic kidney disease. Pediatric Nephrology. 2009;24:83-9.

53. Black S, Shinefield H, Fireman B, Lewis E, Ray P, HANSEN JR, Elvin L, Ensor KM, Hackell J, Siber G, Malinoski F, Madore D, Chang I, Kohberger R, Watson W, Austrian R, Edwards K, The Northern California Kaiser Permanente Vaccine Study Center Group. Efficacy, safety and immunogenicity of heptavalent pneumococcal conjugate vaccine in children. Pediatr Infect Dis J. 2000;19:187-95.

54. O'Brien KL, Moulton LH, Reid R, Weatherholtz R, Oski J, Brown L, Kumar G, Parkinson A, Hu D, Hackell J, Chang I, Kohberger R, Siber G, Santosham M. Efficacy and safety of seven-valent conjugate pneumococcal vaccine in American Indian children: group randomised trial. Lancet. 2003;362:355-61. 
55. Hansen J, Black S, Shinefield H, Cherian T, Benson J, Fireman B, Lewis E, Ray P, Lee J. Effectiveness of heptavalent pneumococcal conjugate vaccine in children younger than 5 years of age for prevention of pneumonia: updated analysis using World Health Organization standardized interpretation of chest radiographs. Pediatr Infect Dis J. 2006;25:779-81.

56. Center for Disease Control and Prevention (CDC). Direct and Indirect Effects of Routine Vaccination of Children with 7-Valent Pneumococcal Conjugate Vaccine on Incidence of Invasive Pneumococcal Disease - United States, 1998--2003. MMWR Morb Mortal Wkly Rep. 2005;54:893-7.

57. Kyaw MH, Lynfield R, Schaffner W, Craig AS, Hadler J, Reingold A, Thomas AR, Harrison LH, Bennett NM, Farley MM, Facklam RR, Jorgensen JH, Besser J, Zell ER, Schuchat A, Whitney CG. Effect of introduction of the pneumococcal conjugate vaccine on drug-resistant Streptococcus pneumoniae. N Engl J Med. 2006;354:1455-63.

58. Grijalva CG, Griffin MR. Population-based impact of routine infant immunization with pneumococcal conjugate vaccine in the USA. Expert Rev Vaccines. 2008;7:83-95.

59. Abraham-Van Parijs B. Review of pneumococcal conjugate vaccine in adults: implications on clinical development. Vaccine. 2004;22:136271.

60. O'Brien KL. Pneumococcal Conjugate Vaccine, Polysaccharide Vaccine, or Both for Adults? We're Not There Yet. Clinical Infectious Diseases. 2009;49:1326-8.

61. Musher DM, Sampath R, Rodriguez-Barradas MC. The potential role for protein-conjugate pneumococcal vaccine in adults: what is the supporting evidence? Clin Infect Dis. 2011;52:633-40. 
62. Shelly MA, Jacoby H, Riley GJ, Graves BT, Pichichero M, Treanor JJ. Comparison of pneumococcal polysaccharide and CRM197conjugated pneumococcal oligosaccharide vaccines in young and elderly adults. Infect Immun. 1997;65:242-7.

63. de Roux A, Schmole-Thoma B, Siber GR, Hackell JG, Kuhnke A, Ahlers N, Baker SA, Razmpour A, Emini EA, Fernsten PD, Gruber WC, Lockhart S, Burkhardt O, Welte T, Lode HM. Comparison of pneumococcal conjugate polysaccharide and free polysaccharide vaccines in elderly adults: conjugate vaccine elicits improved antibacterial immune responses and immunological memory. Clin Infect Dis. 2008;46:1015-23.

64. Goldblatt D, Southern J, Andrews N, Ashton L, Burbidge P, Woodgate S, Pebody R, Miller E. The Immunogenicity of 7-Valent Pneumococcal Conjugate Vaccine versus 23-Valent Polysaccharide Vaccine in Adults Aged 50-80 Years. Clin Infect Dis. 2009;49:1318-25.

65. Lazarus R, Clutterbuck E, Yu LM, Bowman J, Bateman EA, Diggle L, Angus B, Peto TE, Beverley PC, Mant D, Pollard AJ. A randomized study comparing combined pneumococcal conjugate and polysaccharide vaccination schedules in adults. Clin Infect Dis. 2011;52:736-42.

66. Ahmed F, Steinhoff MC, Rodriguez-Barradas MC, Hamilton RG, Musher DM, Nelson KE. Effect of human immunodeficiency virus type 1 infection on the antibody response to a glycoprotein conjugate pneumococcal vaccine: results from a randomized trial. $J$ Infect Dis. 1996;173:83-90. 
67. Feikin DR, Elie CM, Goetz MB, Daniel R, Lennox JL, Carlone GM, Romero-Steiner S, Holder PF, O'Brien WA, Whitney CG, Butler JC, Breiman RF. Randomized trial of the quantitative and functional antibody responses to a 7-valent pneumococcal conjugate vaccine and/or 23-valent polysaccharide vaccine among HIV-infected adults. Vaccine. $2001 ; 20: 545-53$.

68. French N, Gordon SB, Mwalukomo T, White SA, Mwafulirwa G, Longwe H, Mwaiponya M, Zijlstra EE, Molyneux ME, Gilks CF. A trial of a 7-valent pneumococcal conjugate vaccine in HIV-infected adults. N Engl J Med. 2010;362:812-22.

69. Center for Disease Control and Prevention (CDC). Prevention of pneumococcal disease: recommendations of the Advisory Committee on Immunization Practices (ACIP). MMWR Morb Mortal Wkly Rep. 1997;46:1-24.

70. Torling J, Hedlund J, Konradsen HB, Ortqvist A. Revaccination with the 23-valent pneumococcal polysaccharide vaccine in middle-aged and elderly persons previously treated for pneumonia. Vaccine. 2003;22:96-103.

71. Lackner TE, R GH, J JH, Davey C, Guay DR. Pneumococcal polysaccharide revaccination: immunoglobulin $g$ seroconversion, persistence, and safety in frail, chronically ill older subjects. $J A m$ Geriatr Soc. 2003;51:240-5.

72. Poolman J, Borrow R. Hyporesponsiveness and its clinical implications after vaccination with polysaccharide or glycoconjugate vaccines. Expert Rev Vaccines. 2011;10:307-22.

73. Brynjolfsson SF, Henneken M, Bjarnarson SP, Mori E, Del Giudice G, Jonsdottir I. Hyporesponsiveness following booster immunization with bacterial polysaccharides is caused by apoptosis of memory B cells. $J$ Infect Dis. 2012;205:422-30. 
74. Granoff DM, Pollard AJ. Reconsideration of the use of meningococcal polysaccharide vaccine. Pediatr Infect Dis J. 2007;26:716-22.

75. Davidson M, Bulkow LR, Grabman J, Parkinson AJ, Chamblee C, Williams WW, Lanier AP, Schiffman G. Immunogenicity of pneumococcal revaccination in patients with chronic disease. Arch Intern Med. 1994;154:2209-14.

76. O'Brien KL, Hochman M, Goldblatt D. Combined schedules of pneumococcal conjugate and polysaccharide vaccines: is hyporesponsiveness an issue? Lancet Infect Dis. 2007;7:597-606.

77. Kroon FP, van Dissel JT, Ravensbergen E, Nibbering PH, van Furth R. Enhanced antibody response to pneumococcal polysaccharide vaccine after prior immunization with conjugate pneumococcal vaccine in HIV-infected adults. Vaccine. 2000;19:886-94.

78. Jackson LA, Neuzil KM, Nahm MH, Lisa A. Whitney CG, Yu O, Nelson JC, Starkovich PT, Dunstan M, Carste B, Shay DK, Baggs J, Carlone GM. Immunogenicity of varying dosages of 7 -valent pneumococcal polysaccharide-protein conjugate vaccine in seniors previously vaccinated with 23-valent pneumococcal polysaccharide vaccine. Vaccine. 2007;25:4029-37.

79. Lesprit P, Pedrono G, Molina JM, Goujard C, Girard PM, Sarrazin N, Katlamag C, Yéni P, Morineau P, Delfraissy JF, Chêne G, Lévy Y and the ANRS 114-Pneumovac Study Group. Immunological efficacy of a prime-boost pneumococcal vaccination in HIV-infected adults. AIDS. 2007;21:2425-34.

80. Regev-Yochay G, Raz M, Dagan R, Porat N, Shainberg B, Pinco E, Keller N, Rubinstein E. Nasopharyngeal carriage of Streptococcus pneumoniae by adults and children in community and family settings. Clin Infect Dis. 2004;38:632-9. 
81. Nicoletti C, Brandileone MC, Guerra ML, Levin AS. Prevalence, serotypes, and risk factors for pneumococcal carriage among HIVinfected adults. Diagn Microbiol Infect Dis. 2007;57:259-65.

82. MacLeod CM, Hodges RG, Heidelberger M, Bernhard WG. Prevention of pneumococcal pneumonia by immunization with specific capsular polysaccharides. J Exp Med. 1945;82:445-65.

83. Dagan R, Melamed R, Muallem M, Piglansky L, Greenberg D, Abramson O, Mendelman PM, Bohidar N, Yagupsky P. Reduction of nasopharyngeal carriage of pneumococci during the second year of life by a heptavalent conjugate pneumococcal vaccine. J Infect Dis. 1996;174:1271-8.

84. Obaro SK, Adegbola RA, Banya WA, Greenwood BM. Carriage of pneumococci after pneumococcal vaccination. Lancet. 1996;348:2712.

85. Rodriguez-Barradas MC, Tharapel RA, Groover JE, Giron KP, Lacke CE, Houston ED, Hamill RJ, Steinhoff MC, Musher DM. Colonization by Streptococcus pneumoniae among human immunodeficiency virusinfected adults: prevalence of antibiotic resistance, impact of immunization, and characterization by polymerase chain reaction with BOX primers of isolates from persistent S. pneumoniae carriers. $J$ Infect Dis. 1997;175:590-7.

86. Lo YC, Lauderdale TL, Chang SY, Hsiao CF, Hung CC, Chang SC. Streptococcus pneumoniae colonization among patients with human immunodeficiency virus-1 who had received 23-valent polysaccharide pneumococcal vaccine. J Microbiol Immunol Infect 2009;42:234-42.

87. O'Brien KL, Nohynek H; World Health Organization Pneumococcal Vaccine Trials Carriage Working Group. Report from a WHO Working Group: standard method for detecting upper respiratory carriage of Streptococcus pneumoniae. Pediatr Infect Dis J. 2003;22:e1-11. 
88. Organização Mundial da Saúde (WHO). Training manual for Enzyme linked immunosorbent assay for the quantitation of Streptococcus pneumoniae serotype specific IgG (Pn PS ELISA). Genebra: OMS; 2002.

89. Organização Mundial da Saúde (WHO). Laboratory methods for the diagnosis of meningitis caused by Neisseria meningitidis, Streptococcus pneumoniae, and Haemophilus influenzae. Genebra: OMS; 1999.

90. Organização Mundial da Saúde (WHO). Pneumococcal Vaccines WHO position paper-2012. Genebra: OMS 2012:129-44.

91. Bocchini JA Jr BJ, Brady MT, Bernstein HH, Byington CL, Fisher MC, Glode MP, Jackson MA, Keyserling HL, Kimberlin DW, Orenstein WA, Schutze GE, Willoughby RE Jr. Recommendations for the prevention of Streptococcus pneumoniae infections in infants and children: use of 13-valent pneumococcal conjugate vaccine (PCV13) and pneumococcal polysaccharide vaccine (PPSV23). Pediatrics. 2010;126:186-90.

92. Brasil. Ministério da Saúde. Resumo analítico dos Dados do Boletim Epidemiológico 2011. Ministério da Saúde, 2011. Brasília (DF). (Acessado em 26 mar2012) Disponível em: http://www.aids.gov.br/ sites/default/files/anexos/publicacao/2011/50652/resumo_anal_tico_d os_dados_do_boletim_epidemiol_92824.pdf.)

93. Brasil, Ministério da Saúde, Serviço de Vigilância em Saúde/Departamento de DST, Aids e Hepatites Virais. Boletim Epidemiológico Aids e DST 2011. Brasília (DF) (Acessado em 26 mar 2012). Disnponível em: http://www.aids.gov.br/sites/default/files /anexos/publicacao/2011/50652/boletim_aids_2011_preliminar3_pdf_ 20265.pdf.) 
94. Ho YL, Enohata T, Lopes MH, De Sousa Dos Santos S. Vaccination in Brazilian HIV-infected adults: a cross-sectional study. AIDS Patient Care STDS. 2008;22:65-70.

95. Esposito S, Droghetti R, Faelli N, Lastrico A, Tagliabue C, Cesati L, Bianchi C, Principi N. Serum concentrations of pneumococcal anticapsular antibodies in children with pneumonia associated with Streptococcus pneumonia infection. Clin Infect Dis. 2003;37:1261-4.

96. Almeida VD, Mussi-Pinhata MM, De Souza CBS, Kubo CA, Martinez EZ, Carneiro-Sampaio MM, Geraldo Duarte. Immunogenicity of 23valent pneumococcal polysaccharide vaccine in HIV-infected pregnant women and kinetics of passively acquired antibodies in young infants. Vaccine. 2009;27:3856-61.

97. Hare ND, Smith BJ, Ballas ZK. Antibody response to pneumococcal vaccination as a function of preimmunization titer. $J$ Allergy Clin Immunol. 2009;123:195-200.

98. Ridda I, Maclntyre CR, Lindley R, Gao Z, Sullivan JS, Yuan FF. Mclntyr PB. Immunological responses to pneumococcal vaccine in frail older people. Vaccine. 2009;27:1628-36.

99. Penaranda M, Payeras A, Cambra A, Mila J, Riera M. Conjugate and polysaccharide pneumococcal vaccines do not improve initial response of the polysaccharide vaccine in HIV-infected adults. AIDS. 2010.

100. Rodriguez-Barradas M, Goulet J, Brown S, Goetz MB, Rimland D, Simberkoff MS, Crothers K, Justice AC. Impact of Pneumococcal Vaccination on the Incidence of Pneumonia by HIV Infection Status among Patients Enrolled in the Veterans Aging Cohort 5-Site Study. Clin Infect Dis. 2008; 46:1093-1100. 
101. Horster S, Laubender RP, Lehmeyer L, Ankerst DP, Eberle J, Reinert R, Imöhl M, van der Linden M, Schweiger B, Bogner JR. Influence of antiretroviral therapy on immunogenicity of simultaneous vaccinations against influenza, pneumococcal disease and hepatitis $A$ and $B$ in human immunodeficiency virus positive individuals. $J$ Infect. 2010;61:484-91.

102. Timens W, Boes A, Rozeboom-Uiterwijk T, Poppema S. Immaturity of the human splenic marginal zone in infancy. Possible contribution to the deficient infant immune response. J Immunol. 1989;143:3200-6.

103. Weller S, Reynaud CA, Weill JC. Vaccination against encapsulated bacteria in humans: paradoxes. Trends Immunol. 2005;26:85-9.

104. Clutterbuck EA, Lazarus R, Yu LM, Bateman EAL, Diggle L, Angus B, Peto TE, Beverley PC, Mant D, Pollard AJ. Pneumococcal conjugate and plain polysaccharide vaccines have divergent effects on antigenspecific B cells. J Infect Dis. 2012;205:1408-16.

105. Goldblatt D, Hussain M, Andrews N, Ashton L, Virta C, Melegaro A, Pebody R, George R, Soininen A, Edmunds J, Gay N, Kayhty H, Miller E. Antibody responses to nasopharyngeal carriage of Streptococcus pneumoniae in adults: a longitudinal household study. J Infect Dis. 2005;192:387-93.

106. Danilova E, Shiryayev A, Kristoffersen EK, Sjursen H. Attenuated immune response to tetanus toxoid in young healthy men protected against tetanus. Vaccine. 2005;23:4980-3.

107. Concepcion NF, Frasch CE. Pneumococcal type 22F polysaccharide absorption improves the specificity of a pneumococcal-polysaccharide enzyme-linked immunosorbent assay. Clin Diagn Lab Immunol. 2001;8:266-72. 
108. Henckaerts I, Goldblatt D, Ashton L, Poolman J. Critical differences between pneumococcal polysaccharide enzyme-linked immunosorbent assays with and without $22 \mathrm{~F}$ inhibition at low antibody concentrations in pediatric sera. Clin Vaccine Immunol. 2006;13:35660 .

109. Manoff SB, Liss C, Caulfield MJ, Marchese RD, Silber J, Boslego J, Romero-Steiner S, Rajam G, Glass NE, Whitney CGC, Carlone GM. Revaccination with a 23-valent pneumococcal polysaccharide vaccine induces elevated and persistent functional antibody responses in adults aged $65>$ or $=$ years. $J$ Infect Dis. 2010;201:525-33.

110. Miernyk KM, Butler JC, Bulkow LR, Singleton RJ, Hennessy TW, Dentinger CM, Peters HV, Knutsen B, Hickel J, Parkinson AJ. Immunogenicity and reactogenicity of pneumococcal polysaccharide and conjugate vaccines in alaska native adults 55-70 years of age. Clin Infect Dis. 2009;49:241-8.

111. Onwubiko C, Swiatlo E, McDaniel LS. Cross-Sectional study of nasopharyngeal carriage of Streptococcus pneumoniae in human immunodeficiency virus-infected adults in the conjugate vaccine era. $J$ Clin Microbiol. 2008;46:3621-5.

112. Blossom DB, Namayanja-Kaye G, Nankya-Mutyoba J, Mukasa JB, Bakka H, Rwambuya S, Windau A, Bajaksouzian S, Walker CJ, Joloba $\mathrm{ML}$, Kityo C, Mugyenyi P, Whalen CC, Jacobs MR, Salata RA. Oropharyngeal colonization by Streptococcus pneumoniae among HIV-infected adults in Uganda: assessing prevalence and antimicrobial susceptibility. Int J Infect Dis. 2006;10:458-64.

113. Lo YC, Lauderdale TL, Chang SY, Hsiao CF, Hung CC, Chang SC. Streptococcus pneumoniae colonization among patients with human immunodeficiency virus-1 who had received 23-valent polysaccharide pneumococcal vaccine. J Microbiol Immunol Infect. 2009;42:234-42. 
114. Frazão N, Brito-Avô A, Simas C, Saldanha J, Mato R, Nunes S, Sousa NG, Carriço JA, Almeida JS, Santos-Sanches I, de Lencastre H. Effect of the seven-valent conjugate pneumococcal vaccine on carriage and drug resistance of Streptococcus pneumoniae in healthy children attending day-care centers in Lisbon. Pediatr Infect Dis J. 2005;24:243-52.

115. Sa-Leao R, Nunes S, Brito-Avo A, Frazão N, Simões AS, Crisóstomo MI, Paulo ACS, Saldanha J, Santos-Sanches I, Lencastre H. Changes in pneumococcal serotypes and antibiotypes carried by vaccinated and unvaccinated day-care centre attendees in Portugal, a country with widespread use of the seven-valent pneumococcal conjugate vaccine. Clin Microbiol Infect. 2009;15:1002-7.

116. Ghaffar F, Barton T, Lozano J, Muniz LS, Hicks P, Gan V, Ahmad N, McCracken GH Jr. Effect of the 7-valent pneumococcal conjugate vaccine on nasopharyngeal colonization by Streptococcus pneumoniae in the first 2 years of life. Clin Infect Dis. 2004;39:930-8.

117. Hammitt LL, Bruden DL, Butler JC, Baggett HC, Hurlburt DA, Reasonover A, Hennessy TW. Indirect effect of conjugate vaccine on adult carriage of Streptococcus pneumoniae: an explanation of trends in invasive pneumococcal disease. J Infect Dis. 2006;193:1487-94.

118. Millar EV, Watt JP, Bronsdon MA, Dallas J, Reid R, Santosham M, O'Brien KL. Indirect effect of 7-valent pneumococcal conjugate vaccine on pneumococcal colonization among unvaccinated household members. Clin Infect Dis. 2008;47:989-96.

119. Kuo CY, Hwang KP, Hsieh YC, Cheng $\mathrm{CH}$, Huang $\mathrm{FL}$, Shen $\mathrm{YH}$, Huang YC, Chiu $\mathrm{CH}$, Chen PY, Lin TY. Nasopharyngeal carriage of Streptococcus pneumoniae in Taiwan before and after the introduction of a conjugate vaccine. Vaccine. 2011;29:5171-7. 
120. Center for Disease Control and Prevention (CDC). Use of 13-Valent Pneumococcal Conjugate Vaccine and 23-Valent Pneumococcal Polysaccharide Vaccine for Adults with Immunocompromising Conditions: Recommendations of the Advisory Committee on Immunization Practices (ACIP). MMWR Morb Mortal Wkly Rep. 2012;61:816-19. 